\title{
10. HJ und Schule
}

\section{1 „Lehrer und Jugendführer im gleichen erzieherischen Raum“. Zur Schulpolitik der HJ}

„Die Partei als Trägerin der deutschen Volkserziehung schuf neue Erziehungseinrichtungen, unter denen die Hitler-Jugend die hervorragende Rolle übernahm. Die Schule verlor damit ihre Ausschließlichkeit ... Vor allem das Ineinandergreifen von Hitler-Jugend und Schule kann zu hervorragenden Ergebnissen der Jugenderziehung führen. ${ }^{* 1}$

Seit der Entstehung der HJ gehörten die zum Teil heftigen Auseinandersetzungen zwischen dem NS-Jugendverband und dem staatlichen Schulwesen zu den Grundkonstanten nationalsozialistischer Jugendpolitik; diese Konflikte erfuhren zwar nach der Begründung des Dritten Reichs eine modifizierte Akzentuierung, verloren jedoch nichts von ihrer Grundsätzlichkeit. ${ }^{2} \mathrm{Da}$ diese Beziehung vom Anfang bis zum Ende des Dritten Reiches ein elementarer Konfliktherd blieb, der allenfalls phasenweise und sektoral, nie aber prinzipiell und umfassend beigelegt werden konnte - und sollte? -, bleibt angesichts zahlreicher Maßnahmen zur Regelung und Wirkungsoptimierung in einer Reihe anderer als kriegswichtig angesehener Politikbereiche zwar erstaunlich, jedoch nicht außergewöhnlich. Die Hauptursache des beständig schwelenden Grundkonflikts, aus dem darüber hinaus auch eine Reihe von peripheren Disharmonien, Streitigkeiten und Zerwürfnissen resultierten, bestand vor allem in der mit zahlreichen Weiterungen verbundenen Tatsache, daß mit der HJ seit 1933 ein bislang weitgehend unbekannter, zunächst unterschätzter Faktor in ein seit langem bestehendes, relativ ausgewogenes System der traditionellen Erziehungsinstitutionen eingebrochen war und dessen austarierte Machtbalance aus dem Gleichgewicht gebracht hatte.

Während ein Pfeiler dieses Gefüges - das Elternhaus - großflächig systemkonform neutralisiert, ein anderer - die Kirche - weitgehend ausgeschaltet werden konnte, entbrannten in dem entstandenen Vakuum und um die dritte Säule, die staatliche Schulaufsicht, erhebliche Kämpfe, in denen der NS-Jugendverband bei weitem nicht als einziger neuer Kontrahenten auftrat, sich letztlich jedoch als der durchsetzungsfähigste Wettbewerber erwies. Die Schule als die Basis staatlicher Bildungspolitik schlechthin hatte ihre „Ausschließlichkeit“ auch deshalb verloren, wie die Reichsjugendführung 1944 anmaßend und selbstgefällig zugleich betonte, weil „die Partei als [neue] Trägerin der deutschen Volkserziehung neue Erziehungseinrichtungen“ geschaffen habe, „unter denen die Hitler-Jugend die hervorragende Rolle übernahm“"; ${ }^{3}$ die Führung der HJ verschwieg hier

1 BA, NS 26/358 (Kriegsgeschichte der HJ, 1944).

2 Das Thema 'Schule im Dritten Reich' gehört sowohl aus erziehungswissenschaftlichem wie bildungshistorischem Blickwinkel als auch unter den Aspekten von Jugendpolitik und der Geschichte der HJ, aber auch im Kontext der Forschungen zu Herrschaft und Gesellschaft im Dritten Reich zu den insgesamt mit am besten erforschten Bereichen der Geschichte des Nationalsozialismus. Auch deshalb werden im folgenden keine Betrachtungen zur Entwicklung des Bildungswesens im Dritten Reich angestellt, sondern - zumeist unter Betrachtung des Standpunktes der Reichsjugendführung - vor allem Aspekte des Verhältnisses von HJ und Schule skizziert. Vgl. dazu auch die Analyse des Forschungsstandes und kommentierte Literaturbesprechungen bei Keim, Erziehung im Nationalsozialismus. Zu den wichtigen Sammelbänden und übergreifenden Studien zählen etwa Assel, Die Perversion der politischen Pädagogik; Breyvogel, Pädagogische Jugendforschung; Dithmar, Schule und Unterricht im Dritten Reich; Eilers, Die nationalsozialistische Schulpolitik; Flessau/Nyssen/Pätzold, Erziehung im Nationalsozialismus; Flessau, Schule der Diktatur; Fricke-Finkelnburg, Nationalsozialismus und Schule; Gamm, Führung und Verführung; Giesecke, Vom Wandervogel bis zur Hitlerjugend; Heil Hitler, Herr Lehrer; Heinemann, Erziehung und Schulung im Dritten Reich; Herrmann, Die Formung des Volksgenossen; Herrmann/Oelkers, Pädagogik und Nationalsozialismus; Jugend unterm Hakenkreuz; Kanz, Der Nationalsozialismus als pädagogisches Problem; Kater, Hitlerjugend und Schule; Keim, Pädagogen und Pädagogik; Ders., Erziehung unter der Nazi-Diktatur; Kersting, Militär und Jugend im NS-Staat; Kipp/Miller-Kipp, Erkundungen im Halbdunkel; Klafki, Verführung, Distanzierung, Ernüchterung; Kohrs, Kindheit und Jugend unter dem Hakenkreuz; Lingelbach, Erziehung; Nyssen, Schule im Nationalsozialismus; Scholtz, Erziehung und Unterricht unterm Hakenkreuz; Stahlmann/Schiedeck, Erziehung zur Gemeinschaft; Steinaus, Hitlers pädagogische Maximen; Stippel, Die Zerstörung der Person; zur Geschichte von Institutionen und Strukturen nationalsozialistischer Bildungspolitik vgl. etwa Diere, Das Reichsministerium für Wissenschaft, Erziehung und Volksbildung; Feiten, Der Nationalsozialistische Lehrerbund; Horn, National Socialist Schülerbund and the Hitler-Youth; zur Geschichte einzelner Schulfächer vgl. exemplarisch Genschel, Politische Erziehung durch Geschichtsunterricht; Heymen, Erziehung zur Wehrhaftigkeit; zum Komplex Luftwaffenhelfer vgl. etwa Nicolaisen, Gruppenfeuer und Salventakt; Paul, Schüler für die Heimatflak; Schätz, SchülerSoldaten; zu alltags- und mentalitätsgeschichtlichen Darstellungen Reich-Ranicki, Meine Schulzeit im Dritten Reich; Hering u.a., Schüleralltag im Nationalsozialismus.

3 BA, NS 26/358 (Kriegsgeschichte der HJ, 1944). 
allerdings, daß ihr dies nur gelungen war, weil sie mit Hilfe der NSDAP ihre Ansprüche sukzessive und erfolgreich auch auf ehemals nur-staatliche Bereiche ausdehnen konnte.

Daß Stellung und Kompetenzen eines so traditionellen Ressorts wie die des Kultusministeriums überhaupt in Frage gestellt werden konnten, lag neben den sich aus der 'Verreichlichung' dieser Behörde ergebenden Konsequenzen vor allem an der Installierung eines neuen, nationalsozialistischen Erziehungsideals. Durch interessengebundene Interpretationen des entsprechenden 'Führerwillens', mit dem vor allem bislang bildungsferne Faktoren in den Rang einer Staatsdoktrin gehoben wurden und der in einigen Bereichen weit über den Rahmen des 'klassischen' Aufgabenbereichs der Schulpolitik hinausging, in anderen dagegen erheblich darunter blieb, gelang es den Exegeten Hitlerscher Bildungsfeindlichkeit, sowohl den Bestand der Schule als Institut als auch die Praktiken der herkömmlichen Bildungsvermittlung generell in Frage zu stellen. ${ }^{4}$ Hinzu kam, daß der von der Ministerialbürokratie lange Zeit unterschätzte 'Faktor Hitlerjugend' in einem Maße an Bedeutung gewann, das für die in überkommenen Bahnen staatlich regulierter Bildungspolitik denkenden Beamten gar nicht faßbar war. Die HJ war eben nicht nur - wie bislang - eine von vielen Jugendorganisationen der gerade an der Macht befindlichen Parteien, sondern eine durch einen Diktator gestützte Sub-Bewegung mit einem umfassenden, totalisierten Erfassungsund Erziehungsanspruch, der Formen des traditionellen Bildungswesens zwar einschloß, in der Konsequenz jedoch weit darüber hinausging. Bei Bedarf unternahm es die $\mathrm{HJ}$ immer wieder, den beliebig neu zu konstruierenden Generationskonflikt zwischen 'alter' Schule und 'junger' (Jugend-)Bewegung pragmatisch zu instrumentalisieren und die uralten Ressentiments Jugendlicher gegen 'die' Schule und 'die' Lehrer in den Auseinandersetzungen mit den staatlichen Volksbildungsbehörden für sich zu mobilisieren.

Darüber hinaus waren das Reichsministerium für Wissenschaft, Erziehung und Volksbildung und seine nachgeordneten Dienststellen auch zahlreichen Attacken anderer Einrichtungen ausgesetzt, die sie unter ihrem schwachen obersten Dienstherren nur unzureichend parieren konnten, weshalb sie laufend weitere Kompetenzen verloren; die sich in zahllosen Erlassen widerspiegelnden kompetenzerhaltenden Maßnahmen der Reichserziehungsbehörde deuteten zwar Aktivitäten und Regelungsbedürfnisse an, die eigene Gestaltungskraft blieb jedoch immer mehr auf der Strecke. Hitler hielt - typisch für ihn - halbherzig und bis zum Untergang an dem allseits für schwach und unfähig gehalteten Erziehungsminister Bernhard Rust fest - aus genereller Abneigung vor personalpolitischen Veränderungen, aus sentimentaler Treue einem 'Alten Kämpfer' gegenüber, aber auch, weil sich keiner von den zahlreichen möglichen Nachfolgern für dieses komplizierte und undankbare Amt mit seinen komplexen Zuständigkeiten durchsetzen konnte oder entsprechend profilieren wollte. ${ }^{5}$ Erst unmittelbar vor seinem Selbstmord hatte Hitler den bisherigen Chef des NS-Studentenbundes, den Reichsdozentenführer und Gauleiter von Salzburg, Gustav Adolf Scheel, zum neuen Kultusminister bestimmt. Andererseits ließ Hitler seinen Minister Rust immerhin einen der dienstältesten Parteiführer - schon im Dezember 1940 als Gauleiter von Südhannover-Braunschweig ablösen und bezeichnenderweise durch einen seiner stärksten Kritiker, durch Hartmann Lauterbacher, den bisherigen Stabsführer der HJ, ersetzen. ${ }^{6}$

Im Jahre 1944 hatte die $\mathrm{HJ}$ in bezug auf das staatliche Bildungswesen wie zu seinen Institutionen einen Stand erreicht, der es ihr erlaubte, sowohl an der Spitze, der Reichsjugendführung, als auch an der Basis, in den HJ-Einheiten, zufrieden und selbstbewußt aufzutreten. Ungeachtet der

$4 \mathrm{Zu}$ Hitlers bildungspolitischen Vorstellungen vgl. etwa Ders., Mein Kampf, S. 464 ff.; Schwedtke, Adolf Hitlers Gedanken zur Erziehung; Steinaus, Hitlers pädagogische Maximen; Flessau, Schule der Diktatur, S. 22 ff.

5 Vor allem im Kriege ist die Entmachtung des Reichserziehungsministers durch deutliche Kompetenzbeschneidungen bis hin zu direkten Forderungen nach seiner Ablösung mehrfach versucht worden. Anfang 1944 schien eine Amtsenthebung Rusts beschlossene Sache. Zu den von der Partei-Kanzlei in die nähere Wahl gezogenen Nachfolgern für, die schönste Aufgabe ..., die der Führer überhaupt zu vergeben in der Lage ist", gehörten die Gauleiter Siegfried Uiberreither, Hugo Jury, Paul Giesler, Rudolf Jordan, Gustav Simon, Hartmann Lauterbacher sowie Gustav Adolf Scheel, der Wunschkandidat der ParteiKanzlei. BA, NS 6/797 (Vorlage der Partei-Kanzlei für Bormann, betreffend neuen RMWEV, 12.1.1944).

6 Als Lauterbacher sich anläßlich des Ämterwechsels bei Goebbels vorstellte und über die Lage in Hannover berichtete, notierte der Propagandaminister: „Dort herrschen tolle Zustände. Rust hat alles verkommen lassen, sich um nichts gekümmert"; Goebbels, Tagebücher, Teil I, S. 59 (Eintrag vom 19.12.1940). 
ohnehin zumeist nur verbalen Konsensbemühungen der HJ-Zentrale, die die tief verwurzelten Ressentiments gegenüber dem Schulbetrieb und seinen Einrichtungen nur notdürftig überdeckten und den vereinbarten 'Burgfrieden' nur scheinbar zu bewahren suchten, kam es gerade im Kriege wieder zu verstärkten Attacken gegenüber der Schule, etwa wenn die Scharführerin einer Jungmädelgruppe wenige Tage vor 'Führergeburtstag' der Leitung der Volksschule in Biberach mitteilte: „Wie ich schon wiederholt durch einige meiner Jungmädel erfahren habe, sind Sie nicht einverstanden, wenn ich abends für [die] JM Appell ansetze. Nehmen Sie deshalb zur Kenntnis, daß es nicht Sache der Schulleitung ist, wann für JM Appell angesetzt wird. Ich ersuche Sie, künftighin jede Bemerkung gegenüber den JM zu unterlassen." "Im gleichen Geiste, inhaltlich jedoch viel weitreichender als diese Zurückweisung schulischer Einmischungsversuche in Belange der HJArbeit durch eine BDM-Führerin, agierte auch die HJ-Zentrale, wenngleich diese aus taktischen Erwägungen etwas moderater und vorsichtiger auftrat. Für die Reichsjugendführung hatte der Krieg - den sie hinsichtlich ihrer Kulturarbeit euphemistisch als „Vater der Kunsterziehung“ apostrophierte - auch auf dem Arbeitsfeld der Volksbildung ,segensreich“" gewirkt; erst unter den Bedingungen des Krieges seien Reformen des verknöcherten Bildungswesens und ein „Zusammenwirken" von Schule und HJ möglich geworden, letzteres freilich unter Vorzeichen, die keineswegs den Intentionen des unflexiblen Reichserziehungsministeriums entsprachen. Während die Reichsjugendführung für die Friedenszeit resümierte, daß „beide Erziehungsträger jahrelang nebeneinander gearbeitet“ hätten, „ohne daß ein Gleichklang ihrer Tätigkeit spürbar geworden wäre“, stellte sie 1944 fest, daß ,erst den zwingenden Umständen des Krieges die Förderung ihrer praktischen Zusammenarbeit zu danken" sei. $^{8}$

Parallel zur zunehmenden Erschöpfung des Reichserziehungsministeriums, zu der die kriegsbedingt ebenfalls geschwächte HJ erheblich beigetragen hatte, seien, wie die HJ-Führung 1944 hervorhob, immerhin „Tendenzen im Schulwesen deutlich“ geworden, die endlich den Vorstellungen und Erwartungen des NS-Jugendverbandes entsprachen und in deren Gefolge die Schule sich also den Bestrebungen der $\mathrm{HJ}$ angepaßt habe. Auch bei den aktuellen Entwicklungen des Krieges, wie etwa der Kinderlandverschickung oder der neuen Form der Lehrerbildung, seien die „Schwierigkeiten der Schule, die ihr seit Jahren den befriedigenden Erfolg versagt“ hatten, erneut offenbar geworden. Diese Schwierigkeiten könnten „,nur mit Hilfe der Jugendbewegung beseitigt werden“, und es sei klar geworden, daß das unter dem Schlagwort der „Einheit der Jugenderziehung" erzielte Zusammenwirken beider Institutionen aus Sicht der HJ-Zentrale nur unter Führung der Reichsjugendführung vor sich gehen könne. Dieser auf eine totale Jugenderziehung gerichtete Führungsanspruch der $\mathrm{HJ}$, der die schulische Bildungsvermittlung als lediglich eine Facette eines wesentlich weiterreichenden Konzepts der Jugenderziehung einschloß, wurde angesichts des totalen Krieges, zur Vermeidung von möglichen unkontrollierbaren Reaktionen der angeschlagenen Bildungsbehörde und wegen der 1939 mit untaktischem Vorpreschen gemachten negativen Erfahrungen zwar verhalten, aber deutlich formuliert, so etwa wenn die Reichsjugendführung im Herbst 1944 postulierte, daß ,,der völlige Gleichklang von Jugend und Schule endgültig nur von der aktiven Anteilnahme der Jugend her zu erwarten" sei.

Waren Formulierungen wie diese noch eher kryptisch und für einen Nichteingeweihten kaum zu entschlüsseln, gestaltete sich die HJ-seitige Beschreibung des Schulwesens im Kriege für den, der damals zwischen den Zeilen lesen konnte, als eine Fundamentalkritik: Als ein ,aus der Vergangenheit überkommener Erziehungsträger“ habe die Schule spätestens zu Beginn des Krieges ,eine neue Stellung beziehen“ müssen. Der ,langwierige Prozeß“ ihrer „Einordnung in das neue nationale Erziehungswesen" gestaltete sich ,,nicht ohne Reibungen“ und blieb ,problematisch“, vor allem aus immanenten, aus der Anlage des gesamten Bildungssystems resultierenden Gründen. Schon vor dem Krieg waren die Ergebnisse der schulischen Arbeit ,einer lebhaften Kritik“ ausgesetzt, und ,insbesondere Wehrmacht und Wirtschaft" bezeugten ihre ,wachsende Unzufriedenheit" mit einem

7 BA, Film Nr. 14620 (Maria Zeile an Schulleitung Biberach, 26.4.1944). Mit JM sind hier die Jungmädel bezeichnet; gemeint ist nicht der Jungmädelbund.

8 BA, NS 26/358 (Kriegsgeschichte der HJ, 1944); Hervorhebungen im Original. 
Schulsystem, zu dessen markanten Kennzeichen ein „Rückgang der Leistungen“, „Bildungslücken“ und „Leistungsschwächen“ aller Art gehörten; diese Unzulänglichkeiten hätten den militärischen und wirtschaftlichen Aufstieg des Reiches nicht nur nicht gefördert, sondern eher behindert. ${ }^{9}$

Die Reichsjugendführung präsentierte sich als Retter in der Not, als Erlöser und Befreier aus den scheinbar desolaten Zuständen eines angeblich völlig maroden Bildungswesens: Die Schule könne ohne die HJ ihren Erziehungsauftrag nicht mehr wahrnehmen, und die dringend notwendigen Reformen im Bildungswesen seien nur mit der $\mathrm{HJ}$ durchzusetzen. In der letzten HJ-amtlichen Darstellung erfolgte eine Generalabrechnung mit 'der' Schule und 'dem' Schulwesen, deren Quintessenz besagte, daß in der Vergangenheit ohne die HJ keine der so dringend erforderlichen Neuerungen zu realisieren gewesen wären und auch künftig ohne die $\mathrm{HJ}$ nichts zu reformieren sei. $\mathrm{Zu}$ den Hintergründen dieser Einschätzung gehörte, daß es der HJ-Führung trotz aggressiver Bemühungen noch nicht gelungen war, die Führung des Schulwesens auch administrativ an sich zu reißen - entsprechende Versuche hatte es seit Mitte der 30er Jahre in unterschiedlicher Intensität immer wieder gegeben. Und daß mit Hartmann Lauterbacher der bisherige Stabsführer der HJ den Reichsminister Bernhard Rust zwar als Gauleiter, nicht jedoch als Reichserziehungsminister ablösen durfte, lag vor allem daran, daß man in der Partei-Kanzlei noch 1944 gegen eine derartige Ämterkonzentration eingestellt war und fürchtete, daß Lauterbacher oder die HJ-Führung ,darauf hinarbeiten würde[n], die Schule gleichsam in die $\mathrm{HJ}$ zu überführen". ${ }^{10}$

Die Geschichte der Beziehungen von HJ und Schule bestand zu großen Teilen aus einer Kette von mehr oder weniger subtil vorgetragenen Angriffen der HJ, an deren Ende für die Reichsjugendführung trotz zahlreicher Rückschläge etliche Erfolge zu verbuchen waren, die sie wegen des Kriegsendes jedoch kaum mehr materialisieren konnte. Die Aktivitäten der HJ gegenüber der Schule und den Bildungsbehörden lassen sich in vier einander zeitlich überlappenden Phasen und phasenübergreifend - in einer Reihe von thematischen Bereichen ausmachen. Nachdem die NSJugendbewegung - vor allem über den Ende 1929 gegründeten und im März 1933 in die HJ integrierten NS-Schülerbund - schon in der Weimarer Republik intensive Schulkämpfe ausgefochten hatte $^{11}$, ging es unmittelbar nach der Machtübernahme zunächst um die Einräumung von Sonderrechten für die HJ - wie etwa den Staatsjugendtag - und um die Abgabe einzelner Zuständigkeiten aus der Hand des Reichserziehungsministeriums an den immer stärker mit staatlichen Kompetenzen ausgestattenen Jugendverband, so um die Überführung des Landjahres, des Jugendherbergswesens oder der Jugendpflege.

In einer dritten, von etwa 1938 bis 1940 dauernden Phase, die von intensiven Diffamierungskampagnen sowohl gegen die Person des Reichserziehungsministers als auch gegen die von ihm geführte Behörde gekennzeichnet war, strebte Schirach direkt die Übernahme der Gesamtverantwortung an und wollte erreichen, auch zum Chef des deutschen Bildungswesens ernannt zu werden; entsprechende Erlaßentwürfe lagen in der Reichskanzlei schon vor, sind aber von Hitler nicht unterzeichnet worden. Diese mißglückten Versuche waren natürlich im Führerkorps der HJ, insbesondere bei den mit Schulfragen befaßten HJ-Führern bekannt und perpetuierten das schlechte Verhältnis in immer neuen Angriffen. Nach dem Wechsel von Schirach auf Axmann schlug der neue Reichsjugendführer in einer vierten, vor allem durch die Bedingungen des Krieges bestimmten Phase jedoch eine andere Taktik ein. Axmann versuchte nun, von der Basis her, etwa über eine Einflußnahme auf die Lehrerbildung und auf die nach den Erziehungsprinzipien der $\mathrm{HJ}$ gestaltete Hauptschule, das

9 Ebenda.

10 BA, NS 6/797 (Vorlage der Partei-Kanzlei für Bormann, betreffend neuen RMWEV, 12.1.1944).

11 Vgl. dazu Buddrus, Hitlerjugend, Bd. I, S. 25 ff. Wegen der Radikalität der Angriffe des NS-Schülerbundes auf die Weimarer Republik - vgl. etwa dessen Flugblatt „Das System ist jugendfeindlich", in dem es hieß: „Erkennt eure geschichtliche Aufgabe in der Zertrümmerung des Systems und im Aufbau eines nationalsozialistischen Volksstaates!"; BA, RMdI, Nr. 26117, Bl. 167 - ist dieser in einer Reihe von deutschen Ländern verboten worden; zahlreiche der im NSS organisierten Jugendlichen wurden von den Schulen verwiesen. Die daraufhin von Goebbels initiierte „Terrorhilfe der $\mathrm{HJ}^{\text {“ }}$ sollte relegierte Schüler materiell unterstützen und an anderen Schulen unterbringen. Vgl. dazu auch Horn, The National Socialist Schülerbund and the Hitler-Youth. Das gegen die Bildungsbehörden entwickelte Haßpotential wurde auch nach der Machtübernahme fortgeführt und instrumentalisiert. Dazu hatte als psychologisch wichtiges Moment beigetragen, daß der Reichsjugendführer, wenn auch nur vom Mai 1934 bis Anfang 1935, dem Reichserziehungsminister unterstellt gewesen ist. 
Schulwesen zu 'unterwandern' und so zumindest de facto dessen Führung zu erlangen. Alle diese Bestrebungen sind von Versuchen begleitet worden, über den Einbau eigener Funktionäre in schulpolitisch wichtige Ämter - angefangen von der einzelnen Schule, über regionale Bildungsbehörden bis hin zum Reichserziehungsministerium - Einflu $§$ auf die Schulpolitik zu nehmen.

Die Kompetenzkonflikte zwischen der Reichsjugendführung und dem Reichserziehungsministerium sind vor allem deshalb entstanden, weil sich mit dem Anspruch auf die Führung und Erziehung der Jugend beide Institutionen zur selben Zeit, in derselben Angelegenheit auf dieselbe Klientel konzentrierten; man glaubte in beiden Behörden, daß sich der Stellenwert der eigenen Führungsdienststelle im Herrschaftsapparat aus möglichst vielen Zuständigkeiten für möglichst viele Bereiche bei der Erziehung eines möglichst großen Teils dieser Klientel ableiten würde. Weder die traditionelle behördliche Verwaltung noch die sich 'revolutionär' gebärdende Reichsjugendführung hatten erhebliche inhaltliche oder gar ideologische Differenzen; diese wurden lediglich konstruiert, instrumentalisiert und als Waffe zur Diskreditierung des jeweils anderen gebraucht. Die Ziele beider Einrichtungen waren weitgehend identisch; gestritten wurde lediglich über die Mittel und Wege zu ihrer Erreichung und um die Führungspostionen innerhalb dieses Prozesses. Als ,Ziel der deutschen Jugenderziehung und aller Erziehung überhaupt“ sind auch am Ende des Dritten Reiches die schon in der Vorkriegszeit verbindlich formulierten dualen Komponenten der „Erziehung zum rassisch gesunden und tüchtigen Einzelmenschen“ und die „Erziehung zum einsatzbereiten Gemeinschaftsglied" fixiert und bestätigt worden. ${ }^{12}$

Dennoch sind die Beziehungen von $\mathrm{HJ}$ und Schule, von Reichsjugendführung und Reichserziehungsministerium nicht nur als Konfliktgeschichte zu begreifen. Aus der ideologisch und inhaltlich gleichgerichteten Konzentration zweier NS-Behörden auf ein und dieselbe Klientel resultierten auch erhebliche Synergieeffekte, die sich für beide Organisationen und das NS-System insgesamt vorteilhaft auswirkten und die die hohe Effektivität der nationalsozialistischen Jugendsozialisation erst ermöglichten. Der Reichsjugendführung war bewußt, daß gerade im totalen Krieg, der ,,gebieterisch die Einheit der Jugenderziehung“ verlange, ,,vor allem das Ineinandergreifen von Hitler-Jugend und Schule zu hervorragenden Ergebnissen der Jugenderziehung führen" könne. ${ }^{13}$

Im Ringen beider Institutionen besaß das Reichserziehungsministerium den zunächst uneinholbar scheinenden Vorteil, daß sein Anspruch auf die Erfassung und Erziehung der Jugend durch Gewohnheitsrecht und per Gesetz bereits fixiert worden war. Deshalb stellte die Einführung des Staatsjugendtages einen ersten wichtigen Erfolg der Reichsjugendführung im Kampf um Einfluß auf die Jugend und zur Schwächung der staatlichen Erziehungsbehörde dar: In einem Abkommen

12 Benze, Erziehung im Großdeutschen Reich. S. 6 ff. Die sich aus zahlreichen Reibungsflächen ergebenden Kompetenzkonflikte im Bereich des Erziehungswesens des Dritten Reiches waren weit vielfältiger und lassen sich nicht nur auf den einen, hier zu betrachtenden Hauptkonfliktherd - HJ und Schule - reduzieren. Mit dem von der NS-Führung extensivierten Erziehungsanspruch haben ,die Erziehungsaufgaben des neuen Deutschland ein viel größeres Maß [als bislang] erreicht und sind über die Jugendzeit [hinaus] auf fast das gesamte Leben des deutschen Menschen ausgedehnt worden“. Dazu haben „Staat und Bewegung immer weitere Stellen ... mit Erziehungsaufträgen bedacht oder eigens dafür eingerichtet“, mit der bereits 1940 eingestandenen Folge, „daß die Erziehungsbereiche, die Arbeitswege und die Einrichtungen beim ersten Blick [nur noch] schwer zu übersehen" waren; selbst die im Erziehungswesen Tätigen vermochten „kaum [noch] das Ganze und die Wechselbeziehungen der Einzelgruppen ganz zu erfassen", zu denen neben dem Elternhaus und den Bildungseinrichtungen des klassischen Schulwesens, die Erziehungsstätten der HJ, des Reichsarbeitsdienstes, der Wehrmacht, des Hochschulwesens, der NSDAP, der SA und SS, des NSKK und des NSFK, der Deutschen Arbeitsfront, des Deutschen Volksbildungswerkes und der NS-Frauenschaft gehörten. Erziehungsmächte und Erziehungshoheit, Vorwort, passim.

13 BA, NS 26/358 (Kriegsgeschichte der HJ, 1944). Die Bemühungen der HJ-Führung, die Führung des Schulwesens im Reich auch auf der administrativen Ebene an sich zu reißen, resultierten auch aus der Kenntnis der Tatsache, daß das 'System HJ' ohne das 'System Schule' nicht funktionieren konnte. Wie im Kapitel 2 dargestellt, war die HJ bei ihren Angehörigen auf ein Mindestgrundwissen angewiesen, das nur von der Schule vermittelt werden konnte, auf dem dann etwa im Dienstbetrieb der HJ die weltanschauliche Schulung aufbauen konnte; darïber hinaus stellten die nur über die Schule zu vermittelnden Elementarkenntnisse auch eine notwendige Vorbedingung für eine spätere Berufsausbildung dar, an deren genereller Einführung und Durchsetzung die HJ ein großes Interesse zeigte. Hinzu kam, daß neben der Nutzung der traditionellen Autorität der Schule auch die dort bestehende Schulpflicht mit der von der HJ angestrebten Jugenddienstpflicht prinzipiell harmonierte und in Übereinstimmung gebracht werden sollte. Der in der Schule vermittelte Bildungshorizont und die dem 'System Schule' innewohnenden Potenzen bedingten von seiten der HJ also eine Kooperation, weshalb sich die Fundamentalkritik der HJ am Schulsystem und seinen Exponenten immer mit dem Bestreben verband, diese nach ihrem Bilde zu formen, bevor dann beide 'Systeme' unter der Parole von der „Einheit der Erziehung“ in einer Hand vereinigt werden sollten. 
zwischen Rust und Schirach ist am 7. Juni 1934 vereinbart worden, daß neben dem Mitwochnachmittag, der den HJ-Einheiten für Heimabende ohnehin zur Verfügung stand, den der HJ ,unterstellten Schülern [auch] der Sonnabend als schulfreier Tag eingeräumt" wurde, wohingegen für alle anderen Schüler am Samstag ,Unterricht wie üblich“ stattfand. ${ }^{14}$ Während sich für die Schulen und Schulbehörden aus dieser Regelung nur große organisatorische Schwierigkeiten ergaben und sie etwa den ,gleitenden Sechstageplan“ für eine halbierte Schülerschaft entwickeln mußten, bedeutete die Einführung des Staatsjugendtages für die Reichsjugendführung neben dem praktischen Gewinn eines zweiten Tages für den HJ-Dienst und dem allgemeinen Prestigegewinn auch erhebliche handgreifliche Konsequenzen:

Der Staatsjugendtag erhöhte vor allem für die 10- bis 14jährigen Schüler die Attraktivität der HJ beträchtlich, ein Grund dafür, daß die Zunahme der Mitgliederzahl bei den entsprechenden Gliederungen der HJ - Deutsches Jungvolk und Jungmädelbund - im Jahre 1934 mit 840.000 fast doppelt so hoch war wie bei den Gliederungen der 14- bis 18jährigen (447.000). ${ }^{15}$ Was im Schulsektor gelang, ist jedoch im Wirtschaftsbereich gescheitert: Obwohl für die berufstätige Jugend eine analoge Staatsjugendtags-Regelung angestrebt worden war, hatten sich führende Wirtschaftskreise erfolgreich gegen die samstägliche Freistellung der der HJ angehörenden Lehrlinge und Jungarbeiter gewandt, denn diese würde sich, ,überall da besonders störend für die Betriebe auswirken, wo es auf die Kontinuität der Tätigkeit ankommt, vor allem in der Industrie““. ${ }^{16}$

Das HJ-Gesetz, dessen Einführung das Reichserziehungsministerium bis zuletzt zu hintertreiben suchte, stellte einen weiteren wichtigen Erfolg der Reichsjugendführung dar, die sich damit - und nur dieser Aspekt des wesentlich weiterreichenden Gesetzes soll hier betrachtet werden - von der bislang praktizierten ministeriellen Beaufsichtigung weitgehend emanzipieren konnte. Rust hatte alle Gesetzesentwürfe der HJ-Führung abgelehnt und statt dessen - in Unkenntnis der möglichen praktischen Auswirkungen eines derartigen Präzedenzfalles - eigene Konzepte eingebracht, in deren Folge die HJ dem Erziehungsministerium, eine Parteigliederung also einer staatlichen Behörde unterstellt worden wäre. So ließ Rust einen frühen Gesetzentwurf der Reichsjugendführung für ein HJ-Gesetz mit „erheblichen Bedenken“ und der Erkenntnis zurückweisen, daß dieser ,an dem Dasein dieser [seiner] obersten Reichsbehörde ... völlig vorbeigeht “ ${ }^{17}$ Damit hatte er nicht unrecht. ${ }^{18}$ Und auch als im November 1936 über den abschließenden Entwurf beraten wurde, der unter Federführung und im Interesse der Reichsjugendführung entstanden war, konnte im Reichserziehungsministerium zwar vermerkt werden, daß die „geplante Regelung tatsächlich einen so schweren Einbruch in den Aufgabenkreis des Reichserziehungsministeriums“ bedeuten würde, daß deren „Folgen gar nicht zu übersehen“ seien $^{19}$; aber auch hier ging der politische Pragmatismus über Rusts störrischen Ressortegoismus und sein mangelndes Verständnis für den Charakter der Beziehungen von Partei und Staat im Dritten Reich hinweg: Hitler ließ seinen Erziehungsmini-

14 Das von Schirach und Staatssekretär Stuckart [!] am 7.6.1934 unterzeichnete und von Reichsminister Rust am 30.7.1934 mit Durchführungsbestimmungen [!] versehene Abkommen ist veröffentlicht und kommentiert bei Mushardt/Tietjen, Staatsjugendtag, S. $8 \mathrm{ff}$.

15 Dieser Trend setzte sich bis zur Einführung des HJ-Gesetzes fort: Noch Ende 1936 waren immerhin 75,7\% der infrage kommenden 10- bis 14jährigen Mitglied der HJ, während der Erfassungsgrad der 14- bis 18jährigen Jugendlichen lediglich bei $49 \%$ lag.

16 So in einem Gutachten der Reichswirtschaftskammer für das Reichswirtschaftsministerium vom 6.12.1935, hier zitiert nach Petrick, Arbeiterjugend, S. 34. Der Staatsjugendtag ist mit einem Erlaß des Reichserziehungsministers vom 4.12.1936 wieder abgeschafft worden (MBIWEV, 1936, S. 536), weil nach der Einführung des HJ-Gesetzes am 1.12.1936 eine völlig neue Situation bestand. Der Staatsjugendtag, der sich ohnehin nur auf die Schuljugend erstreckte, wurde - vor allem aus Sicht der HJ - nicht mehr benötigt. Als lediglich marginale Etappe einer weit größer dimensionierten Entwicklung tauchte er in späteren HJ-Darstellungen kaum noch auf.

17 BA, REM, Nr. 11936, B1. 73 ff. (Rust an Lammers, 18.4.1936).

18 Denn in der Reichskanzlei wurde der Widerspruch Rusts, der die Zeichen der Zeit nicht erkannt hatte, nicht emstgenommen; auf Rusts Gegenentwurf vermerkte Ministerialrat Wienstein: „Der Führer hat Kenntnis. Er billigt die Ausführungen des Reichserziehungsministers nicht."BA, R 43 II/525, BI. 117. Und Lammers konnte den nach Rusts Vorstößen verunsicherten Reichsjugendführer beruhigen und teilte diesem nach einem „Vortrag beim Führer“ mit, „daß der Widerspruch des RMfWEV gegen den Gesetzentwurf erfolglos bleiben wird“". Ebenda, Bl. 129 (Lammers an Schirach, 25.4.1936).

19 BA, REM, Nr. 11936, Bl. 79 (Referentenvermerk im RMfWEV, 30.11.1936). 
ster deutlich auffordern, ,seine Bedenken zurückzustellen und in der Kabinettssitzung am 1. Dezember nicht geltend zu machen" 20

Eine dritte schwere Schlappe, die wiederum mit einer erheblichen Aufwertung der Reichsjugendführung verbunden war, erlitt Rust kurz darauf mit der am 15. Januar 1937 verfügten Einrichtung der Adolf-Hitler-Schulen; von ihrem Namensgeber ausdrücklich autorisiert, hatte - personifiziert in Robert Ley und Baldur von Schirach - erneut die Partei dem Reichserziehungsministerium Zuständigkeiten beschnitten und eine Schulgattung eingerichtet, in der der Nachwuchs für Führungspositionen des NS-Staates ausgebildet werden sollte. Vollkommen dem Einfluß der staatlichen Bildungsbürokratie entzogen, existierten die Adolf-Hitler-Schulen als Einheiten der HJ und unterstanden einer von der Partei ausgeübten Schulaufsicht. Während die Lehrpläne der Adolf-Hitler-Schulen durch die Führungen von HJ und NSDAP bestimmt wurden, berechtigte das Abschlußzeugnis dieser Parteischulen jedoch zum Studium auch an staatlichen Hochschulen. ${ }^{21}$

Im Jahre 1938 begann die HJ eine konzertierte Aktion, an deren Ende die Verwirklichung der Schirachschen Pläne stehen sollte, die Jugenderziehung von HJ und Schule auch institutionell zusammenzuführen und - dafür sprechen sowohl alle Indizien ${ }^{22}$ als auch Schirach selber - ihn, den Reichsjugendführer, zum Reichserziehungsminister zu ernennen. Ein deutlicher Ausdruck dieser Bemühungen war die damals vielbeachtete Rede, die Schirach am 24. Mai 1938 vor dem HJ-Führerkorps im Weimarer Nationaltheater gehalten hat und die er anschließend in einem Sammelband mit dem programmatisch gemeinten, tatsächlich jedoch plagiierten Titel „Revolution der Erziehung ${ }^{623}$ veröffentlichen ließ. Unter der zum Programm profilierten Schlagzeile „Um die Einheit der Erziehung" trug Schirach - teils massiv, teils subtil - sehr geschickte Angriffe zwar nicht gegen die Schule und die Lehrer 'als solche', sondern 'lediglich' gegen die momentanen Zustände im Bildungswesen und in der Lehrerschaft vor, die nur mit Hilfe der $\mathrm{HJ}$ zu überwinden seien; seine verbal verklausulierten Machtansprüche auf Mitgestaltung und Prägekraft im deutschen Erziehungswesen wurden durch ihre häufige Dementierung nur um so deutlicher. So wolle die $\mathrm{HJ}$ zwar „nicht der alleinige Erziehungsfaktor für die Jugend“ sein, und die „sachlichen Auseinandersetzungen mit der Schule [seien] nicht durch Machtstreben bedingt"; Schirach wollte aber immerhin „darauf hinweisen“, daß in dem von ihm, ,geleiteten Sektor unseres höheren Schulwesens, nämlich in den Adolf-Hitler-Schulen, der Gedanke der Selbstverantwortung der Jugend seit nunmehr eineinhalb Jahren täglich verwirklicht" werde. Die HJ könne die „nationalsozialistische Erziehung [nur] als eine Einheit" sehen, in der sie als ,mitverantwortlicher und mitgestaltender Teil der erzieherischen Kräfte" die innovativeren Gedanken und Vorstellungen habe und demzufolge ein Mitspracherecht fordere.

Bislang mußten „alle Fragen der Umgestaltung der Schule im nationalsozialistischen Sinne daran scheitern, daß nicht jener Lehrertyp zur Verfügung" stand, der der Reichsjugendführung vorschwebte: „Was wir brauchen, ist eine Lehrerschaft, die eine charakterliche Auslese bedeutet.“ Nur damit könne man „ein Schulsystem aufbauen ..., innerhalb dessen die Jugend selbst für die Schülerschaft verantwortlich“ sei, so daß es „zwischen Lehrerschaft und Schülerschaft im all-

20 BA, R 43 II/525, Bl. 176 f. (Lammers an Rust, 28.11.1936). „Er [Hitler] vermag die Gründe Ihrer Bedenken nicht anzuerkennen und ist der Auffassung, daß, wenn er den Jugendführer des Reichs sich unmittelbar unterstellt, eine Unterstellung unter Ihren [Rusts] Geschäftsbereich nicht in Frage kommen kann."

$21 \mathrm{Zu}$ den Adolf-Hitler-Schulen vgl. unten. Der SD hatte festgestellt, daß ,die durch die Gründung der Adolf-HitlerSchulen entstandene Diskussion über die Grundsätze von Erziehung und Unterricht auch im Jahre 1938" anhalte und zum „Kernproblem pädagogischer Auseinandersetzung“ avanciert sei. Diese Diskussionen hätten „klare Fronten zwischen [der] Lehrerschaft auf der einen und [der] Hitler-Jugend auf der anderen Seite" geschaffen. Während die „Lehrerschaft und mit ihr der NS-Lehrerbund und das Reichserziehungsministerium an den bisherigen Grundsätzen einer vorwiegend durch die Schule wahrgenommenen Menschenführung" festhielten, machte „die HJ ihren Totalitätsanspruch geltend". Meldungen aus dem Reich, S. 133 f. (Jahreslagebericht 1938).

22 Die aus den Verlautbarungen der HJ erkennbaren Bestrebungen richteten sich, so auch der SD, deutlich auf eine "Verlagerung der Erziehungsaufgaben von der Schule in die Jugendarbeit". Als Folge dieser Bemühungen hätten sich „besonders in den letzten Monaten des Jahres [1938] immer wieder auftretende Gerüchte einer Übernahme des REM "durch den Reichsjugendführer" verstärkt. Ebenda.

23 Vgl. Schirach, Um die Einheit der Erziehung, in: Ders., Revolution der Erziehung, S. 104 ff. Der Buchtitel und das dahinterstehende Konzept sind schon vor der Machtiibernahme verwandt und von Schirach lediglich 'entlehnt' worden; vgl. etwa Höper, Revolution der Erziehung (1932). 
gemeinen keine Feindschaft mehr geben“" werde. Schirach sah zwar „im Lehrer keinen Feind“, präferierte jedoch Beziehungen zu einer teils bereits vorhandenen, teils erst noch auszubildenden Schicht von Pädagogen, „die um jeden Preis mit der Jugend [d.h. der Hitlerjugend] zusammen an die Neuordnung der Fragen der Gesamterziehung herangehen“ sollte. Daran, daß ,der Mangel an Nachwuchs im Lehrerberuf derart groß geworden" sei, daß man ,,in einigen Jahren einen systematischen Unterricht überhaupt nicht mehr werde erteilen können“, und daran, ,daß der ganze Lehrerstand unpopulär geworden“" sei und ,jede Anziehungskraft eingebüßt" habe - an diesem ,unerfreulichen gegenwärtigen Zustand" mag zwar die Hitlerjugend ,die Hauptschuld“ tragen. Dies aber liege wiederum nur daran - so die Attacke auf die Lehrerschaft ,alten Stils“ -, daß „,in der jungen Generation das Gefühl für echte Autorität und wahre Führereigenschaften so stark geworden“ sei, daß ,jede ausschließlich auf Examenspapieren und Titeln aufgebaute, also falsche Autorität ... durchschaut und damit vernichtet“" werde. Die „Verehrung unechter menschlicher Autoritäten aber [sei] eine völkische Sünde“, die Jugendliche „lebensuntüchtig“ mache.

Der Tenor war also eindeutig: Da man 'die Schule' - die allein schon durch ihre Existenz den Totalitätsanspruch der HJ in Bezug auf die Jugenderziehung beschränkte - nicht abschaffen konnte und wollte, müßten das Schulwesen sowie die es prägende und von ihm geprägte Lehrerschaft so umgestaltet werden, daß sie den Erziehungsidealen der die nationalsozialistische Deutungsmacht beanspruchenden HJ entsprachen. Schirach: Die HJ „kämpfe nicht gegen die Schule“, sondern nur „gegen jeden, der sie anders als nationalsozialistisch gestalten möchte“. Er glaube an die „Sendung des nationalsozialistischen Jugendführers“, der - multifunktional einsetzbar - zugleich „Priester des nationalsozialistischen Glaubens“, „Offizier des nationalsozialistischen Dienstes“ und ,Träger einer weltweiten Bildung“" sein sollte. ${ }^{24}$

Und Schirach entwickelte einen fiktiven Ausbildungsgang, eine visionäre Karriereleiter, eine quasi-idealtypische Laufbahnausbildung für diesen neuen Jugendführertypus, die in ihrer inhaltlichen Substanz und ihren rhetorischen Mustern sowohl den Aufbau als auch den Duktus derjenigen Passage aus Hitlers berühmt-berüchtigter Reichenberger Rede vom Dezember 1938 vorwegzunehmen schien, deren Wiedergabe oft mit der vielzitierten Sequenz beendet wird: , ... und sie werden nicht mehr frei ihr ganzes Leben!“‘. So betonte der Reichsjugendführer im Mai 1938 -, daß ,eine unaufhaltsame Entwicklung“ dahin treibe, ,daß der Erzieher der Zukunft während der verschiedenen Stationen seines Lebens und Dienstes auch verschiedene erzieherische Funktionen ausüben" werde: „So sehen wir ihn zunächst als Jugendführer, der durch jährliche Übungen sich für seine spätere Funktion als Volksschullehrer vorbereitet. Wir sehen ihn dann in diesem Amte, wie er als Jugendführer und durch Dienst und Rang mit der Jugend verbundener Nationalsozialist in dem gleichen Geiste unterrichtet, in dem er bisher geführt hat. Wir sehen ihn dann nach einigen Jahren auf der weiteren Wanderschaft wieder im aktiven Dienst der Jugendführung, aber diesmal mit höherer Verantwortung. Dann als Erzieher auf einer Adolf-Hitler-Schule, später in einer deutschen Schule des Auslandes, dann im Grenz- und Auslandsamt der Reichsjugendführung oder im Amt für weltanschauliche Schulung. Vielleicht begegnen wir diesem Mann später auf einem Lehrstuhl der Akademie für Jugendführung, es kann aber auch ebensogut sein, daß wir ihn als Gauschulungsleiter in unserer Partei wiedertreffen oder als aktiven Führer in der SA oder SS ... Dieser Mann wird nicht bis zu seinem vollendeten fünfundsechzigsten Lebensjahr Tag für Tag auf dem Katheder sitzen! ... Ich sehe sie alle vor mir, diese körper- und geistgestählten Kameraden, die nicht Schulmeister sein werden, sondern Meister des Lebens. “25

Für den, der lesen und hören konnte, war dies eine massive Kampfansage an die Struktur des bisherigen Bildungssystems und an die Adresse des Reichserziehungsministeriums. Deutlich ist zu spüren, daß sich Schirach hier mit einer nationalsozialistischen Erziehungsvision für höhere Aufgaben empfahl. Dies ist in der Lehrerschaft und im Reichserziehungsministerium denkbar schlecht aufgenommen worden; sogar der NS-Lehrerbund rügte, daß sich die Lehrer ,,immer wieder öffent-

24 Schirach, Um die Einheit der Erziehung, in: Ders., Revolution der Erziehung, S. 105 ff.

25 Ebenda; Hitlers Reichenberger Rede vom 2.12.1938 über die Stufen nationalsozialistischer Erziehung ist auszugsweise veröffentlicht bei Jahnke/Buddrus, Deutsche Jugend, S. 155; auch in: Die tödliche Utopie, S. 141 
lich beschimpfen lassen“ müßten. ${ }^{26}$ Die hier zutage tretenden Machtambitionen Schirachs waren indes nur die vorläufige Kulmination einer längerwährenden Entwicklung.

Denn schon im Frühjahr 1937 war die Organisation der Schulbeauftragten der HJ aufgebaut worden, zu der in allen HJ-Gebieten und -Bannen sowie in allen Ober- und -Untergauen des BDM sogenannte Beauftragte für Schulfragen eingesetzt wurden, die möglichst in einer Person HJ-Führer, Lehrer und Mitglied des NSLB sein sollten. Diese HJ-Schulbeauftragten waren den jeweiligen Gebiets- bzw. Bannführern der HJ unmittelbar unterstellt und als Verbindungsführer zu den entsprechenden Kreisamtsleitern des NSLB und den zuständigen staatlichen Schulbehörden tätig. ${ }^{27}$ Ein Jahr später, im März 1938, wurde zwischen dem Reichserziehungsministerium und der Reichsjugendführung eine Vereinbarung über die Einsetzung von sogenannten HJ-Vertrauenslehrern an jeder Schule getroffen. Als Lehrer der Schule, die aus der HJ hervorgegangen sein und zugleich dem NS-Lehrerbund angehören sollten, mußten die Vertrauenslehrer von den Schulleitungen nach Vorschlägen der zuständigen HJ-Bannführungen jährlich neu ernannt werden. Als Mittler zwischen den regionalen HJ-Strukturen und dem Schulleiter war der Vertrauenslehrer an allen schulrelevanten Ereignissen wie Prüfungen, Versetzungen, Strafen und Erziehungsbeihilfen zu beteiligen und hatte darüber hinaus die Eltern und Lehrer über die Ziele und Aufgaben der HJ zu unterrichten und die zuständigen HJ-Führer über das schulische Verhalten der entsprechenden HJ-Angehörigen zu informieren. ${ }^{28}$

Hatte die HJ-Führung bereits mit diesen Maßnahmen nicht nur einen Fuß in die Tür der Schule gesetzt, ging sie im Frühjahr 1939 noch einen Schritt weiter: Die im Reichsführerlager der HJ in Braunschweig bekanntgegebene Gründung der „Arbeitsgemeinschaft der HJ-Lehrer“ galt - man beachte die hier noch subtile Sprache - als, ein weiterer Beitrag für die praktische Anwendung unserer Ideen". Über diese Arbeitsgemeinschaft der HJ-Lehrer - der einzigen originären Berufsorganisation der HJ überhaupt - sollten ,die in der Hitler-Jugend bewährten erzieherischen Ideale auch in der Schule ihren allgemeinen positiven Einsatz erfahren“. Schließlich hätte - jetzt folgte der 'Autoritätsbeweis' - das ,Werk der vom Führer selbst gegründeten Adolf-Hitler-Schulen gezeigt, wie erfolgreich die praktische Anwendung der gegebenen erzieherischen Grundsätze [der HJ] auch im Bereich des täglichen Unterrichts [an einer Schule]“ gelungen sei. Damit seien „,die Gedanken Baldur von Schirachs ... heute zur Grundlage der künftigen Aufbauarbeit in allen Kreisen unseres Volkes geworden, die sich mit der Erziehung der Jugend mittelbar oder unmittelbar beschäftigen". 29

Ein Reichsjugendführer mit Richtlinienkompetenz und die bewiesene praktische Durchführbarkeit der HJ-Erziehungsgrundsätze im Schulalltag, die nun auf ihren ,allgemeinen positiven Einsatz" warteten, - dies war der Grundtenor eines programmatischen Aufsatzes, den das HJ-Führerorgan Mitte Juli 1939 veröffentlichte und darin anonym - etwa Lehrer B. aus A. - Pädagogen und Schulbeamte zu Wort kommen ließ, die dem Schirachschen Konzept einer ,Einheit der Erziehung“ zujubelten. Zur Herstellung dieser Einheit brauchte man noch eine organisierte Gruppe von Pädagogen, die - auf die HJ fixiert und quasi als 'Fünfte Kolonne' - die Ziele der HJ an den Schulen auch praktisch umsetzen und in Einfluß verwandeln konnte. Dieser Arbeitsgemeinschaft der HJ-Lehrer, deren Angehörigen ungeniert schulische Aufstiegsmöglichkeiten versprochen wurden, sollte eine ,wertvolle Mittlerrolle zwischen den einzelnen Erziehungsträgern im Dienste einer künftigen Einheit der Erziehung zufallen“" ${ }^{30}$ Und wie diese „Einheit der Erziehung“ aussehen

26 BA, NS 6/322, Bl. 62 ff. (Wächtler an Bormann, 9.1.1939).

27 Vgl. RB, 10/II, 12.3.1937 (Anweisung der RJF zur Einsetzung von Schulbeauftragten der HJ).

28 Vgl. RB, 11/III, 25.3.1938.

29 Kaufmann, Stimmen für die Einheit der Erziehung, S. 1 ff.

30 Ebenda. Der SD hatte schon im Vorjahr konstatiert, daß es ,auf dem Gebiete der Erziehung auch 1938 nicht gelungen“ sei, ,der Schule ein neues Gesicht zu geben“. Die „Stimmung der Lehrerschaft“ sei nach wie vor ,ungünstig"; sie fühle sich ,zurückgesetzt" und vertrete „die Auffassung, daß ihr eine ihrer Bedeutung entsprechende Stellung innerhalb der Volksgemeinschaft nicht eingeräumt werde“. Meldungen aus dem Reich, S. 119 (Jahreslagebericht 1938). Anfang 1939 hätte sich, so der SD, ,das Verhältnis zwischen Hitler-Jugend und Lehrerschaft weiter verschlechtert“; besonders die „Erörterungen über Erziehungsprobleme in der Zeitschrift 'Wille und Macht' und die damit verbundenen Kritiken" hätten bei „,den Lehrern ernste Bedenken ausgelöst", so daß sich sogar ,Junglehrer von der aktiven Arbeit in der HJ zurück[ge]zogen“ hätten. Vgl. ebenda, \$. 286 (1. Vierteljahresbericht 1939). 
sollte, darüber ließ Reichsjugendführer Schirach zwei Monate später keinen Zweifel mehr zu - er selbst müsse Reichserziehungsminister werden.

Am 5. September 1939 hatten der mit der Verwaltung der Regierungsgeschäfte beauftragte Hermann Göring und Joseph Goebbels die ihnen vom Reichsjugendführer vorgeschlagene Möglichkeit erwogen, Reichsminister Rust die Verantwortung für die Schulverwaltung zu entziehen und diese Schirach zu übertragen, jedoch keine Entscheidung getroffen. ${ }^{31}$ Um vollendete Tatsachen zu schaffen, begann Schirach - sich dabei auf angebliche Vollmachten Görings berufend mit präjudizierenden Maßnahmen zur Neuordnung des Schulwesens. ${ }^{32}$ In einem als "Geheim" klassifizierten Schreiben an die HJ-Gebietsführer und BDM-Obergaufuihrerinnen teilte der Reichsjugendführer den 72 höchsten regionalen HJ-Funktionären am 11. September 1939 mit, daß beabsichtigt sei, ihm ,die Zusammenfassung aller erzieherischen Kräfte während des Krieges zu übertragen", also zumindest auch die Leitung des Reichserziehungsministeriums; daß Schirach ohne Konsultation mit Hitler - eine schriftliche Mitteilung von derartiger Reichweite herausgab, gehörte auch zur üblichen Taktik des Schaffens von vollendeten Tatsachen und zeigte gleichermaßen, wie sicher Schirach sich seiner Sache wähnte und wie sehr er die Verhältnisse in der Reichsführung fehlinterpretierte. Dafür, daß Schirach das Erziehungsministerium meinte, sich seiner Berufung ziemlich sicher war und nicht nur an eine vorübergehende Beauftragung dachte, sprachen auch seine nachfolgenden Warnungen und Verhaltensanweisungen. Seine Ernennung zum Chef aller ,erzieherischen Kräfte“ dürfe ,innerhalb der [Hitler-]Jugend nicht als Sieg eines Erziehungsfaktors über den anderen ausgelegt werden“, denn dies würde seine „Tätigkeit unnötig erschweren". Da „während des Krieges keinerlei innere Auseinandersetzung geduldet werden“ könne, sei die ,im Interesse der Landesverteidigung erforderliche Vereinheitlichung der Befehlsgewalt auf erzieherischem Gebiet von der [Hitler-]Jugend und ihren Dienststellen mit dem in diesem Falle notwendigen Taktgefühl" aufzunehmen. ${ }^{33}$

Doch Schirach hatte sich verkalkuliert; eine allgemeine Unzufriedenheit mit Rusts initiativloser, sich halsstarrig an Kompetenzen klammernden Amtsführung reichte zu dessen Ablösung nicht aus. Über die Ursachen, die letztlich Schirachs Ernennung zum Reichserziehungsminister verhinderten - Rusts Bedenken werden sicherlich nicht maßgeblich gewesen sein ${ }^{34}$ - können nur Vermutungen angestellt werden. Dazu gehörte offensichtlich die Tatsache, daß im gerade begonnenen Krieg - man hatte ja noch keine Erfahrungen mit Blitzsiegen und Niederlagen - keine großen personellen Veränderungen stattfinden sollten, die geeignet gewesen wären, die Bevölkerung zu verunsichern und institutionelle Kämpfe zu provozieren. Zudem scheint es, daß Hitler trotz seiner kritischen Einstellung Rust gegenüber möglicherweise auch unter dem Einfluß der einen Präzedenzfall fürchtenden Ministerialbürokratie davor zurückschreckte, den Gesamtkomplex der Jugenderziehung in eine Hand zu geben, und damit ein weiteres der klassischen Ressorts einem Gliederungsführer der NSDAP zu unterstellen.

31 Goebbels hatte über eine am 5.9.1939 mit Göring geführte Besprechung u.a. festgehalten: „Schirach soll nun die Schulen übemehmen und Rust ein reines Wissenschaftsministerium bilden. Am besten wäre es, er ginge ganz in Pension.“ Goebbels, Tagebücher, Teil I, Bd. 7, S. 95 (Notiz vom 6.9.1939).

32 Vgl. BA, R 43 IV/945 a (Aktenvermerk RK, 23.9.1939). Schirach berief sich bei den Kriegsplanungen für das Schulwesen u.a. auf von Göring während einer Sitzung des Reichsverteidigungsrates geäußerte Vorstellungen, nach denen eine absolute Verkürzung der Schulzeit auf Volks- und höheren Schulen notwendig und wünschenswert sei. Weil in dem den Schulunterricht ergänzenden, nunmehr täglichen HJ-Dienst die Fächer Musik, Sport und Werken gelehrt würden, könnten diese aus der Stundentafel der Schule herausgenommen werden; vgl. dazu Wortmann, Schirach, S. 180.

33 BA, NS 28/30, Bl. 3 (Schirach an die HJ-Gebietsführer und BDM-Obergauführerinnen, 11.9.1939, geheim); veröffentlicht bei Jahnke/Buddrus, Deutsche Jugend, S. 309.

34 Der von Schirachs Aktivitäten völlig überraschte Rust bat Göring um Aufklärung, da die „von dem Reichsjugendführer eingeleiteten Maßnahmen in der Schulverwaltung die größte Verwirrung anrichten" würden. Wie immer hatte Rust gegen eine „Neuordnung die schwersten Bedenken“. Außerdem stehe, und das war sein zu diesem Zeitpunkt stärkstes Argument, ,die in Aussicht genommene Verkürzung der Schulzeit völlig im Gegensatz zu Forderungen, die der Oberbefehlshaber des Heeres für den Offiziersnachwuchs stelle. Dieser verlangt besonders gut ausgebildete Abiturienten". Vgl. BA, R 43 II/945a (Aktenvermerk RK, 23.9.1939). Nachdem Hitler sich über die Vorgehensweise Schirachs hatte unterrichten lasssen und Göring erklärte, daß es sich dabei „lediglich um einen von dem Reichsjugendführer vorgetragenen Wunsch" gehandelt habe, jedoch „noch nichts“ entschieden sei, wurde Schirach gestoppt, und Hitler untersagte vorerst weitere Eingriffe des Reichsjugendführers in das bestehende Erziehungssystem. Ebenda (Lammers an Göring, 24.9.1939, Aktenvermerk Lammers, 28.9.1939.) 
Als sich Schirachs Pläne nicht verwirklichen ließen und die auch als Resultat der von ihm gezüchteten Kriegsbereitschaft seit Kriegsbeginn fast führerlose HJ-Organisation wegen der sich in Richtung 'Jugendverwahrlosung' verstärkenden Vorwürfe immer mehr ins Kreuzfeuer der Kritik geriet - wofür jetzt vor allem die Reichsjugendführung verantwortlich gemacht wurde, während Heydrich und Göring auf den von ihnen geleiteten Krisensitzungen gerade dem bislang für unfähig erklärten Reichserziehungsministerium die Rolle eines Ordnungsfaktors zuerkannten ${ }^{35}$-, gab der HJ-Führer auf. Schirach ließ sich - auch, um nicht in den Strudel einer möglichen Suche nach einem Sündenbock für die Zustände in der HJ hineingerissen zu werden - zu einem kurzfristigen Militäreinsatz einberufen und begann, sich nach anderen Verwendungsmöglichkeiten umzusehen; im August 1940 wurde er zum Gauleiter und Reichsstatthalter von Wien ernannt. Nur einmal noch, im Zusammenhang mit der Einrichtung der Erweiterten Kinderlandverschickung im September 1940, flackerte sein Interesse an der Übernahme des Erziehungsressorts erneut auf. Ein Jahr nach der für ihn blamablen, sang- und klanglosen Erledigung seiner großspurigen Ankündigung vom September 1939 schien für Schirach nun die Gelegenheit günstig, mit einer Politik der kleinen Schritte das angestrebte Ziel doch noch zu erreichen. Wie weiter unten gezeigt wird, stellte für ihn die Erweiterte Kinderlandverschickung, in der Schirach im Herbst 1940 wenigstens Teilkompetenzen für den Bereich der Schuljugend übertragen wurden, eine neue Möglichkeit dar, ,eine 'Machtergreifung' auf dem Schulsektor mittels einer zunächst kriegsbedingt motivierten Verknüpfung von Schule und [HJ-]Lager, wie sie die Erweiterte KLV darstellte ${ }^{636}$, doch noch durchsetzen zu können.

Dennauffällig ist immerhin, daß es im August und September 1940 - synchron zur Ablösung Schirachs als Reichsjugendführer und seiner Ernennung zum Gauleiter und Reichsstatthalter in Wien, parallel zu der letztlich erfolgreichen Verdrängung Rusts aus seinem Amt als Gauleiter und zeitgleich mit der Planung und Einrichtung der Erweiterten Kinderlandverschickung - zu Versuchen kam, den amtierenden Reichserziehungsminister mittels weitreichender Denunziationen auch aus seinem staatlichen Amt abzulösen: Möglicherweise auch von dem immer noch ambitionierten, auf jeden Fall informierten Schirach ${ }^{37}$ präpariert, mit dem Goebbels damals noch eng verbunden war, hatte sich der Reichspropagandaminister am 8. August 1940 zum ersten Mal mit der Schulbuchsituation im Reich beschäftigt ${ }^{38}$ und sich am 25. September mit Hitler, einen Tag später mit Hitler und Schirach über diese Thematik unterhalten. So informierte Goebbels den Führer am 25. September darüber, daß es „,in der Schulfrage“ noch „schlimm“ aussehe, die „Lehrbücher in den Schulen ... noch von anno Tobak“ seien und Rust „garnichts“ tue. Daraufhin gab Hitler „Auftrag an Bouhler, sich der Lehrbücherfrage anzunehmen" ${ }^{39}{ }^{39}$ Bormann hatte schon nach dem ersten Gespräch von Hitler und Goebbels den Sachverhalt polemisch zugespitzt zusammengefaßt und Lammers darüber informiert, daß, in den Schulen fast restlos noch Schulbücher verwandt [würden], die längst vor der Machtübernahme verfaßt worden seien"; daraufhin habe Hitler angeordnet, daß nachdem das zuständige Ministerium versagt habe - eben „die Partei die notwendigen Arbeiten

35 Vgl. dazu die Darstellung im Kapitel 6.

36 Kock, Kinderlandverschickung, S. 79.

37 Im Zuge der 1938/39 eingeleiteten Umgestaltung des Schulwesens und der Lehrerbildung hatte sich Schirach wegen einer Maßnahme des Reichserziehungsministeriums beim Stellvertreter des Führers beschwert, in dieser Angelegenbeit nicht gehört worden zu sein, gleichzeitig aber hervorgehoben, daß die bildungspolitischen Mitarbeiter von Heß mit denen der Reichsjugendführung sonst immer ,in einem lebhaften Gedankenaustausch“ stünden; außerdem, so Schirach lobend, werde er selbst von $\mathrm{Heß}$ ' Mitarbeitern ,laufend über die geplanten Neuordnungen auf dem Gebiete des Schulwesens unterrichtet". BA, NS 6/322, BI. 159 (Schirach an Heß, 4.4.1939); dann wird Schirach auch Kenntnis von der kurz zuvor für Heß angefertigten Vorlage zum Problem des Volksschullehrermangels gehabt haben, in der es u.a. hieß. „Wir haben keine neuen Lehrbücher und wir haben keine richtigen nationalsozialistischen Lehrpläne." Ebenda, Bl. $120 \mathrm{ff}$. (Vorlage Sommers für $\mathrm{Heß}, 21.12 .1938$ ).

38 Vgl. Goebbels, Tagebücher, Teil I, Bd. 8, S. 259 (Eintrag vom 8.8.1940); darin: „Reform unserer Lehrbücher in den Schulen eingeleitet. Mit Rust ist das nicht zu machen. In den Schulen werden Geschichtsbücher von 1905 gebraucht. Ich sammle nun Material und werde das dem Führer zur Entscheidung vorlegen." Unklar bleibt, von wem Goebbels auf diese Thematik aufmerksam gemacht wurde, die nicht zu seinem Ressort gehörte.

39 Ebenda, S. 34 (Eintragung vom 26.9.1940). Einen Tag später bekräftigte Goebbels diesen Sachverhalt: „Bouhler hat nun den Auftrag, die Schullehrbücher umzugestalten. Rust muß sich fügen. “Ebenda, S. 348 (Eintrag vom 27.9.1940); vgl. auch den Eintrag vom 13.12.1940, in: ebenda, Bd. 9, S. 50, mit einer scharfen Kritik von Goebbels an Rust. „Es ist zum Weinen. Dieser Dilettant müßte verjagt werden“". 
durchführen“ müsse und „bestimmt, daß Reichsleiter Bouhler mit der Parteiamtlichen Prüfungskommission und dem NS-Lehrerbund beschleunigt für die Abfassung von Schulbüchern, die den nationalsozialistischen Anforderungen entsprächen, sorgen solle“.40

Genau zu der Zeit also, als die Einrichtung der Erweiterten Kinderlandverschickung geplant und in Angriff genommen wurde, teilte der Chef der Reichskanzlei dem Reichserziehungsminister mit, daß „dem Führer von beachtenswerter Seite berichtet worden“ sei, ,daß noch heute in den Schulen fast restlos Lehrbücher verwendet würden, die längst vor der Machtübernahme verfaßt worden seien“. Lammers, der die Formulierungen Bormanns fast wörtlich aufgriff und zu von Hitler geäußerten Vorgaben umformte, informierte Rust darüber, daß angeblich im gesamten Reich „Klagen über die veralteten Schulbücher laut geworden [seien], die durch ihren überholten Lehrstoff sich nicht im Sinne der nationalsozialistischen Weltanschauung“" auswirken würden und ,daher in hohem Maße schädlich" seien. Hitler habe daher die Parteiamtliche Prüfungskommission und den NS-Lehrerbund beauftragt, ,, beschleunigt für die Abfassung von Schulbüchern, die den nationalsozialistischen Anforderungen entsprechen, Sorge zu tragen“, und gleichzeitig den Reichserziehungsminister ,für die Dauer von zehn Jahren von der Verantwortung für die Verwendung geeigneter Lehrbücher an den Schulen entbunden"“."

Dem Bildungsminister derart gravierende Pflichtversäumnis und parteischädigendes Verhalten vorzuwerfen, war natürlich ein starkes Stück, ebenso die Aberkennung seiner Zuständigkeit für Schulbücher, die de facto einer Entmachtung gleichkam. Rust wehrte sich zwar und stellte in einer mehr als 60seitigen Dokumentation die Voraussetzungen als unzutreffend dar, die Hitler zu seiner Entscheidung bewogen haben. Er verwies detailliert auf seine Anstrengungen zur Schaffung nationalsozialistischer Schulbücher und machte vor allem darauf aufmerksam, daß er von ,der Partei“" erst im Januar 1938 bzw. im Dezember 1939 die schulpolitischen Richtlinien erhalten habe, die sowohl die Basis für entsprechende Unterrichtspläne bilden mußten als auch als Grundlage für adäquate Schulbücher notwendig waren; seitdem hätte eine immer noch andauernde intensive Schulbucherneuerung stattgefunden. ${ }^{42}$

$\mathrm{Da}$ jedoch kaum ein Führerbefehl rückgängig gemacht wurde - der in diesem Fall von Rust beschuldigte Philipp Bouhler nutzte als Chef der Kanzlei des Führers seinen unmittelbaren Zugang zu Hitler für sich und hatte kein Interesse an der detaillierten Aufklärung dieser Angelegenheit, die ihm in dem von Bormann betriebenen Prozeß auch seiner Kaltstellung zumindest geringen Kompetenzzuwachs einbrachte -, blieb es bei Hitlers Anordnung ${ }^{43}$, wenngleich der angeschlagene Erziehungsminister - schon aus Gründen der fachlichen Kompetenz und um sein „Ansehen in der Öffentlichkeit und in der Schulbehörde zu wahren" - von Bouhler an den Schulbuchangelegenheiten „,beteiligt" werden sollte. ${ }^{44}$ Der zum Reichsbeauftragten für das Schul- und Unterrichtsschrifttum ernannte Bouhler richtete im November 1940 eine gleichnamige Reichsstelle ein, die sich neben der Schulbuchproduktion in steigendem Maße auch in die Lehrplangestaltung und in die Schulreformen und damit in "das Kerngebiet der Aufgaben des Reichserziehungsministers" einzumischen begann. ${ }^{45}$ Rust ist jedoch auch nach diesen Angriffen, deren Ausläufer sich jahrelang hinzogen und denen er mit geschicktem Taktieren zu begegnen suchte, nicht abgelöst worden. ${ }^{46}$

40 BA, R 43 II/953 b, Bl. 2 (Bormann an Lammers, 25.9.1940); Bormann gab auch Hitlers Anweisung weiter, einen Erlaß zu entwerfen, durch den das Ministerium auf die Dauer von zehn Jahren von der Verantwortung für die Schulbücher entbunden werde.

41 Ebenda, Bl. 5 f. (Lammers an Rust, 2.10.1940).

42 Ebenda, Bl. 11 ff. (Rust an Lammers, 5.10.1940).

43 Ebenda, Bl. 59 f. (Lammers an Rust, 20.10.1940); Hitler könne einen persönlichen Vortrag von Rust, in absehbarer Zeit leider nicht entgegennehmen“; er habe auch „davon abgesehen, seine Anordnung zurückzunehmen oder abzuändern“, er wünsche vielmehr, „daß die ihm sehr am Herzen liegende Frage der Schulbücher von Reichsleiter Bouhler im engsten Einvernehmen" mit Rust gelöst werde.

44 Ebenda, Bl. 50 ff. (Bouhler an Lammers und Rust, 17.10.1940).

45 Ebenda, Bl. 74 ff. (Rust an Lammers, 7.6.1941).

46 Die Auseinandersetzungen zwischen Rust und Bouhler dauerten bis Ende 1944 an, füllten mehrere hundert Seiten Papier und kamen zu keinem befriedigenden Ergebnis. Lediglich die Zahl der Schulbücher ist durch Bouhlers Versuche zur Schaffung von wenigen reichseinheitlichen Lernmitteln - Slogan: „Ein Volk, ein Reich, ein Schulbuch“ drastisch reduziert worden: Gab es 1943 noch insgesamt 16.545 verschiedene Titel, von denen 1.195 auf Volks-, 
Als dies für Schirach klar wurde und sich zudem herausstellte, daß mit der Notmaßnahme der Erweiterten Kinderlandverschickung eher ermüdende und lästige organisatorische Maßnahmen verbunden waren als daß die KLV Raum und Anlaß für große Auftritte, Publizität und Popularität geboten hätte und zudem in der Bevölkerung weitgehend unbeliebt war, begrub er die früheren Pläne zur „Einheit der Erziehung“.

Ab 1940/41 war auch unter dem Eindruck des Kriegsgeschehens und mit dem Führungswechsel in der HJ-Zentrale, angesichts des desolaten Zustandes der weitgehend führerlosen, mit vielfachen neuen Aufgaben konfrontierten und im organisatorischen Umbruch befindlichen HJ hinsichtlich des Kampfes um die 'neue', nationalsozialistische Schule eine Zeit der äußerlichen Ruhe eingekehrt. Die praktische Durchführung der Jugenddienstpflicht, die Organisation der Kriegseinsätze, die Kompensation der durch Kriegseinsätze abwesenden HJ-Führer beanspruchten die Kräfte der Jugendorganisation über Gebühr; zudem war unklar, wie sich der Krieg weiterentwickeln und ob er vielleicht sogar bald beendet sein würde, so daß mit dem großen Kontrahenten zunächst eine Art 'Burgfriedensabkommen' abgeschlossen werden mußte. Die Intiative dazu ging vom neuen Reichsjugendführer Artur Axmann aus, der in der Vergangenheit eher mit der berufstätigen Jugend und sozialen Fragen beschäftigt war und nicht so stark wie sein Vorgänger in die Querelen mit dem Reichserziehungsministerium involviert gewesen ist.

Axmann war bemüht, einen - für die HJ positiven - Ausgleich zu schaffen und legte dem Stellvertreter des Führers am 29. Oktober 1940 seine Vorstellungen zur Gestaltung des künftigen Verhältnisses zwischen Schule und $\mathrm{HJ}$ dar. ${ }^{47} \mathrm{Heß}$ billigte und unterstützte diese Vorschläge, nicht zuletzt deshalb, weil sie der HJ - auf Kosten der Schule - einen größeren Spielraum für die Durchführung ihrer Erziehungsarbeit und ihrer Kriegseinsätze verschafften. Daraufhin vereinbarten der Reichserziehungsminister und der Reichsjugendführer am 31. Januar 1941 eine Abgrenzung der Zuständigkeiten beider Erziehungsträger und formulierten - ,in Anerkennung der beiderseitigen Erziehungsaufgaben an der deutschen Jugend“ - Grundsätze, die für die künftige „Inanspruchnahme der Jugend durch Schule und Hitler-Jugend" maßgebend sein sollten. Danach war vorgesehen, daß die Vormittage sämtlicher Wochentage der Schule, die Nachmittage der HJ und dem Elternhaus zustehen sollten, zwei Tage grundsätzlich frei von Schulaufgaben sein mußten und HJFührer zur Teilnahme an Führerschulungen vom Unterricht zu befreien waren. ${ }^{48} \mathrm{Im}$ Vergleich zur Situation neun Jahre zuvor, als die Reichsjugendführung der Erziehungsbehörde mit dem Staatsjugendtag lediglich einen schulfreien Vormittag abtrotzen konnte, stellte diese Regelung einen deutlichen Machtgewinn der HJ dar; sie demonstrierte zugleich den Kompetenzverlust der Schulbehörde und den weiter gesunkenen Stellenwert von schulischer Bildung überhaupt.

Schon beim Abschluß dieser Einflußfelder und Zuständigkeiten absteckenden Vereinbarung, die zwar bis Kriegsende gültig blieb, von Seiten der HJ aber beständig ausgehöhlt wurde, war offensichtlich, daß sich bei deren Durchführung ,während des Krieges Schwierigkeiten ergeben“ würden, die von den regionalen Schulaufsichtsbehörden und den $\mathrm{HJ}$-Gebietsführungen dezentral geregelt werden sollten. ${ }^{49}$ Und diese Schwierigkeiten ergaben sich schon bald darauf, zum einen durch den Kriegsverlauf selbst, der der HJ weit höhere Beanspruchungen auferlegte, sie zu weit größeren Leistungen zwang und ihr wesentlich mehr Aufgaben zuwies, als lediglich an den Nachmittagen zu lösen gewesen wären; zum anderen nutzte die HJ-Führung alle sich bietenden Gelegenheiten, die Bestimmungen dieses Abkommens unter Hinweis auf echte oder vermeintliche Sachzwänge zu unterlaufen.

Haupt- und höhere Schulen, 1.450 auf Klassenlesestoffe und 13.900 auf Fachschulen entfielen, so sollte diese Zahl für das Schuljahr 1944/45 auf 838, also um 95\% reduziert werden. vgl. dazu BA, R 43 II/953 b, Bl. 234 ff. (Rundschreiben des Reichsbeauftragten für das Schul- und Unterrichtswesen an die Reichsminister, Reichsstatthalter und Gauleiter der NSDAP, April 1944). Hinter der Übernahme der Schulbuchkontrolle, der Reduzierung der Zahl der Schulbücher und den Versuchen zu deren konzentrierter Herausgabe im Deutschen Schulbuchverlag standen auch finanzielle Motive: Der Deutsche Schulbuchverlag war ein dem Eher-Verlag angeschlossener Parteibetrieb, und eine dort monopolisierte Schulbuchpublikation wäre einer Lizenz zum Gelddrucken gleichgekommen.

$47 \mathrm{Vgl}$. BA, NS 28/81 (Notiz von Friedrichs für Bormann über einen Vortrag Axmanns bei Heß, 29.10.1940).

48 ANBI., 1941, S. 15 ff. (Vereinbarung zwischen dem RMWEV und dem JFdDtR über die Inanspruchnahme der Jugend durch Schule und HJ, 31.1.1941).

Ebenda. 
So stellten die von dieser Vereinbarung erhoffte Ruhe und Kompetenzabgrenzung nur ein äußerliches Stillhalten dar; unter Leitung des neuen Reichsjugendführers Axmann konzentrierte sich die HJ-Zentrale mit ihren Versuchen zur Vereinnahmung bzw. Instrumentalisierung des Schulwesens vorrangig auf zwei Tätigkeitsfelder, auf das Gebiet der Lehrerbildung und die sich aus der Einführung des neuen Schultyps Hauptschule ergebenden Aufgaben, zwei Bereiche, mit denen man das Schulwesen gewissermaßen 'von unten' in den Griff kriegen wollte ${ }^{50}$ :

Als Goebbels Ende September 1940 notierte: „Auch die Lehrererziehung liegt ganz falsch. Man darf die Lehrer nicht akademisch ausbilden. Das macht sie nur unzufrieden mit dem ABC ... Höhere Bildung schreit nach höherem Amt. Gibt man das nicht, dann kommt Unzufriedenheit “51, bewegte er sich damit in einem von verschiedenen Fraktionen getragenen allgemeinen Trend. Darin bildeten sowohl Hitler, der sich aus weltanschaulichen und 'erziehungstheoretischen' Erwägungen für eine Entakademisierung der Lehrerbildung einsetzte ${ }^{52}$ - auch darin eifrig von Bormann assistiert, der den Lehrerberuf als erlernbares Handwerk betrachtete -, als auch das Reichsfinanzministerium die entscheidenden Pole. Letzteres ging aus ganz pragmatischen Erwägungen davon aus, daß für höhere Leistungen auch höhere Besoldungen erforderlich seien; höhere Leistungen aber würden erst durch höhere Ausbildung möglich. Schon aus Gründen der Kostenersparnis müsse das Niveau der Lehrerbildung daher möglichst gering gehalten werden, weil eine qualifizierte Ausbildung ansonsten unumgängliche Besoldungserhöhungen nach sich ziehen würde. Auch die HJ sah wie immer in der „Lehrerfrage“ den „Kern des Problems“, sowohl für ,alle Reformen des Schulwesens“ als auch zur Steigerung ihres Einflusses auf die Schule, ein Problemkreis, der von ihr mit den Eckpunkten einer permanenten „Änderung der Lehr- und Stoffpläne“, der ,,anderweitigen Inanspruchnahme der Schule“ sowie der „außerschulischen Belastung der Lehrkräfte, aber auch der Schüler“ umrissen wurde. Hinzu komme, daß „dank der bevölkerungspolitischen Vorsorge“ des Reiches die Schulklassen der jüngeren Jahrgänge überfüllt seien, während auf seiten der Lehrer durch Einberufungen zur Wehrmacht, ,drohende Überalterung“ und starken Nachwuchsmangel eine entgegengesetzte Entwicklung zu beobachten sei.

Nachdem die HJ jahrelang in starkem Maße zum Ansehensverfall des Lehrerstandes beigetragen hatte, sah die Reichsjugendführung nunmehr, wo es um ihren Einstieg in die Lehrerbildung, also um eigene Interessen ging, in der Aufhebung der ,Minderung des Ansehens des Lehrers" ${ }^{\star 53}$ die entscheidenden Angriffs- und Eingriffsmöglichkeiten auf und in den Schulbetrieb. Die aus der „Minderung des Ansehens" resultierenden Nachwuchsschwierigkeiten hatten schon Ende der 30er Jahre zu einem erheblichen Mangel vor allem an Volksschullehrern geführt, eine Tatsache, die zwar von maßgeblichen Staats- und Parteistellen beklagt, von den Ämtern mit Entscheidungskraft

50 Dies belegen auch unmittelbar nach 1945 von der amerikanischen Militärregierung angestellte Untersuchungen über die Konflikte der Reichserziehungsbehörde mit den Dienststellen der Partei, in denen hochrangige Beamte des Ministeriums vernommen wurden. Auch hier tauchten als Ergebnis der Einmischung der $\mathrm{HJ}$ in den Erziehunsgbereich immer wieder die Frage der Neugestaltung der Lehrerbildung, die Einführung der Hauptschule und die Verkürzung der Ausbildungszeiten der höheren Schulen als die Felder auf, auf denen sich das Reichserziehungsministerium den stärksten Angriffen ausgesetzt sah und die größten Niederlagen hinnehmen mußte. Vgl. dazu BA, R 21/708 und 707 (vom Education Branch des Ministerial Collecting Center des Office of Military Government for Germany zusammengestellte Analysen, Befragungen und Dokumente).

51 Goebbels, Tagebücher, Teil I, Bd. 8, S. 346 (Eintrag vom 26.9.1940).

52 In einem Schreiben an Gunther d'Alquen, den Schriftleiter des SS-Organs Das Schwarze Korps, hatte Walther Sommer, Chef der Abteilung III (Staatliche Angelegenheiten) beim Stellvertreter des Führers, am 2.2.1939 einen Aufsatz im Schwarzen Korps über die "Sicherung des Lehrernachwuchses“ gerügt. Dieser entspreche „nicht der Linie der Partei“" und unterstütze lediglich ,,die Bestrebungen der Lehrerschaft, ihr Scheinakademikertum zu erhalten“; ,,sämtliche Gauleiter" lehnten „die Hochschulbildung der Lehrer ab", und der Führer habe „als beste Nachwuchsquelle für die Volksschullehrer den 12jährig gedienten Unteroffizier bezeichnet". BA, NS 6/322, B1. 72.

53 So in BA, NS 26/358 (Kriegsgeschichte der HJ, 1944). 
und -befugnis jedoch nicht behoben wurde. ${ }^{54}$ So kritisierte die Gauleitung Halle-Merseburg bereits im Herbst 1937 den fehlenden Lehrernachwuchs; dies sei ,eine Folge der vollkommen unzureichenden Planwirtschaft" des Reichserziehungsministeriums. Die Städte müßten bereits dazu übergehen, „Pensionäre, die schon jahrelang im Ruhestand lebten, wieder aufzuscheuchen“; dabei sei „Zweifelhaft, ob ihre altersmüden, zittrigen Hände ... den gewaltigen Anforderungen der Schule des Dritten Reiches gewachsen" seien. ${ }^{55}$ Auch das württembergische Kultusministerium sah im Januar 1938 „für das Volksganze schwere Gefahren, wenn nicht in Bälde die notwendigen Maßnahmen ergriffen“ würden, „um die Nachwuchsfrage für den Lehrerstand zu lösen“. ${ }^{56}$ Und noch ein Jahr später wandte sich der Chef des NS-Lehrerbundes, Fritz Wächtler, zum wiederholten Male an Bormann, diesmal mit dem scheinbar finalen Fazit: „Es kann so nicht weitergehen“. Was würden alle Bestrebungen nach ausreichendem Facharbeiternachwuchs nützen, ,wenn man den Lehrermangel, der noch durch eine verständliche Flucht aus dem Lehrerberuf täglich größer wird, nicht beseitigt oder doch stoppt“. Bereits jetzt bestünden im Reich Katastrophen als „Dauerzustand“, etwa Schulklassen, ,die wochenlang ohne Lehrer" seien, oder Fälle, ,in denen Lehrer zwei und mehr überfüllte Klassen gleichzeitig zu betreuen" hätten. Immer mehr ältere Lehrer verließen den Beruf, weil ,sie wirtschaftlich vor die Hunde gehen“, und der männliche Nachwuchs - so vorhanden - würde ,immer mehr eine Auswahl der Minderwertigen“. ${ }^{57}$

Anfang 1939, Rust hatte nach einer qualifizierten Analyse der komplexen Gründe für den Mangel an Nachwuchs für den Volksschullehrerberuf die aus Sicht der Partei letztlich untaugliche Einrichtung von staatlichen Aufbaulehrgängen angeordnet ${ }^{58}$, sind - weil Heß Hitler über die Zustände im Volksbildungswesen berichten mußte - im Stab des Stellvertreters des Führers schon 1938 enstandene Analysen hervorgeholt und konkretisiert worden, die zeigen, daß die Probleme dort seit langem bekannt waren. Als bei der Behebung des Lehrerproblems zu lösende Kernfragen galten in der Parteispitze die Abschaffung der akademischen Volksschullehrerbildung - diese „biete keine Gewähr, den Volksschullehrernachwuchs sicherzustellen“ -, die Erhöhung der Besoldung der Volksschullehrer - deren Besoldungsumfang sei „nicht als ein Werbemittel“ für den

54 Situation im Schulwesen und Stand der Lehrerversorgung 1938 auf dem Gebiet des Altreiches; zusammengestellt und berechnet nach Koppelmann, Die Entwicklung des deutschen Schulwesens, S. $104 \mathrm{ff}$.

\begin{tabular}{|l|r|r|r|r|}
\hline & \multicolumn{1}{|c|}{ Volksschulen } & Mittlere Schulen & Höhere Schulen & NPEA \\
\hline Schulen & 51.426 & 1.531 & 2.381 & 15 \\
\hline Klassen & 189.312 & 9.469 & 25.811 & 151 \\
\hline Schüler & 7.621 .220 & 271.188 & 662.411 & 3.701 \\
\hline Lehrer & 180.323 & 10.568 & 46.110 & 400 \\
\hline Klassen pro Schule & 3,7 & 6,8 & 10,8 & 10 \\
\hline Schüler pro Klasse & 40,3 & 28,6 & 25,7 & 24,5 \\
\hline Schüler pro Lehrer & 42,3 & 25,7 & 14,4 & 9,3 \\
\hline
\end{tabular}

BA, NS 26/322, Bl. 1 f. (Auszüge aus Monatsberichten der Gauleitungen, November 1937).

56 Ebenda, Bl. 4 ff. (Mergenthaler an Heß, 24.1.1938).

57 Ebenda, B1. 62 ff. (Wächtler an Bormann, 9.1.1939). Die ,überall mit Besorgnis gestellte Frage nach dem Lehrernachwuchs" hatte, wie auch der SD vermerkte, 1938 ,an der Spitze aller Erörterungen gestanden“. Die Arbeit besonders im Volksschulwesen werde durch den Lehrermangel erheblich gehemmt. So konnte ,in verschiedenen Regierungsbezirken ein ordnungsgemäßer Schulbetrieb z.Zt. nicht mehr aufrechterhalten werden". Allein in Preußen fehlten ,heute über 3.000 Lehrkräfte“", in Ostpreußen seien 500 Lehrkräfte ausgefallen, aus Bayern wurden 600 freie Stellen gemeldet, aus Württemberg 150. Meldungen aus dem Reich, S. 136 ff. (Jahreslagebericht 1938). Diese besorgniserregenden Meldungen aus dem Erziehungsbereich setzten sich auch 1939 fort; vgl. ebenda, S. 282 ff. (1. Vierteljahresbericht 1939). Im Frühjahr 1940 häuften sich „aus allen Teilen des Reiches" die Meldungen über ein „Absinken des Leistungsstandes an den Schulen“, das sich „zu einem wirklich ernsten Problem auswachse“. Lehrer und Eltern meinten, der Krieg habe diese seit mehreren Jahren zu beklagende Entwicklung noch deutlicher sichtbar gemacht; "Wirtschaftskreise“ bezeichneten den Leistungsstand neu beginnender Lehrlinge als ,miserabel und beschämend“; diese Lehrlinge seien ,wegen schlechter Schrift, mangelhaften Rechnens, aber auch aus einem Mangel an Pflichtgefühl kaum zu gebrauchen“. Die „Klagen der Hochschullehrer über das Abiturientenmaterial“" seien nicht geringer; ebenda, S. 958 (Bericht vom 6.4.1940).

58 Vgl. ebenda, Bl. 75 ff. (Rust an Heß, 6.2.1939); vgl. dazu Haupt, Neuordnung im Schulwesen. 
Lehrerberuf anzusehen - und die Abstellung der „nach wie vor ständigen Angriffe“ auf den Lehrerstand. Leider habe sich ,gerade auch die $\mathrm{HJ}$... besonders darin gefallen, das Ansehen des Lehrerstandes durch ihre Angriffe stark zu untergraben". So sei verständlich, daß gerade die in und von der HJ erzogenen Jugendlichen ,wenig Lust" empfänden, einen Beruf zu ergreifen, der ,dauernd Verunglimpfungen ausgesetzt“ sei. Die „Verpönung des Lehrers durch [die] HJ“ habe „moralisch den Lehrerberuf äußerst schwer geschädigt"; dies werde ,noch lange Zeit im Bewußtsein der Jugend" existieren.

Hinzu komme ,die Tatsache“, so die fundamentale Kritik im Stab Heß”, daß das gesamte Erziehungssystem, ,,besonders das staatliche Schulwesen, heute durchaus nicht als nationalsozialistisch bezeichnet werden“ könne; die Schulreform sei „im Sande verlaufen“, es existierten „keine neuen Lehrbücher" und ,keine richtigen nationalsozialistischen Lehrpläne“. Das „ganze Schulwesen" stehe ,in einer organisatorischen Mißgestalt da, die jegliche praktische Arbeit und jegliche Verwirklichung großer Ziele schlechterdings scheitern" lasse. Diese Bankrotterklärung war elementar, gravierend und total, ein Ausweg erschien angesichts dieser Bilanz kaum noch möglich. Als ,Sofort-Maßnahmen“ wurden vorgeschlagen, die Hochschulen für Lehrerbildung abzuschaffen und an ihrer Stelle Ausbildungsstätten in den Landkreisen zu errichten, das Abitur als Eingangsvoraussetzung zum Lehrerberuf wegfallen zu lassen - „Lehrer muß jeder werden können, der durch die Volksschule hindurch gegangen ist" -, die Besoldung der Volksschullehrer der der gehobenen mittleren Beamten anzupassen und die Volksschullehrer zu unmittelbaren Staats- oder Reichsbeamten zu ernennen, um sie damit aus den gemeindlichen Abhängigkeitsstrukturen zu befreien. ${ }^{59}$

Doch in der Phase der unmittelbaren Kriegsvorbereitung, als die materiellen, geistigen und personellen Ressourcen für die bevorstehende Auslösung des Aggressionskrieges gegen Polen gebündelt wurden, gab es in den Führungsspitzen der NSDAP und des Reiches kein Verständnis und keinen Raum für die Behebung dieses Problems; es wurde einfach verschoben, holte die zuständigen Akteure nach dem Sieg über Polen aber sofort wieder ein. Im Dezember 1939 galt im Stab des Stellvertreters des Führers die „Beseitigung des Lehrermangels als dringendstes Problem im Schulwesen“. Durch zahlreiche Einziehungen junger Lehrer zur Wehrmacht hatte sich die ohnehin prekäre personelle Situation im Schulwesen weiter verschärft; berichtet wurde, daß „,zahlreiche Schulen überhaupt keinen Lehrer" mehr hätten, und in ,,vielen Schulen nur drei Mal in der Woche Unterricht" stattfinde. ${ }^{60}$

Es ist zwar bedacht worden, die zur Wehrmacht einberufenen Lehrer zu reklamieren und zurückzuführen; dies wurde aber letztlich nicht realisiert, weil nun gerade die Angriffsvorbereitungen gegen Frankreich und England begonnen hatten. Auch bei retrospektiver Betrachtung bleibt unverständlich und kaum nachvollziehbar, warum - und das gilt ebenso für das personell ausgedünnte Führerkorps der Hitlerjugend - mit den Lehrern eine verhältnismäßig kleine Personengruppe, deren Zahl und 'Kampfwert' im Rahmen der gesamten Wehrmacht eher marginal war und mit Sicherheit als nicht kriegsentscheidend bezeichnet werden kann, 'aus Prinzip' nicht vom Wehr- und Kriegsdienst befreit wurde, woraus im zivilen Leben der Heimatfront aber Probleme resultierten, deren ständige Verschärfung in keinem sinnvollen Verhältnis zur geringen Bedeutung der Jugenderzieher in den Wehrmachtsformationen gestanden hat.

Erst Anfang 1941, mitten im Luftkrieg gegen England und parallel zum deutschen Ausgreifen auf den südosteuropäischen Kriegsschauplatz, ging man daran, das Problem endlich zu lösen. Zu diesem Zeitpunkt war der Lehrermangel bereits in einem Maße akut geworden war, das eine von zahlreichen Folgeerscheinungen begleitete innere Krise kaum noch abwendbar erscheinen ließ. Weil man aber gerade jetzt begann, alle personellen Ressourcen bis an die Grenze auszuschöpfen, mußten die Bemühungen um einen ausreichenden Lehrernachwuchs notwendigerweise proviso-

$59 \mathrm{Vgl}$. BA, NS 26/322, Bl. 80 ff. (Vorlagen von Wemmer, 21.12.1938 und 23.1.1939, Vorlage von Fischer, 10.2.1938, betreffend Volksschullehrermangel).

60 Ebenda, Bl. 260 f. (Aktennotiz Sommer, 1.12.1939); im Regierungsbezirk Dresden seien etwa in den Kreisen Freiberg 32 $\%$, Löbau $82 \%$, Hoyerswerda 31\%, Meißen $24 \%$ und Dresden Stadt $13 \%$ aller Lehrer zum Heeresdienst einberufen worden, in den Schulaufsichtsbezirken Großenhain und Kamenz etwa 50\%; im Gau Schwaben waren zu diesem Zeitpunkt bereits $23 \%$ aller Lehrer bei der Truppe, „noch stärker“" kompliziere sich „die Lage in den Westgebieten“. 
risch und unzureichend bleiben. Die einzige Personengruppe, die dafür überhaupt zur Verfügung stand und die Gewähr für eine nationalsozialistische Ausrichtung bot, war die der älteren HJ-Angehörigen; deshalb wurden der Reichsjugendführung schließlich maßgebliche Kompetenzen bei der Lehrerbildung übertragen. Wegen der dramatischen Verschlechterung der Schulversorgung durch die nicht nachlassenden Einziehungen von Lehrern zur Wehrmacht bei gleichzeitig weiter rückläufigen Zahlen von Nachwuchskräften war der Reichserziehungsminister also gezwungen, gegen seine Überzeugung die Hochschulen für Lehrerbildung aufzulösen und die Staatlichen Aufbaulehrgänge zu beenden; statt dessen mußte Rust auf dem Erlaßwege die Lehrerbildungsanstalten einführen ${ }^{61}$ und die $\mathrm{HJ}$ an deren Betrieb maßgeblich beteiligen.

Basierend auf einer Entscheidung Hitlers vom Dezember $1940^{62}$ wurden bereits im Frühjahr 1941 die ersten Lehrerbildungsanstalten eröffnet, und parallel dazu wurden bis zum April 1941 alle 26 Hochschulen für Lehrerbildung in Lehrerbildungsanstalten umgewandeit; 1942 bestanden bereits 223 Lehrerbildungsanstalten ${ }^{63}$, und bis 1943 wurden insgesamt 257 dieser Einrichtungen geschaffen. ${ }^{64}$ Die Einführung dieser Berufsausbildungsstätten für die in der Hierarchie der Pädagogen ganz unten rangierenden Volksschullehrer - von der Reichsjugendführung als ,wichtigster Schritt in der Schulpolitik des letzten Jahrzehnts" bezeichnet, der für die HJ ,den Beginn eines neuen Verhältnisses zur Schule und zum Lehrerstand ${ }^{\text {"65 }}$ markiere -, stellte einen der größten expansiven Erfolge des NS-Jugendverbandes in bezug auf das staatliche Erziehungssystem dar, der bei einem längeren Bestand des Regimes seine volle Tragweite entwickelt hätte. Das begann mit der „Auslese" der Schüler der Lehrerbildungsanstalten. Diese war keine schulinterne Angelegenheit mehr, sondern hatte ,,in engster Zusammenarbeit" mit der HJ zu erfolgen; auch die Musterungslager, in denen die am Lehrerberuf interessierten Jugendlichen auf ihre Eignung getestet wurden, standen unter Leitung von HJ-Führern und wurden ,,nach den Erziehungsgrundsätzen der Hitler-Jugend" geführt ${ }^{66}$, wenn auch nicht immer mit dem gewünschten Erfolg ${ }^{67}$.

61 Vgl. dazu Gutzmann, Die Ausbildung zum Volksschullehrerberuf.

62 Gebrdschr. RJF, 16/41, 26.5.1941. Darin teilte die Reichsjugendführung mit: „Der Führer hat im Dezember vorigen Jahres entschieden, daß die Heranbildung von Volksschullehrern nicht an den Hochschulen für Lehrerbildung, sondern in Lehrerbildungsanstalten erfolgen soll."

63 Vgl. MBIWEV, 1942, S. 364 ff. (Runderlaß des RMWEV, 24.9.1942, mit einem Verzeichnis aller - auch in den besetzten Gebieten - nach dem Stande vom 1.9.1942 bestehenden Lehrerbildungsanstalten).

64 Vgl. dazu die grundlegende Studie von Scholtz, Erziehung und Unterricht, hier S. 101. Nach einer durch die Reichsjugendfuihrung angeregten Anweisung Bormanns (RVBl., Folge 39/42, 23.9.1942) und im Einvernehmen mit den Führungen von SA, SS, NSKK und NSFK, blieben die Schüler von Lehrerbildungsanstalten bis zum Abschluß ihrer Ausbildung, d.h. zumeist bis zu ihrem 19. Lebensjahr, Angehörige der HJ. Die Situation auf dem Schulsektor wurde sogar als so dramatisch eingeschätzt, daß die 'Lehrer-Lehrlinge' nicht als Luftwaffenhelfer eingesetzt werden durften; dies hätte möglicherweise ihr Leben gefährdet oder ihre ohnehin schmalspurige Ausbildung weiter ausgedünnt.

65 BA, NS 26/358 (Kriegsgeschichte der HJ, 1944). Die „Vorzüge der Lehrerbildungsanstalten“ lagen für die HJ in folgenden Bereichen: Da das Abitur nicht mehr als Zugangsvoraussetzung galt, könne die „Nachwuchslenkung ... auf breitester Grundlage" erfolgen. Darüber hinaus sei „die Erziehung in den Anstalten nicht mehr nur Allgemeinbildung, sondern zugleich Berufsausbildung"; vor allem aber werde durch die „von den Lehrerbildungsanstalten in idealer Form verwirklichte Gemeinschaftserziehung ein neuer Typ des Schulerziehers geprägt, der nicht nur Staatsbeamter, sondern vor allem Repräsentant der politischen Bewegung" sein solle. Ebenda.

66 Diese Praxis ging auf Vorschläge von Schirach zurück, der im Sommer 1939, als er noch Reichserziehungsminister werden wollte, in Zusammenarbeit mit Bormann die Planungen für die Lehrerbildungsanstalten konkretisierte und so vorbereiten ließ, daß Bormann bei günstiger Gelegenheit - diese ergab sich im Herbst 1940 - eine 'Führerentscheidung' herbeiführen konnte. So hatte Schirach dem mit ihm noch befreundeten „lieben Martin“ Erfahrungen einer bereits HJ-beeinflußten Lehrerbildung aus den neuen ,ostmärkischen Reichsgauen“ übermittelt und mitgeteilt, daß diese auch im Altreich problemlos durchzuführen wäre. Auch hier sollte ,die Auslese für die Lehrerbildungsanstalten“" von HJ und Schule ,gemeinsam gemacht" werden; von der HJ würden ,nur solche Jungen vorgeschlagen, die sich in der Hitler-Jugend bereits bewährt" hätten, und durch die Beteiligung der HJ an der Lehrerbildung erhalte „diese Berufsausbildung ein ganz anderes Interesse in der Jugend“, das sich in einem „erheblichen Zustrom" zu điesem Beruf ausdrücken würde. Akten der Partei-Kanzlei, Bl. 3074959 f. (Schirach an Bormann, 28.6.1939).

67 Anläßlich eines Erfahrungsberichtes über die Praktiken und Ergebnisse dieser Ausleselager resümierte der SD, ,daß die aus den Musterungslagern in die Lehrerbildungsanstalten eintretenden Jungen und Mädchen durchaus keine einheitlich mit ideellem Schwung dem Lehrerberuf zustrebenden Bewerber" waren; so kamen etwa aus einem fränkischen Ausleselager nur 19 Bewerber „aus innerer Neigung“, dagegen ,25 aufgrund der Lehrerwerbung“ und zehn „hätten gerne andere Berufe gewählt, die sie aus wirtschaftlichen Gründen [jedoch] nicht ergreifen konnten“. Als negativ, aber symptomatisch wurde weiterhin vermerkt, daß $75 \%$ der Bewerber vom Lande, dagegen nur $25 \%$ aus Städten stammten und sich insgesamt mehr Mädchen als Jungen gemeldet hätten. Hierin sah man eine „Gefahr der weiteren Verlagerung auf die weiblichen Erziehungskräfte", die „zwar im Kriege hinzunehmen“ sei, im Frieden jedoch eine „besorgniserregende Entwicklung“ darstelle. Beobachtet wurde auch ein „Überwiegen des Bauern- und 
Die pädagogische und fachliche Ausbildung in den Lehrerbildungsanstalten - jedes Jahr wurden 15.000 Jungen und Mädchen im Alter von 14 Jahren nach Abschluß der achtklassigen Volksschule ,ausgelesen“ - war jeglicher akademischer Formen entkleidet und von wissenschaftlichen Ansprüchen weitgehend befreit worden und entsprach mit ihrem den Oberschulen angeglichenen Lehrplan eher einer funktionalisierten Berufsausbildung. Vorgesehen war, nach einem fünfjährigen Bildungsgang die erste Prüfung für das Lehramt abzulegen und danach die Arbeitsdienst- und Wehrpflicht abzuleisten. Nach zweijährigem Dienst an einer zugeteilten Volksschule und parallel dazu pflichtmäßig zu absolvierenden Fortbildungsveranstaltungen - in denen dafür gesorgt werden sollte, daß den Junglehrern ,die Kunst des Unterrichtens in Fleisch und Blut übergeht ${ }^{668}$ - sollte der Lehramtsanwärter die zweite Prüfung ablegen können und hätte danach zumeist eine Anstellung auf Lebenszeit erhalten.

Der Jubel der Reichsjugendführung über diese neue Einrichtung zur Schaffung eines proletarisierten pädagogischen Fußvolkes bezog sich vor allem auf den Einfluß, der der HJ eingeräumt werden mußte. Denn nicht nur auf die - durch den Wegfall des Abiturs als Studiumsvoraussetzung - wesentlich verbreiterte Auslesebasis gewann die HJ-Führung einen bestimmenden Einfluß - ohne Zustimmung des zuständigen Bannführers war die Aufnahme einer 'Volksschullehrer-Lehre' unmöglich -, sondern auch auf die direkten Ausbildungsprozesse konnte tiefgreifender Einfluß ausgeübt werden. Das Leben an den Lehrerbildungsanstalten verlief nach den Prinzipien der formationsgebundenen "Gemeinschaftserziehung der Hitler-Jugend", und die zu HJ-Einheiten zusammengefaßten Ausbildungsgruppen der Lehreraspiranten hatten außerschulischen HJ-Dienst nach den Vorschriften für reguläre HJ-Einheiten zu leisten. ${ }^{69}$ Aber der Einfluß der HJ erstreckte sich selbst auf die Ausbildungsstrukturen und -inhalte, die sich an den Richtlinien für die HJ-Führerausbildung orientierten; das bedeutete - so die an Schirachs Forderungen von 1938 orientierte Idealvorstellung -, daß ein Absolvent dieser Lehrerbildungsanstalten ein von der $\mathrm{HJ}$ ausgesuchter, nach ihren Richtlinien ausgebildeter neuer Typ von Jugenderzieher sein sollte, der später wahlweise als Lehrer oder/und HJ-Führer einzusetzen war. Wäre diese Maßnahme etwa bei einer Verlängerung bzw. einem anderen Ausgang des Krieges zum Tragen gekommen, hätte die HJ einen zusätzlichen Ort für die Ausbildung ihrer Führer erschlossen ${ }^{70}$ und einen fast unbegrenzten Einfluß auf die dann lediglich noch staatlich zu nennende Lehrerbildung erlangt; die ausgebildeten Jugendlichen wären dann als multifunktional zu verwendende Jugenderzieher ${ }^{71}$ tätig gewesen.

In welchem Maße es der HJ-Führung geglückt ist, der neuformierten staatlichen Lehrerbildung ihren Stempel aufzuprägen und die Ausbildung an den neuen Lehrerbildungsanstalten der der HJund NSDAP-geführten NS-Eliteschulen anzugleichen, dokumentierte Kaufmann, der 1943 einschätzte, daß ,der Weg, der mit der Einrichtung der Adolf-Hitler-Schulen zur Heranbildung einer Führerauslese beschritten worden ist, folgerichtig durch Erlasse des Reichserziehungsministers ... auch für die neue Lehrerbildung beschritten"werden konnte. Die neuen Ausbildungseinrichtungen hätten „weniger mit den bekannten höheren Schulen gemein“, sie ähnelten ,vielmehr in ihren Erziehungsprinzipien den Adolf-Hitler-Schulen“. Nicht mehr „die wirtschaftliche Lage der Eltern,

Arbeitertums als Herkunftsschichten des Lehrernachwuchses“" und ein „fast völlige[r] Ausfall von Lehrersöhnen“; zwar sei - im Sinne der Volksgemeinschaft - die Tatsache, „daß dem Lehrernachwuchs die Begabungen der breiten Volksschichten zugeführt" würden, „erfreulich", dennoch dürften die Auswirkungen des „Anreiz[es] der beinahe kostenfreien Ausbildung nicht übersehen“ werden. Meldungen aus dem Reich, S. 3843 ff. (Bericht vom 18.6.1942).

68 Kaufmann, Das kommende Deutschland, S. 159.

69 Vgl. ANBl., 16/42, und RB, 27/42 K, 12.11.1942 (Vereinbarung zwischen dem JFdDtR dem RMWEV über den HJDienst und die Gemeinschaftserziehung an den Lehrerbildungsanstalten).

70 „Dadurch, daß die Leiter und Erzieher der Lehrerbildungsanstalten Hitlerjugend-Führer sein sollen, wird die Einheit der Erziehung als gemeinsame Aufgabe von Schule und Hitlerjugend gewährleistet. “ Die Ausbildung an den Lehrerbildungsanstalten stand, ,auch unter dem Gesichtspunkt, daß der künftige Erzieher nach Abschluß seiner Ausbildung berufen ist, in der Partei und ihren Gliederungen führend tätig zu sein. Das bedingt die Entwicklung seiner vorhandenen Führereigenschaften", und daher komme dem HJ-Dienst in den Lehrerbildungsanstalten ,,in erster Linie Bedeutung als einem Führerausbildungs- und einsatzdienst zu“. Der Angehörige einer Lehrerbildungsanstalt müsse „seine gewonnenen Kenntnisse und Fähigkeiten [auch] danach täglich im Einsatz als Führer und Ausbilder von Einheiten“" beweisen. Kaufmann, Das kommende Deutschland, S. 160.

71 Vgl. dazu Freudenthal, Schulmeister, Jugendführer, Volkserzieher; Klemer, HJ-Führer als Lehrer und Erzieher. 
sondern allein die Erbanlage ${ }^{672}$ sei entscheidend für die künftige Lehrerausbildung, deren Kosten und das war der zweite Triumph der $\mathrm{HJ}$ - allein vom Staat getragen wurden. ${ }^{73}$ Zwar hatte Bormann noch im April 1942 verfügt, daß ,künftighin eine Verächtlichmachung des Lehrerstandes in der Öffentlichkeit [!]“ zu unterbleiben habe ${ }^{74}$, aber aus Sicht der Reichsjugendführung war das nunmehr kein Problem mehr, denn wenn die $\mathrm{HJ}$,,ihre besten erzieherischen Begabungen diesem Beruf" zuführe, sei damit ,auch die Frage des Ansehens und der Anerkennung des Lehrers erledigt" ${ }^{\text {" }}{ }^{75}$

Die volle Durchsetzung dieser Form der Lehrerbildung im öffentlichen Bewußtsein scheiterte jedoch teilweise an der nach wie vor unzureichenden Ausstattung der Volksschullehrer, die in der angespannten Lage der Kriegsfinanzen keine Besserung erfuhr. So brachte die Maßnahme zunächst nicht den gewünschten Erfolg; bereits 1942 war in der NS-Führung bekannt, daß der ,Volksschullehrermangel nicht nur ein ideelles, sondern auch ein materielles Problem" sei, das den Anreiz, Lehrer zu werden, in engen Grenzen gehalten haben dürfte: Während etwa ein 21jähriger Junglehrer nach fünfjähriger Ausbildung, Reichsarbeits- und Wehrdienst 217,30 RM brutto erhalte, bekomme ein gleichaltriger Facharbeiter nach dreieinhalbjähriger Ausbildung, Wehr- und Reichsarbeitsdienst bereits 280,80 RM. ${ }^{76}$ Während an den Fronten und in den Lagern des Dritten Reiches Milliardensummen für die Vernichtung von Menschen ausgegeben wurden, waren die Führungen von Staat und Partei nicht willens, die Volksschullehrer mit einer geringen Gehaltsaufstockung zu motivieren, um damit einen Beitrag zur Ausbildung der 'Volksgemeinschaft von morgen' zu leisten.

Neben dieser neuen Form der HJ-beeinflußten Lehrerbildung, einem - wenn sie denn voll entwickelt worden wäre - verkappten Modell nichtelitärer Adolf-Hitler-Schulen für die breite Masse, entstand ab 1941 als Sonderform einer HJ-dominierten Lehrerausbildung das Berufsbild der BDM-Schulhelferin für die besetzten Ostgebiete. Resultierend aus einer „Notstandsmaßnahme“ - die in den Reichsgauen Wartheland und Danzig-Westpreußen anstelle der vertriebenen Polen angesiedelten Volksdeutschen müßten erst für das „Deutschtum zurückgewonnen“ werden, ihnen war also die deutsche Sprache und das, was als ,deutsche Kultur“ definiert wurde, beizubringen -, sollte mit der Etablierung der Institution BDM-Schulhelferin der ,Typ eines neuen Volkserziehers für den Osten“77 entwickelt werden. Während die nach dem Modell der Reichsjugendführung ausgebildeten Volksschullehrer des Altreichs - zumindest was deren Funktion im Bereich des klassischen Bildungswesens betraf - eher zur Spezies der Grundwissen vermittelnden Handwerker gehörten ${ }^{78}$, galten die lediglich propagandistisch groß herausgestellten BDM-Schulhelferinnen als pädagogisches Proletariat, als angelerntes Hilfspersonal, dessen Fähigkeiten für die Dörfer des eroberten Ostens als gerade gut genug galten. In ihnen verkörperte sich - von den ohnehin zentrifugal und autonom orientierten Gauleitern gefördert und unterstützt ${ }^{79}$ - die von der $\mathrm{HJ}$ angestrebte „Einheit der Erziehung“" auf einem dem Reichserziehungsministerium nicht zugänglichen Testgelände.

Eine immer größer werdende Zahl der in den Osten abgeordneten BDM-Führerinnen erhielten ab dem Frühjahr 1941 nach der Absolvierung von Kurzlehrgängen auf den eigens eingerichteten Lehrerinnenbildungsanstalten in Posen, Elbing, Hirschberg und Lauenburg - der Reichserziehungsminister mußte auch diese als eigenständige Ausbildungsformen sanktionieren und finanzieren ${ }^{80}$ - ein Volksschullehrerdiplom mit der als Zielsituation deklarierten Auflage, ,für

72 Kaufmann, Das kommende Deutschland, S. 159. Vgl. auch Schmidt-Bodenstedt, Die neue Lehrerbildung; dieser Verfasser - und das entsprach der HJ-Konzeption auf der oberen Ebene - war Ministerialdirigent im Reichserziehungsministerium und zugleich $\mathrm{HJ}$-Gebietsführer.

73 Aus dem Etat des Reichserziehungsministeriums mußten die Kosten für Unterkunft, Verpflegung, Bekleidung, Krankenund Unfallversicherung, Lehr- und Lernmittel, Reisen und ein Taschengeld der Jugendlichen bezahlt werden.

74 Vgl. VAB, Bd. II, S. 371

75 BA, NS 26/358 (Kriegsgeschichte der HJ, 1944).

76 BA, NS 19/1531 (Lagebericht zur Nachwuchsfrage der Erzieher aus dem Persönlichen Stab des RFSS, 15.3.1942).

77 BA, NS 26/358 (Kriegsgeschichte der HJ, 1944).

78 Vgl. dazu Krebs, Die nationalsozialistische Volksschule.

79 Vgl. dazu etwa den Aufsatz des Posener Gauamtsleiters Sprenger: Wir brauchen Junglehrer für den Osten.

80 Der Weg, ,über die Schulhelferinnenausbildung in den Lehrerberuf zu gelangen“, führte für die 19- bis 30jährigen BDM-Angehörigen über eine Eignungsprüfung an die Lehrerinnenbildungsanstalten des Ostens. Nach Absolvierung der kostenlosen fünfmonatigen Lehrgänge wurden die Absolventinnen ,unter Anleitung erfahrener Lehrer" bei einer Vergütung von $150 \mathrm{RM} /$ Monat im praktischen Schuldienst angelernt und konnten nach ein- bis zweijähriger Bewäh- 
immer im Osten zu bleiben" - im Altreich wäre mit dieser Ausbildung selbst ein Einsatz an einer Volksschule undenkbar gewesen. Doch die als BDM-Schulhelferinnen eingesetzten BDM-Führerinnen sollten im Osten mehr als nur Lese- und Schreibhilfen für analphabetische Umsiedler sein, nämlich „Lehrerin und Führerin zugleich“; darin lag für die Reichsjugendführung die „,wesentliche Ursache ihres Erfolges“. Aber nicht nur das: Ihre Verwendung galt ,in jeder Beziehung [als] wirklicher Kriegseinsatz“, denn „68 v.H. aller BDM-Schulhelferinnen leisten die Arbeit von Männern, die bei den Waffen stehen". Zudem agierten die Schulhelferinnen in den eingegliederten Ostgebieten als BDM-Führerinnen, mehr als zwei Drittel standen ,,in der aktiven Arbeit der Ortsgruppenoder Kreisleitungen“ der NSDAP, halfen beim DRK, führten Volksbüchereien und übernahmen darüber hinaus „Erwachsenenunterricht im Rahmen des Volksbildungswerkes“. ${ }^{81}$ Multivalent einsatzbar als BDM-Führerin und Hilfslehrerin, als politische Leitfigur und allgegenwärtige Ansprechpartnerin der um- und angesiedelten Volksdeutschen, sollten die BDM-Schulhelferinnen als 'Kulturbringerinnen Großdeutschlands' fungieren. Für die HJ war dies eine Maßnahme, mit der die Synthese Lehrer/Jugendführer unbeeinflußt von traditionellen Reichsstrukturen ausprobiert werden konnte, und die über diesen Personalzuwachs hocherfreuten Gauleiter Greiser und Forster sahen in den Schulhelferinnen einen ordnungs- und bildungspolitischen Faktor ${ }^{82}$, der die „Haltung des Dorfes" prägen sollte. ${ }^{83}$

Die im Frühjahr 1941 ebenfalls per Führererlaß eingeführte Institution der Hauptschule ${ }^{84}$ - ein vereinfachter Bildungsgang zur Erlangung der mittleren Reife - sollte durch verkürzte, niveaureduzierte und kostenfreie Ausbildung den Bemühungen der HJ zur 'Brechung des Bildungsprivilegs' sekundieren. Ebenso wie die neue Form der Lehrerbildung ist auch die Einführung der Hauptschule von der Reichsjugendführung als „Revolutionierung des deutschen Schulwesens ${ }^{\star 85}$ gefeiert worden. In den zu Hauptschulen umgewandelten Mittelschulen sollten über kürzere Ausbildungszeiten, vereinfachte Bildungsprogramme und kostenlosen Schulbesuch diejenigen Jugendlichen zunächst ausgelesen und dann bis zur Fach- bzw. Hochschulreife beschult werden, die aufgrund der materiellen Situation des Elternhauses nicht in der Lage gewesen wären, eine höhere Bildung zu erlangen. ${ }^{86}$ Wer aber für die Hauptschule als geeignet befunden wurde - hier kontrollierten die Volksschulen in Zusammenarbeit mit der HJ ein Ausleseverfahren -, der war, so die Intention, dann auch verpflichtet [!], diesen Bildungsweg einzuschlagen. ${ }^{87}$ Beabsichtigt war, neben bereits für Jugendliche bestehenden Verpflichtungen, wie etwa der staatlichen Schulpflicht und der HJ-seitigen Jugenddienst-, Ertüchtigungs- oder Gesundheitspflicht, auch eine Bildungspflicht zu etablieren. Abgeleitet aus einer „Verantwortung [des Staates und des einzelnen] für das geistige Begabungsgut" des Volkes, sollte derjenige, der ,,ausgelesen“" war und damit als 'berufen' galt, der Verpflichtung unterworfen werden, eine höhere Bildung zu erlangen. Und die Einführung der Hauptschule galt der Reichsjugendführung als ,der hoffnungsvollste Ansatz", die Jugend zu verpflichten, ,sich auch auf geistigem Gebiet bis an die Grenze ihrer Leistungsfähigkeit zu ertüchtigen“. Mit dieser Form der „Bildungspflicht“ sollten darüber hinaus auch diejenigen „Löcher ver-

rung zu einer einjährigen Schlußausbildung an einer Lehrerbildungsanstalt des Reiches zugelassen werden; BA, R 43 II/955 a, Bl. $4 \mathrm{f}$.

81 BA, NS 26/358 (Kriegsgeschichte der HJ, 1944).

82 Vgl. dazu Greiser, BDM-Schuldienst im Osten; Forster, BDM-Schuldienst im Osten.

83 Wolpert, Die BDM-Schulhelferin, S. 23.

84 Bekanntgemacht mit Schreiben Bormanns vom 5.1.1941, veröffentlicht bei Scholtz, Erziehung und Unterricht, S. 84.

85 BA, NS 26/358 (Kriegsgeschichte der HJ, 1944).

86 Aber auch für den Volksschulbereich hatten HJ- und NSDAP-Führung vorgesehen, ,die Schulzeit um zwei Jahre zu verkürzen und damit auf sechs Jahre zu beschränken"; damit sollten Freiräume für die Berufsausbildung gewonnen und dadurch wiederum Gelegenheit zu früherer Familiengründung geschaffen werden. Schirach und Ley: „Diese Einschränkung ist notwendig, um für die weitere Fortbildung Zeit zu gewinnen, damit die Menschen zur Gründung ihrer Existenz und Familien aus bevölkerungspolitischen Gründen nicht zu alt werden. Jedes gewonnene Jahr wird in erhöhter Kinderzahl zum Ausdruck kommen." Parteiinterne Denkschrift Die Adolf-Hitler-Schule, S. 8.

87 Im § 7a des Gesetzes zur Änderung des Reichspflichtschulgesetzes (RGBl., 1941, T. I, S. 799 ff.) war vorgesehen: „Volksschulpflichtige Kinder, bei denen die für die Aufnahme in die Hauptschule erforderlichen Voraussetzungen vorliegen, sind zum Besuch der Hauptschule verpflichtet.“ Vgl. auch MBIWEV, 1942, S. 127 ff. (Erlaß des RMWEV über Erziehung und Unterricht in der Hauptschule, 9.3.1942), und ebenda, 1941, S. 271 (Runderlaß des RMWEV über die Schülerauslese für die Hauptschulen, 3.7.1941). 
stopft" werden, durch die ,die für die Hochschule bestimmten Begabungen immer wieder vorzeitig abfließen". 88

Mit der endgültig erst 1943 installierten und also kaum noch wirksam gewordenen Form der Hauptschule schienen sich die Kontroll- und Erfassungsabsichten der HJ-Zentrale und die Anstrengungen zur kriegsbedingt-sparsamen Ressourcenbewirtschaftung mit den längerfristigen Planungen zur Umgestaltung der Gesellschaft scheinbar idealtypisch verbinden zu lassen. In diesem Schultyp trafen etwa die von der sozialpolitischen 'Fraktion' der Reichsjugendführung seit der Weimarer Republik verfolgten Bemühungen um die Chancengleichheit für Jugendliche aus unterprivilegierten Schichten mit kurzfristigen Bestrebungen der NS-Führung zur Instrumentalisierung von bislang brachliegendem 'Humankapital', zur wirksamen Mobilisierung aller geistigen Kräfte und Reserven im totalen Krieg zusammen, durch die gleichzeitig - das war beiden Intentionen gemeinsam - langfristig ein Elitenwechsel herbeigeführt werden sollte. Der HJ-Führung war durchaus bewußt, daß sie im Rahmen ihres Konzepts einer totalen Jugenderziehung bei der Durchsetzung ihrer bildungspolitischen Ziele eine ,,vorïbergehende Abwendung von der höheren Schule und Hochschule“ und eine ,Minderbewertung der Bildung überhaupt" akzeptieren mußte. Das nahm sie zugunsten einer HJ-dominierten ,Einheit der Erziehung“" in diesem Bildungsbereich in Kauf. Bei der Kreation einer neuen Jugendvolksgemeinschaft müsse neben der ,Verpflichtung des einzelnen, seine Gesundheit zu erhalten, seinen Körper zu stählen und seinen Charakter zu schulen", auch ein verantwortlicher Umgang mit dem ,geistigen Begabungsgut" gefordert werden, ,das jedem Jungen und Mädel vom Blutstrom seines Volkes mitgegeben" sei. Aus dem HJ-bestimmten „Ertüchtigungswillen der Jugend" und der HJ-geprägten ,Einheit des Jugenderziehers“ sollte, so die Vision, die „Schule ihr neues Gesicht ${ }^{469}$ gewinnen - das sie dann kaum noch von der HJ unterschied.

Die in der letżten HJ-amtlichen Darstellung unter dem Stichwort ,praktische Zusammenarbeit“ beschriebenen 'Kooperationen' von HJ und Schulwesen sollten die Tatsache kaschieren, daß es der HJ neben der Einführung der Lehrerbildungsanstalten und der Hauptschule in weiteren Bereichen gelungen war, Zuständigkeiten und Sektoren aus dem staatlichen Bildungswesen herauszubrechen, zu okkupieren oder auch neue zu schaffen, die durch das Reichserziehungsministerium dann lediglich nachträglich auf dem Erlaßwege sanktioniert werden konnten; auch damit wurde die ganze Hilflosigkeit der immer defensiver reagierenden obersten Schulbehörde sichtbar, die einen Bereich nach dem anderen der sich zunehmend 'verstaatlichenden' $\mathrm{HJ}$ überlassen mußte. Wie sehr sich die Gewichtung im Verhältnis beider Institutionen in der Kriegszeit zugunsten der HJ verschoben hatte, können zwei Formfragen berührende Beispiele schlaglichtartig demonstrieren: Ende 1941 erbat der erstmals zu einer der jährlichen HJ-Gebietsführertagungen eingeladene, zu diesem Zeitpunkt stark in die Defensive geratene Reichserziehungsminister Rust in fast devoter Form um die Mitarbeit der HJ bei der Lösung des „Nachwuchsproblems“ - und übernahm dabei fast durchgängig deren Argumentationsmuster und Sprachregelungen. Um gegen die USA, „den großen Gegner", antreten zu können, sei es notwendig, ,,alle germanischen Kräfte zu sammeln“. Leider sei es „zur Zeit so, daß alle deutschen Neuschöpfungen [in Wissenschaft und Technik] durch die katastrophale Lage im Hinblick auf [den] Erziehernachwuchs in Frage gestellt" seien. Von 100 Abiturienten würden nur 71 studieren und von diesen nur fünf den Lehrerberuf. Notwendig sei deshalb - eine alte Forderung der HJ - eine „bessere Auslese ohne Berechtigungswesen“ [Abitur]; gleichzeitig beklagte Rust aber, daß ,heute auf Grund zwingender Notwendigkeiten die Schulzeit von neun auf $7 \frac{1}{2}$ Jahre herabgesetzt worden sei“. Infolge der ,Ausdehnung des Deutschen Reichs" seien „durch die vielen Versetzungen der Väter Schwierigkeiten in der Jugenderziehung aufgetreten"; das war zwar eine indirekte Kritik an der HJ, die dies nicht habe auffangen können, ein Vorwurf aber, der von Rust mit dem zeitgenössisch-scherzhaften Slogan: „Vater versetzt, Sohn sitzengeblieben“" wieder entschärft wurde. Denn nunmehr komme es für das Reichserziehungsministerium darauf an, in ,enger Zusammenarbeit mit der Hitler-Jugend die Lösung des Nachwuchsproblems“" in Angriff zu nehmen. 
Wie sehr der Erziehungsminister mittlerweile auf Positionen der HJ-Führung übergegangen war, demonstriert die Einschätzung des anwesenden SS-Berichterstatters: „Die Rede des Reichsministers Rust wurde vom HJ-Führerkorps ausschließlich bejahend aufgenommen"; so etwas hatte es noch nie gegeben. Im Gegenzug kam der als Reichsleiter für die Jugenderziehung anwesende Schirach auch dem Erziehungsminister scheinbar entgegen, als er sich etwa „gegen die frühere Einstellung der Hitler-Jugend zur Lehrerschaft“ wandte und konstatierte, ,,daß die Hitlerjugend einen grundlegenden Fehler“ dadurch begangen habe, daß sie „den Lehrerberuf schlecht und lächerlich gemacht" hatte. Nunmehr müsse - mit der Geste 'Asche aufs Haupt' kaschierte Schirach die parallel laufenden Okkupationsbestrebungen der HJ-Zentrale - dieser „Fehler" wieder gutgemacht werden: „Mit allen Kräften“" sei jetzt ,ein neuer Kurs zu steuern und dem Lehrerberuf der notwendige Nachwuchs aus den Reihen der HJ-Führer [!] zu geben. Die Hitlerjugend trage eine große Verantwortung um die Nation und habe darum die Aufgabe, als Nachwuchsorganisation hier vorherrschende Lücken zu schließen. Es sei ehrenhaft, gemachte Fehler einzusehen und zu bessern. ${ }^{c 90}$

Zwei Jahre später - die HJ hatte ihre Teilsiege über die Bildungsbürokraten manifestiert - war der Ton schon ein ganz anderer. So etwa, als der Schulbeauftragte der Reichsjugendführung Wilhelm Blume, ein zum HJ-Führer avancierter früherer Lehrer, das Reichserziehungsministerium im März 1944 wie eine nachgeordnete Behörde ultimativ aufforderte, ihm sofort sämtliche der dort vorhandenen Bestimmungen, Erlasse und Vereinbarungen zur „Zusammenarbeit“ von Hitlerjugend und Schule zu übersenden - was dieses ,wunschgemäß“ unverzüglich erledigte -, weil die HJ-Zentrale beabsichtigte, für ihre Gebiets- und Bannführungen einen Sonderdruck zusammenzustellen, der die einschlägigen Anordnungen und Vorschriften enthalten sollte; ${ }^{91}$ auch daraus wird sichtbar, daß die HJ in diesem Bereich bereits die Federführung übernommen hatte. Getreu Schirachs Anweisungen, aus Gründen des inneren Friedens und der Staatsräson während des Krieges die Siege des einen Erziehungsfaktors über den anderen nicht lautstark zu bejubeln, äußerte die Reichsjugendführung den Triumph über ihre Erfolge nur verhalten, so etwa, als sie auf die vom Salzburger Gauleiter Gustav Adolf Scheel sanktionierte und in dessen Gau bereits praktizierte Regelung verwies, wonach das Dienstleistungszeugnis der $\mathrm{HJ}$ als „Führungszeugnis im Dienst der Gemeinschaft bei Versetzungen in die nächsthöhere Klasse“" ebenso zu berücksichtigen war wie bei der Zulassung zum Hochschulstudium. ${ }^{92}$ Dieser Dualismus in der Jugenderziehung war das eigentliche Wunschbild der HJ-Führung: die Schule als bloßer Vermittler positiven Tatsachenwissens, während die HJ die Deutung und Wertung dieser Kenntnisse übernahm und über die eigentliche Verwendung der 'Beschulten' entschied.

Doch diese Vision kam nicht mehr zum Tragen, zu schnell änderten sich die Verhältnisse: Galt noch Mitte 1943 die Aufrechterhaltung der Schulerziehung als „kriegswichtig“, so wurde es Anfang 1945 kriegswichtig, die Schulen zu schließen. Ende Juli 1943, parallel zu den verheerenden britischen Bombardements auf westdeutsche Industriegebiete und den deutschen Angriffsvorbereitungen im Rahmen des Unternehmens „Zitadelle“ unterlag es für den Reichserziehungsminister ,keinem Zweifel“, daß die ,den allgemeinbildenden Schulen obliegende Schulerziehung als kriegswichtige Aufgabe anzusehen“ sei, ,,deren Erfüllung auch unter den Bedingungen des totalen Krieges weiterhin sichergestellt werden“ müsse. Bei längerer Kriegsdauer komme „dieser Aufgabe [sogar] eine stets wachsende Bedeutung zu, da die Leistungen der jungen Nachwuchskräfte in Wehrmacht, Wirtschaft und Verwaltung in entscheidendem Maße von den Ergebnissen der Unterrichts- und Erziehungsarbeit der Schule abhängig“ seien. ${ }^{93}$ Ende Januar 1945 jedoch, als die Rote Armee Schlesien erreichte und aus den Häfen der Danziger Bucht die Räumungstransporte gen Westen begannen, wurden dem in den meisten Gebieten ohnehin schon in Agonie befindli-

90 BA, NS 19/3872 (Bericht von Fritz Rubach über die HJ-Gebietsführertagung in München, 10.12.1941).

91 BA, REM, Nr. 3219, Bl. 23 ff. (Blume an Bittner, 15.3.1944; Klamroth an Blume, 12.5.1944).

92 BA, NS 26/358 (Kriegsgeschichte der HJ, 1944).

93 Auch deshalb habe der Reichsinnenminister in einem Runderlaß an die Reichsverteidigungskommissare vom 30.1.1943 unter den kriegswichtigen Einzelaufgaben „die Sicherstellung des ordnungsgemäßen Schulwesens ausdrücklich hervorgehoben.“ Dtsch. Wiss., Erz. u. Volksbldg., 1943, S. 226 f. (Erlaß des RMWEV über die Sicherstellung der Schulerziehung als kriegswichtige Aufgabe, 30.6.1943). 
chen Bildungswesen die letzten Grundlagen entzogen, und es hörte damit vollends auf zu existieren. Da „die Lage im Osten eine große Umquartierungsbewegung ausgelöst“" habe, so Bormann beschönigend, müsse zur „Unterbringung von Lazaretten, zur Aufnahme von Schwangeren, von Frauen mit Kleinkindern" usw. ,ausreichender Unterbringungsraum ... auf jeden Fall geschaffen“ werden. Dazu sollten nunmehr, ,wenn es die Lage erfordert", neben den Lehrerbildungsanstalten auch ,sämtliche Schulen geschlossen werden“ ${ }^{94}$

\section{2 Die Adolf-Hitler-Schulen}

„Die Adolf-Hitler-Schulen sind Einheiten der Hitler-Jugend und werden von dieser verantwortlich geführt ... Aufnahme in die Adolf-Hitler-Schule finden solche Jungen, die sich im Deutschen Jungvolk hervorragend bewährt haben ... Nach erfolgter Reifeprüfung steht dem Adolf-Hitler-Schüler jede Laufbahn der Partei und des Staates offen. “95

Als Idealform und Vollendung ihrer bildungspolitischen Bestrebungen, in der die „Einheit von Schule und Hitler-Jugend ... vollendet gestaltet" war, galten der Reichsjugendführung die AdolfHitler-Schulen, die zwischen 1937 und 1945 zwar nur provisorisch errichtet werden konnten und deren - tatsächlich geringe - Bedeutung in einem umgekehrten Verhältnis zu dem ihretwegen produzierten Behördenschriftwechsel stand, deren Installierung jedoch als ,wahrhafte Revolution auf schulischem Gebiet" gefeiert wurde. ${ }^{96}$ Dabei sollte mit dieser Form der Eliteschulen ,keineswegs ... eine Schulgattung geschaffen werden, die für die Allgemeinheit“" gedacht war; es ging da dem deutschen Volk, ,in seinen Notzeiten immer ... eine politische Herrenschicht gefehlt" habe, weshalb diese „Fehlerquelle der deutschen Geschichte beseitigt“" werden müsse - ganz dezidiert darum, daß an den Adolf-Hitler-Schulen ,,nur eine Elite herangebildet ${ }^{497}$ und „erstmals in der

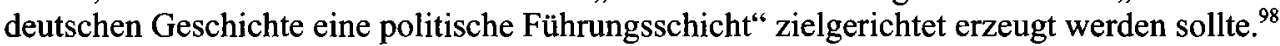

Von der Reichsjugendführung, die nach dem Erlaß des HJ-Gesetzes vom 1. Dezember 1936 glaubte, ihre Ansprüche auf immer weitere Beteiligung an ihrem Zugriff bislang verschlossenen Arbeitsgebieten nunmehr mit größerem Nachdruck durchsetzen zu können, bereits seit 1936 geplant $^{99}$, unterzeichnete Hitler am 15. Januar 1937 eine von Schirach und Robert Ley ausgearbeitete

94 BA, NS 6/353, Bl. 7 (Rundschreiben 16/45 des Leiters der Partei-Kanzlei zur Schließung von Schulen, 21.1.1945, nach einem Erlaß des GBR vom gleichen Datum); lediglich die Adolf-Hitler-Schulen, die Nationalpolitischen Erziehungsanstalten und die Heimschulen sollten ,mit Rücksicht auf die darin stattfindende Ausbildung des Offiziersnachwuchses“" ihren Schulbetrieb fortsetzen. Nach einem Führererlaß vom 12.11.1943 über den Ausgleich kriegswichtigen Raumbedarfs war es schon seit Ende 1943 möglich gewesen, der Wehrmacht für Zwecke der operativen Kriegsführung auch Schulgebäude zur Verfügung zu stellen.

95 Aus den von Robert Ley und Baldur von Schirach am 17.1.1937 unterzeichneten „Grundsätzen“ für die Adolf-HitlerSchulen, hier zitiert nach: Die Adolf-Hitler-Schule, S. 3.

96 BA, NS 26/358 (Kriegsgeschichte der HJ, 1944). Ungeachtet der zahlreichen bloßen Erwähnungen hat die Forschung von den Adolf-Hitler-Schulen bislang nur in geringem Umfang Notiz genommen. In der bislang ausfuihrlichsten Darstellung - Scholtz, NS-Ausleseschulen - wird die Entwicklung dieses Schultyps zu stark nach den anfänglichen, später jedoch modifizierten und teilweise revidierten Intentionen beurteilt, was zu teilweise verzerrten Schlußfolgerungen führt; Orlow, Adolf-Hitler-Schulen, konzentriert sich - basierend auf einer schmalen Quellenbasis - vor allem auf die Kompetenzkonflikte zwischen dem Reichserziehungsministerium und der Reichsorganisationsleitung der NSDAP, die jedoch im wesentlichen bereits 1938 beigelegt waren; die Apologie von Klüver, Adolf-Hitler-Schulen, die eine eklatante Unkenntnis der Materiallage offenbart und selbst eindeutige Aussagen in den benutzten Quellen ignoriert, basiert vor allem auf den Reminiszenzen ehemaliger Schulführer und Erzieher von Adolf-Hitler-Schulen und auf eigenen Erinnerungen. Klüver versucht, jeden Einfluß der NSDAP auf die Adolf-Hitler-Schulen zu leugnen bzw, herunterzuspielen und sie ausschließlich als von Schirach unbeeinflußte HJ-Einheiten mit modernem pädagogischem Konzept zu präsentieren. Dem assistiert Schneider, Adolf-Hitler-Schüler heute, der die AHS-Erziehung als konstituierend für erfolgreiche Nachkriegskarrieren in der Bundesrepublik darstellt. Vgl. auch Buchheim, AdolfHitler-Schulen; Naake, Faschistische Eliteschulen. Nicht mehr berücksichtigt werden konnte die neue Darstellung von Feller/Feller, Adolf-Hitler-Schulen.

97 Kaufmann, Das kommende Deutschland, S. 161; dort, S. 161 - 173, auch ausführliche zeitgenössische Interpretationen der Adolf-Hitler-Schulen.

98 BA, NS 26/358 (Kriegsgeschichte der HJ, 1944). In diesem Zusammenhang werden die Nationalpolitischen Erziehungsanstalten (NPEA) vor allem deshalb nicht behandelt, weil der Einfluß der HJ-Führung auf diesen anderen Schultyp zur Herausbildung einer NS-originären Elite gering blieb. In der letzten HJ-amtlichen Leistungsbilanz vom Herbst 1944 werden diese 1934 vom Reichserziehungsministerium begründeten, ab 1943 fast vollständig unter dem Einfluß der SS stehenden Schulen nicht einmal mehr erwähnt.

99 BA, Sammlung Schumacher/270, Bl. 172 ff. (Bericht des StF über den Stand der Errichtung von Adolf-Hitler-Schulen, 25.1.1941). 
Konzeption und genehmigte gleichzeitig, „daß die neu zu errichtenden nationalsozialistischen Schulen, die gleichzeitig als Vorschulen für die nationalsozialistischen Ordensburgen gelten“ sollten, seinen Namen tragen durften ${ }^{100}$. Mit dieser Namensgebung, die Patronat und Programm zugleich anzeigte, waren die Schulen eigentlich sakrosankt gegenüber jedem Zugriffsversuch der obersten Schulbehörde des Reiches, der zwar sofort erfolgte, sich jedoch nicht gegen den neuen Schultyp an sich, sondern nur dagegen richten konnte, daß diese Schulen nicht dem Kompetenzbereich des Reichserziehungsministeriums zugeschlagen wurden.

So teilte Rust dem Reichsorganisationsleiter der NSDAP am 21. Januar 1937 in einem Schnellbrief mit, daß die von Ley und Schirach ausgearbeiteten Grundsätze der Adolf-Hitler-Schulen ,mit den bestehenden Gesetzen, nach denen die Schulaufsicht dem Staate obliegt, ... völlig unvereinbar" seien. Der Schulminister zeigte sich ,aufs höchste überrascht und befremdet", bezweifelte, daß ,diese Grundsätze dem Willen des Führers“ entsprachen, warf Ley und Schirach Täuschung und Taschenspielertricks vor und artikulierte seinen Eindruck, ,daß hier mit dem Willen des Führers ein unverantwortlicher Mißbrauch getrieben“ werde. Rust verlangte von Ley anzuerkennen, daß für ,die Gestaltung, Leitung und Beaufsichtigung der Schulen in Deutschland ... allein der Reichserziehungsminister" zuständig sei; er forderte den Reichsorganisationsleiter der NSDAP, der ,,insbesondere" nicht befugt sei, Schulgründungen zu initiieren, auf, die Ankündigung über die Einrichtung der Adolf-Hitler-Schulen auf demselben Wege wieder zurückzuziehen, auf dem sie veröffentlicht worden war - über die Presse. Hier offenbarten sich erneut Rusts Selbstüberschätzung und dessen Unkenntnis der tatsächlichen Machtstrukturen und Entscheidungsgänge des Führerstaates. Zwar war ihm von Hitler noch am 30. November 1936, gewissermaßen als Kompensation für die durch das einen Tag später erlassene HJ-Gesetz beschnittenen Kompetenzen zugesichert worden, als ,verantwortlicher Reichserziehungsminister das gesamte deutsche Schulwesen verantwortlich zu leiten ${ }^{* 101}$, aber natürlich konnte ein von Hitler unterzeichneter Erlaß, der noch dazu in fast allen deutschen Zeitungen breit kommentiert veröffentlicht worden war, nicht zurückgezogen werden, ohne das Staatsoberhaupt zu desavouieren.

Ley, der den Wert von mündlichen Äußerungen Hitlers und dessen pragmatische Vorgehensweise: 'Was schert mich mein Geschwätz von gestern?' besser kannte als Rust, reagierte entsprechend ruhig und teilte diesem mit, daß sich die Zuständigkeiten eines Reichserziehungsministers noch „,niemals auf die Parteischulen“ erstreckt hätten: „Deshalb gehen Dich die Adolf-HitlerSchulen genau wie die nationalsozialistischen Ordensburgen gar nichts an“. Deutlich verlangte er von Rust, sich aus diesem Komplex herauszuhalten, da ihn ,die ganze, völlig parteieigene Angelegenheit als Reichserziehungsminister absolut nichts" angehe. ${ }^{102}$ Auch Schirach konterte überlegen und ließ Rust wissen: „Es scheint Ihnen unbekannt zu sein, daß die Verfügung des Führers [über die Gründung der Adolf-Hitler-Schulen] auf Grund einer von Dr. Ley und mir ausgearbeiteten Denkschrift erlassen wurde, die der Führer gelesen und gebilligt hat." Danach seien die AdolfHitler-Schulen „Einheiten der Hitler-Jugend und gehören als solche ebensowenig zu Ihrem Geschäftsbereich wie die anderen Führerschulen der Hitler-Jugend und die Ordensburgen der NSDAP. “103 Damit war die Angelegenheit eigentlich erledigt. Eine letzte Demütigung in dieser Sache erlebte Rust, als Hitler im Oktober 1941 auf Schirachs Initiative entschieden hatte, daß die Abschlußbeurteilung der Adolf-Hitler-Schulen „ohne weiteres dem Reifezeugnis der höheren staatlichen Schulen gleichzustellen" sei und - mit der Unterschrift des Reichsleiters für die Jugend-

100 Dieser eher in Form einer Genehmigung ergangene Führererlaß ist vielfach publiziert worden; vgl. etwa die ausführlichste und am authentischsten erscheinende, von Schirach und Ley verfaßte, zeitgenössisch und im folgenden als „Denkschrift“ bezeichnete parteiamtlich-interne Veröffentlichung: Die Adolf-Hitler-Schule, Berlin 1937, darin auch die gemeinsame Erklärung und die mit diesem Schultyp verbundenen Intentionen; veröffentlicht auch in: Das Junge Deutschland, Heft $2 / 1937$.

101 BA, R 43 II/956 a, Bl. 4, 8 ff. (Rust an Ley und Hitler, 21.1.1937).

102 Ebenda, Bl. 12 f. (Ley an Rust, 22.1.1937).

103 Ebenda, Bl. $14 \mathrm{ff}$. (Schirach an Rust und Hitler, 22./23.1.1937). Trotz weiterer Interventionen von Rust - z.B. ebenda, Bl. 17 ff. (Rust an Ley und Hitler, 25.1.1937) - mußte der Erziehungsminister, dem im eigenen Hause schon die Zuständigkeiten für die formal bei ihm ressortierenden Nationalpolitischen Erziehungsanstalten durch die SS immer weiter beschnitten wurden, auch diese Niederlage einstecken. 
erziehung der NSDAP - „Zum Studium an allen deutschen Hochschulen berechtigen“ solle ${ }^{104}$, womit der Reichserziehungsminister gezwungen war, dies in einem von ihm herauszugebenden Erlaß auch noch zu bestätigen. ${ }^{105}$

Die Errichtung der Adolf-Hitler-Schulen basierte zunächst auf parteiinternen Entwicklungsproblemen, an deren Lösung dann auch die HJ - als Nachwuchsorganisation der NSDAP - beteiligt wurde: Parallel zur Auswertung der nicht in jedem Fall befriedigenden Ergebnisse der statistischen Erhebungen zur Entwicklung der Partei nach der Machtübernahme ${ }^{106}$ und zeitgleich zur Aufhebung der damit im Zusammenhang stehenden Mitgliedersperre der NSDAP und zur Öffnung der Partei im Frühjahr $1937^{107}$ war die Erkenntnis von der Notwendigkeit einer mit diesen Prozessen korrelierenden, in organisiertem Rahmen durchzuführenden „Auslese für ein instinktsicheres, glaubensstarkes Führertum“ gereift; diese Auslese aber erforderte „die Errichtung und den Ausbau eines parteiamtlichen Schulkörpers für den Führernachwuchs" - erstaunlich nur, daß dies im Unterschied etwa zur HJ bis 1937 noch nicht geschehen war. Offensichtlich hatte sich erst im Rahmen der Etablierung des Regimes herausgestellt, daß sich viele der zwar 'kampfzeittauglichen' Kräfte für die Lenkung eines modernen Staatswesens und für Führungspositionen in den immer komplizierter werdenden Parteistrukturen als ungeeignet erwiesen. Dieser „Schulkörper“ sollte aus einem dreistufigen System bestehen: Auf den Adolf-Hitler-Schulen, der Grundstufe, sollten Jungen ab dem zwölften Lebensjahr in sechsjähriger Schulzeit ihre dem Abitur entsprechende höhere Reife erwerben; nach dem nationalsozialistischen 'Dreisatz' von Körper, Seele und Geist sollten ein Drittel des Tages ,,der geistigen Wissenschaft, ein Drittel der körperlichen Ausbildung und ein Drittel der kameradschaftlichen Arbeit in der Hitler-Jugend" gehören. ${ }^{108}$

Nach einer siebenjährigen Praxisbewährung, innerhalb derer ein Beruf zu erlernen oder ein Universitätsstudium zu absolvieren, der Arbeits- und Wehrdienst abzuleisten und aktiver Dienst in der SA, SS, dem NSKK oder als Block- und Zellenleiter zu leisten war, sollten etwa ein Viertel der Adolf-Hitler-Schüler, und zwar ,die Besten, Bereitesten und Härtesten als Elite die Ordensburgen beziehen “. ${ }^{109}$ Es war vorgesehen, daß diese die Ordensburgen in vier Jahren zu durchlaufen hatten, unterbrochen von einem jeweils vierteljährlichen „Dienst an der Front der Parteiarbeit", wobei die Ordensburgen Crössinsee, Sonthofen und Vogelsang der körperlichen und charakterlichen Ertüchtigung dienen und die Marienburg ,die Stätte der letzten geistigen und politischen Ausreifung sein“ sollte. Als „,oberste Stufe dieses Erziehungssystems, die nach all den vorausgegangenen Erprobungen“ wiederum nur von einer „Auslese der Durchsiebten“ erreicht werden konnte, war die Hohe Schule der Partei vorgesehen, die unter Leitung Alfred Rosenbergs nach dem Krieg am Chiemsee errichtet werden sollte. ${ }^{10}$ Bei einer Verwirklichung dieses Konzepts

104 Ebenda, Bl. 29, 32 (Bormann an Lammers, 31.10.1941; Schirach an Lammers, 17.11.1941). Während im Reichserziehungsministerium noch überlegt wurde, „wie es ermöglicht werden könne, den Reifezeugnissen der von der Partei getragenen Schule den Charakter und die Berechtigung staatlicher Zeugnisse zu geben", gedacht war zumindest an eine „Mitzeichnung“ des Erziehungsministeriums, ebenda, Bl. 34 (Zschintzsch an Lammers, 3.1.1942), hatte Hitler bereits entschieden, daß das auf parteigeführten Schulen abgelegte Examen staatlich anzuerkennen sei.

105 Vgl. ANB1., $3 / 42$ (Erlaß des RMWEV, 6.2.1942).

$106 \mathrm{Vgl}$. dazu NSDAP. Parteistatistik.

$107 \mathrm{Vgl}$. dazu die von Reichsschatzmeister Schwarz und Parteirichter Buch herausgegebenen ,Richtlinien für das Verfahren bei der Aufnahme neuer Mitglieder in die NSDAP“, die sich auf die Anordnung 18/37 des Stellvertreters des Führers vom 20.4.1937 bezogen, mit der bestimmt worden war, daß, nach dem Willen des Führers die Partei im Reich etwa zehn vom Hundert der Einwohnerzahl an Parteigenossen umfassen“, also kräftig aufgestockt werden sollte. Die Lockerung galt zunächst vor allem für diejenigen, bevorzugt HJ-Angehörige, ,die durch ihre nationalsozialistische Haltung und Betätigung in den Jahren seit der Machtübernahme sich eine Anwartschaft auf Aufnahme in die NSDAP erworben" hatten; ebenda, S. 3, 17.

108 Denkschrift Die Adolf-Hitler-Schule, S. 8 f., 13.

109 Frankfurter Zeitung, 24.11.1937. Die Ordensburgen Crössinsee in Pommern, Vogelsang in der Eifel und Sonthofen im Allgäu sind von Hitler am 24.4.1936 bei einer „Weiheveranstaltung“" in Crössinsee eröffnet worden; später kam noch die Ordensburg Marienburg in Ostpreußen hinzu. Zur Thematik vgl. Scholtz, Die NS-Ordensburgen; Arntz, Ordensburg Vogelsang.

110 Nach ersten Vorstellungen sollte die Hohe Schule aus einem „Forschungsinstitut mit Zentralbücherei“, einer Akademie, in der ,die Lehrkräfte für die Adolf-Hitler-Schulen und die Ordensburgen wissenschaftlich ausgebildet" werden, und einem Lager, das in jedem Jahr vier Wochen lang $600 \mathrm{Mann}$,zu weltanschaulicher und willensmäßiger Festigung vereinen" sollte, sowie aus einer Adolf-Hitler-Schule bestehen, damit die Hohe Schule ,eng mit der Jugend verbunden" bleibe; Frankfurter Zeitung, 24.11.1937. 
hätten also die ersten, vollkommen nach nationalsozialistischen Erziehungsprinzipien ausgerichteten Führernachwuchskräfte etwa 1954, also nach 17 Jahren, im Alter von etwa 30 Jahren für leitende Aufgaben in der NSDAP zur Verfügung gestanden.

Ausgehend von der Forderung, ,daß die Führerauslese und Heranbildung schon beim Kinde beginnen muß ${ }^{\star 111}$, sollte mit den Adolf-Hitler-Schulen also die Grundlage eines mehrstufigen Elitebildungsprozesses geschaffen werden. Da die Reichsjugendführung, die mit der HJ eine Nachwuchsorganisation für so ziemlich alle Sachverhalte und Gegebenheiten im Dritten Reich aufgebaut hatte, bereits über erste Erfahrungen in der Führerschulung verfügte und zudem das bislang existierende Schulwesen heftig angegriffen und dessen Erneuerung gefordert hatte und darüberhinaus mit dem Modell der Adolf-Hitler-Schulen eine Lösungsvariante präsentieren konnte, mit der sowohl das überkommene Bildungswesen 'revolutionär' zu reformieren war als auch entscheidender Einfluß auf die personelle Zusammensetzung der künftigen Elite des Reiches genommen werden konnte, war es nur logisch und folgerichtig, daß sie ihre Mitwirkung für diesen Weg der Elitenrekrutierung nicht nur anbot, sondern von der Parteiführung auch herangezogen wurde.

Die Führung der Adolf-Hitler-Schulen war dual: Die Schulen selbst galten als Einheiten der HJ und wurden von dieser geführt; Schulträger war - zumindest auf dem Papier - die NSDAP. Es war vorgesehen, daß die Gauleiter die Schulaufsicht übernehmen sollten, was jedoch nur in Ansätzen verwirklicht wurde. Lehrstoff, Lehrpläne und Lehrkörper wurden von HJ und NSDAP gemeinsam bestimmt. In der Reichsorganisationsleitung war dafür das im Hauptschulungsamt gebildete Amt Adolf-Hitler-Schulen unter Heinz Pehmöller sowie das im Hauptpersonalamt geschaffene Amt Führernachwuchs unter Leitung von Leo Jennes zuständig. Als Reichsamtsleiter Jennes Anfang 1945 zum Personalchef des Reichsministeriums für die besetzten Ostgebiete ernannt wurde, übernahm der aus der HJ stammende Hans Klauke die Funktion des Amtschefs für Führernachwuchs. Hauptbannführer Klauke, der zunächst selbst als Schulführer von Adolf-Hitler-Schulen in Sonthofen gewirkt hatte, gehörte als Leiter des Freikorps „Adolf Hitler“ im 'Endkampf” auch zum Führungspersonal der 1. Panzervernichtungsbrigade „Hitlerjugend“.

In der Reichsjugendführung übernahm zunächst Kurt Petter als Inspekteur für die Adolf-HitlerSchulen die faktische Leitung dieser Ausbildungsstätten. Der studierte Kinderarzt, der zunächst den HJ-Bann Weimar geführt hatte und nach seiner Versetzung in die HJ-Zentrale als Verbindungsführer zum Reichserziehungsministerium und zum NS-Lehrerbund berufen wurde, amtierte seit 1936 als stellvertretender Chef des Personalamtes der Reichsjugendführung. 1939 war Petter der oberste Schulfunktionär der $\mathrm{HJ}$; ihm unterstanden als Leiter der Reichsführerschule in Potsdam, als Reichsinspekteur für die Adolf-Hitler-Schulen und als Kommandeur der Akademie für Jugendführung alle zentralen HJ-Ausbildungsstätten. Nachdem die Führung und Verwaltung der Adolf-Hitler-Schulen in den Rang eines eigenständigen Amtes der Reichsjugendführung gehoben und die Funktionsbezeichnung vom Inspekteur zu Kommandeur der Adolf-Hitler-Schulen aufgewertet wurde, stand dieses Amt unter kriegsbedingt wechselnder Leitung von Kurt Petter und Kurt Budäus; dieser hatte zunächst als Stabsleiter in der HJ-Gebietsführung Niedersachsen amtiert, bevor er zum stellvertretenden Chef der Behördenabteilung der Reichsjugendführung und zu Petters Stellvertreter als Inspekteur der Adolf-Hitler-Schulen ernannt wurde; nach seinem Kriegseinsatz übernahm Ritterkreuzträger Budäus sowohl die Akademie für Jugendführung als auch die Leitung der Adolf-Hitler-Schulen und fungierte daneben auch zeitweise als Chef des Amtes für Führerausbildung und Schulen sowie als Chef des Amtes für weltanschauliche Schulung der Reichsjugendführung.

Die künftigen Adolf-Hitler-Schüler sind in einem aufwendigen und mehrstufigen, im Kriege weiter verschärften Ausleseverfahren von der NSDAP und der HJ ausgewählt worden, das auf der Ortsgruppen- bzw. Jungbannebene begann und mit Einzelfallbestätigungen durch den jeweiligen Gauleiter abschloß, der an der Spitze einer Musterungskommission die von den Ortsgruppenleitungen vorgeschlagenen und von den Kreisleitungen überprüften Jungen persönlich in Augenschein

111 Denkschrift Die Adolf-Hitler-Schule, S. 9. 
nehmen mußte. Für die Auswahl der Schüler galten der „Nachweis der deutschblütigen Abstammung, völlige Gesundheit des Vorgeschlagenen, Erbgesundheit der Familie" ebenso als Vorbedingung wie eine positive Bewertung durch die HJ. Darüber hinaus war die „Betätigung der Eltern in der Partei, ihren Gliederungen und angeschlossenen Verbänden für die Entscheidung maßgebend“" ${ }^{112}$

Schon ein Jahr später sind zwar auch noch ,gute schulische Leistungen“ verlangt worden, jedoch war eine Einschätzung durch die bisherige Schule nicht mehr erforderlich; da als nunmehr ,einzige[r] Weg in die Adolf-Hitler-Schule die Auslese der Pimpfe aus dem Jungvolk“ galt und das Vorschlagsrecht ausschließlich den Hoheitsträgern der NSDAP und den Einheitenführern der HJ zustand, erfolgten die Beurteilungen ab Ende 1938 nur noch durch die HJ. Ausgehend von den den einzelnen Gauen zugeteilten Kontingenten potentieller Adolf-Hitler-Schüler - die mitgliederstarken Gaue Berlin, Sachsen und Schlesien durften jeweils 18, die neu hinzugekommenen Ostmarkgaue lediglich je vier Schüler nominieren -, sollten zunächst dreimal mehr Jungen als benötigt vorgeschlagen werden, deren Zahl dann auf einem zehntägigen Ausleselehrgang an den jeweiligen HJ-Gebietsführerschulen stufenweise auf die zugewiesene Größenordnung zu reduzieren war; die Gauschulungsleiter der NSDAP hatten ,den Lehrgang eingehend [zu] beobachten“. ${ }^{113}$

War 1937 noch vorgesehen, jährlich 600 Adolf-Hitler-Schüler auszumustern und einzuberufen, mußte diese Zahl auf Anordnung des Reichsorganisationsleiters schon ein Jahr später auf 300 beschränkt werden, vor allem weil der ,Ausbau der Ordensburg Sonthofen als vorläufiger Sitz der Adolf-Hitler-Schulen ... nicht in dem Maße fortgeschritten“" war, das „,eine ordnungsgemäße Unterbringung" gewährleistet hätte. ${ }^{114}$ Diese Halbierung der Musterungszahlen infolge mangelnder Unterbringungsmöglichkeiten war nur ein erstes, wenngleich typisches Indiz für die chaotische Planung des Gesamtkomplexes Adolf-Hitler-Schulen.

Legt man die anfänglichen Intentionen als Maßstab zugrunde, so ist das System der AdolfHitler-Schulen bei genauerer Betrachtung als ein deutlicher Fehlschlag, als gravierender Mißerfolg zu bewerten, ungeachtet dessen, daß zeitgenössische Interpretationen die Entwicklung dieser Schulen als eine Erfolgsgeschichte zu präsentieren suchten und, davon abgeleitet, auch historische Analysen der Nachkriegszeit diese Fußnote der NS-Elitebildung, diese Marginalie der $\mathrm{HJ}-\mathrm{Ge}-$ schichte mit einer Aura des Geheimnisvollen versehen und ihr eine Bedeutung zumessen, die sie nie besessen hat. Angesichts der großspurigen Ankündigung dieses Elitenrekrutierungsmodells, seiner ihm zugedachten Tragweite und der der NSDAP zur Verfügung stehenden Machtmittel erstaunt die halbherzige, zwischen apathischer Gleichgültigkeit und unproduktivem Aktionismus schwankende, dürftige und behelfsmäßige Umsetzung dieser einzigen amtlich institutionalisierten - zudem nach Hitler benannten - Form zur Rekrutierung systemkonformen Nachwuchses für die Führungspositionen des Reiches. Es fehlte an allem, an einem durchdachten Konzept, an Lehr-

112 BA, Film Nr. 18774 (vom Amt Führernachwuchs des Hauptpersonalamtes der Reichsorganisationsleitung der NSDAP erlassene Richtlinien für die Auswahl, Ausmusterung, Einberufung und Betreuung der Schüler für die AdolfHitler-Schulen, 13.2.1937).

113 Ebenda (Rundschreiben Nr. 38 des Amtes Adolf-Hitler-Schulen des Hauptschulungsamtes der Reichsorganisationsleitung der NSDAP an alle Gauschulungsleiter als Arbeitsanweisung zur Auslese und Mustenung der Adolf-HitlerSchüler, 12.10.1938). Vgl. auch RB, 20/K, 12.1.1940 (von der RJF herausgegebene Bestimmungen für die Auslese der Adolf-Hitler-Schüler), und VHB, S. $1865 \mathrm{ff}$. (nicht veröffentlichte Arbeitsanweisung Nr. 12 a des Hauptpersonalamtes der Reichsorganisationsleitung der NSDAP über Auswahl, Ausmusterung und Einberufung der Adolf-HitlerSchüler, 1.2.1940). Vgl. auch BA, NS 45/132 (darin Aufsätze, Diktate, Mathematikaufgaben, Zeichnungen u.a. von einem Ausleselehrgang im Mai 1944). Der 11 jährige Klaus P. aus der 5. Klasse der Volksschule Waldzell schrieb z.B. in einem Aufsatz unter dem Titel „Warum ich Pimpfenführer werden will“: „Ich möchte gern ein Pimpfenführer werden. Wenn ich Jugend[!]schaftsführer werde, kann ich eine Jugendschaft [!] führen. Wenn man ein Pimpfenführer werden will, muß man immer in Appell gehen. Dort muß man sich durch Mut, Tapferkeit und Ehre durchschlagen. Wenn das nicht ist, so kann er kaum einer werden. Ich gehe in jeden Appell, damit ich ja recht bald einer werde. Also immer Mut und Tapferkeit beweisen.“ Aus einem Aufsatz unter dem Thema „Nachtalarm“ desselben Schülers: „Es war spät in der Nacht. Auf einmal hörte ich etwas pfeifen. Bald erschien ein Führer der HJ und sagte: 'Aufstehen, es ist Fliegeralarm'. Wir standen auf. Ich dachte, es wäre wirklich Fliegeralarm. Jetzt dachte ich an die armen Menschen, die jetzt den Tod erleiden müssen.“ In seiner Abschlußeinschätzung des Ausleselehrganges hieß es, der „Lehrgang gefiel mir sehr gut. Wir hatten hier sehr gute Verpflegung. Das schönste war das Geländespiel in der Nacht. Wir stürmten im Wald eine Verschanzung des Feindes. Alles mußte gut aufpassen, damit ihn ja kein Feind von hinten angreifen konnte. Wir mußten auch raufen. Wir hatten gestern eine Partisanenjagd. Wir waren die Angreifer"

114 BA, Film Nr. 18774 (Rundschreiben Nr. 1/38 des Hauptpersonalamtes bei der Reichsorganisationsleitung der NSDAP über die Ausmusterung von Schülern für die Adolf-Hitler-Schulen, 13.1.1938). 
plänen und Lehrern, an geeigneten Schülern, an zur Verfügung stehenden Grundstücken und Schulgebäuden, aber auch an Finanzmitteln und Baumaterialien, um diese zu errichten.

Geplant war zunächst, in jedem der damals 32 NSDAP-Gaue eine Adolf-Hitler-Schule zu gründen. Bis 1942 bestanden jedoch nur zehn Schulen, und erst 1943 kamen zwei weitere hinzu. Diese zehn Schulen befanden sich infolge fehlender bzw. anderweitig eingesetzter Ressourcen bis 1941 alle zusammen auf der Ordensburg Sonthofen ${ }^{115}$ - von April bis Herbst 1937 zunächst auf der Ordensburg Crössinsee -, da schon ab 1938 im Zuge der forcierten Aufrüstung die Arbeitskräfte und Materialien für die über die Grundsteinlegung nicht hinausgekommenen Schulen aus den betreffenden Gauen für kriegswichtige Zwecke abgezogen worden sind. ${ }^{116}$ Erst 1941 konnten vier Schulen von Sonthofen in die vorgesehenen Gaue verlegt und in Behelfsbauten untergebracht werden, wie etwa die thüringische Adolf-Hitler-Schule in Blankenhain bei Weimar, die bezeichnenderweise in einer ehemaligen Irrenanstalt Quartier fand. Neben den Baukapazitäten zur Errichtung von nur zehn Schulen - entsprechend der Zahl der Gaue hätten es eigentlich 36 und im Kriege sogar 42 Schulen sein sollen - fehlte selbst das Geld für den Unterhalt der zehn in Sonthofen residierenden Schulen. Diese konnten bis 1941/42 nur existieren, weil sie aus Mitteln der Deutschen Arbeitsfront finanziert wurden; der prestigesüchtige Reichsorganisationsleiter konnte - da er gleichzeitig Chef der DAF war - die Zweckentfremdung von Mitteln der Arbeitsfront verfügen.

Noch im Sommer 1939 mußte der Reichsschatzmeister der NSDAP, deren Nachwuchs ja eigentlich auf den Adolf-Hitler-Schulen ausgebildet werden sollte, konstatieren, daß, ,die Finanzlage der Partei" es nicht gestattete, diese Schulen von der DAF zu übernehmen. Schwarz rügte zwar die Verantwortungslosigkeit von Ley und Schirach, mit der Errichtung von Parteischulen zu beginnen, ohne deren Finanzierung zu klären, obwohl beiden klar gewesen sei, ,daß hier nicht nur eine Schulfrage zu lösen war, sondern ein Finanzproblem". ${ }^{117}$ Aber selbst wenn die beiden 1937 den Reichsschatzmeister konsultiert hätten, wäre kein Geld dagewesen. Erst nach langwierigen Verhandlungen - und Leys Drohung: ein Aussteigen der finanziell überlasteten DAF würde ein Ende der Adolf-Hitler-Schulen zur Folge haben - erklärte sich Schwarz im Juli 1941, einen Monat nach dem Überfall auf die Sowjetunion, bereit und in der Lage, die vier in die Gaue Sachsen, Thüringen, Ostpreußen und Köln-Aachen verlegten Schulen zu übernehmen und im Mai 1942 - parallel zu den deutschen Offensiven um Charkow und in Nordafrika - auch die übrigen. Dahinter stand eine gleichfalls drängende HJ-Führung, die schon seit Anfang 1941 wegen der katastrophalen Lage auf der Ordensburg ,aus erzieherischen und hygienischen Gründen“ für eine „,notwendige Verlegung von 1.500 Jungen von Sonthofen" plädierte und eine ,sofortige Bereitstellung von behelfsmäßigen Unterkünften von Adolf-Hitler-Schulen bis zur Fertigstellung der geplanten Neubauten“ forderte ${ }^{118}$; aber auch die „Gauleiter ihrerseits drängten nun darauf, daß die Adolf-HitlerSchulen in den Gaugebieten errichtet ${ }^{\text {‘1 } 19}$ wurden.

115 Die zehn Adolf-Hitler-Schulen, die auf der Ordensburg Sonthofen dem Hauptschulführer Hans Klauke und seinem Stellvertreter Ernst Senkel unterstanden, waren nach ihren geplanten Standorten bzw. Gauen benannt und wurden von jeweils einem hochrangigen HJ-Führer geleitet, der gelegentlich aus dem Lehrerberuf kam: AHS Tilsit/Ostpreußen, geleitet von Hans Klauke; AHS Potsdam/Mark Brandenburg, geleitet von Hans Klauke, der von Reinhard Meinung vertreten wurde; AHS Waldbröl/Köln-Aachen, geleitet von Werner Kirsch; AHS Koblenz-Trier/Westmark, geleitet von August Buttkereit; AHS Plauen-Pirna/Sachsen, geleitet von Rudolf Raab; AHS Weimar-Blankenhain/Thüringen, geleitet von Horst Munske; AHS Hesselberg-Chiemsee/München-Oberbayern, geleitet von Hans Kreiß1; AHS Heiligendamm/Mecklenburg, geleitet von Max Klüver, verteten von Helmut Gause; AHS Landstuhl/Saarpfalz, ?; 1943 kamen die Schulen Wartha/Niederschlesien und Iglau/Böhmen und Mähren hinzu. Die Reichsjugendführung beschönigte das jahrelange Notquartier noch 1944: „Es kam der jungen Schulart sehr zugute, daß sie in den ersten Jahren geschlossen an einer Stätte, auf der Ordensburg Sonthofen, entwickelt und aufgebaut wurde. Obwohl jeder Gau seine eigene Adolf-Hitler-Schule besitzt, haben die Schulen hier in Gemeinsamkeit die Grundlagen erarbeitet und einen neuen Typus geschaffen, der in Zukunft jeder Schule, unabhängig von ihrem Standort, das Gepräge geben wird.“ BA, NS 26/358 (Kriegsgeschichte der HJ,1944).

116 Im Sommer 1938 hatte man an den geplanten Standorten Plauen, Heiligendamm, Hesselberg, Koblenz, Waldbröl und Landstuhl zwar mit den Bauarbeiten begonnen; diese sind wegen „kriegswichtiger Bauten“ jedoch zunächst zurückgestellt worden. „Bei Ausbruch des Krieges wurde die Arbeit auf allen Baustellen eingestellt.“ Bis 1941 wurden für Planungen und begonnene Bauten 6 Millionen RM ausgegeben. BA, Sammlung Schumacher/270, Bl. 172 f. (Bericht des $\mathrm{StF}$ über den Stand der Errichtung von Adolf-Hitler-Schulen, 25.1.1941).

117 Ebenda, Bl. 152 ff. (Schwarz an Ley, 1.6.1939).

118 BA, Sammlung Schumacher/270, B1. 172 f. (Bericht des StF über den Stand der Errichtung von Adolf-Hitler-Schulen, 25.1.1941).

119 Ebenda, B1. 170 (Aktennotiz Stabsleiter Saupert, 10.2.1941). 
Anläßlich eines Spitzentreffens der drei beteiligten Reichsleiter Schwarz, Ley und Schirach am 23. Juli 1941 auf der Ordensburg Sonthofen ist das arbeitsteilige Vorgehen beim Erhalt und Betrieb der Adolf-Hitler-Schulen besprochen und festgelegt worden. Da die Schulen ,zu den Hoheitsaufgaben der NSDAP zu zählen" seien - was sie jedoch schon seit ihrer Gründung waren - und ,als Reichsaufgabe der NSDAP bezeichnet werden" müßten, erklärte sich der Buchhalter der Partei nunmehr bereit, die Gesamtfinanzierung zu übernehmen. In einem gemeinsamen Protokoll wurde festgelegt, daß also der Reichsschatzmeister die finanziellen Belange und die Verwaltung der Adolf-Hitler-Schulen übernehmen werde, einschließlich der „Anstellung des Lehrkörpers“, während „Lehrstoff, Lehrplan und [Auswahl des] Lehrkörper[s] der Adolf-Hitler-Schulen, die Einheiten der Hitler-Jugend sind und unter deren verantwortlicher Führung stehen“, vom Reichsorganisationsleiter und vom Reichsleiter für die Jugenderziehung ,reichseinheitlich bestimmt“ werden sollten. ${ }^{120}$

Unterrichtet von einem ausgesuchten Stab von Erziehern, dessen Angehörige auf der seit 1938 in Sonthofen eingerichteten Erzieherakademie unter Leitung des HJ-Führers Otto-Wilhelm von Vacano ausgebildet und zu einem neuartigen Erzieherkorps - Lehrer und Jugendführer in einer Person - geformt werden sollten ${ }^{121}$, lernten die Adolf-Hitler-Schüler nach neu entwickelten Plänen und einem für revolutionär gehaltenen didaktischen Konzept: „Auf den Adolf-Hitler-Schulen gibt es kein Klassenbuch, kein Katheder, keinen großen und kleinen Eintrag, und ebenso keine Zensuren und Strafarbeiten. Sämtliche Imponderabilien der herkömmlichen alten Schule sind also abge-

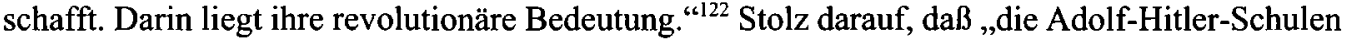
sich durch nichts [haben] bewegen lassen, sich der Einrichtungen des überkommenen Schulwesens zu bedienen ${ }^{\star 123}$, wich natürlich auch der Lehrplan von dem , anderer Schulen erheblich ab. Körperliche, geistige und musische Erziehung stehen gleichberechtigt nebeneinander. Italienisch ist Pflichtsprache. Volkskunde und Biologie sind Kernfächer der geistigen Erziehung. Deutsch, Erdkunde und Geschichte sind in völlig neuer Sicht zu einem Fach zusammengefaßt. Sport wird in allen Formen getrieben. Ein eigenes, neues Unterrichtsfach ist der 'Blick in die Welt'“. ${ }^{124}$ Aus der bewußten Ablehnung aller schulischen Vorbilder und der ungenügenden konzeptionellen Vorbereitung resultierte, daß ,bis ins Ende des Jahres 1943 ... an der Erstellung der Lehr- und Erziehungspläne, an der Beschaffung der Lehrmittel - jede Adolf-Hitler-Schule besitzt heute eine Bücherei von durchschnittlich 7.000 Bänden - und am Ausbau der Erzieherakademie gearbeitet“" werden mußte. Selbst die „Entwicklung eigener Schul- und Arbeitsbücher“ wurde ,auch während des Krieges nicht eingestellt". ${ }^{125}$

120 Ebenda, Bl. 203 ff. (Gesprächsvermerk und gemeinsames Protokoll, 23.7.1941).

$121 \mathrm{Vgl}$. dazu VHB, S. 1876 ff. (nicht veröffentlichte Richtlinien für die Auswahl, Auslese, Einberufung und personelle Betreuung der Schulführer, Erzieher und Fachlehrer an den Adolf-Hitler-Schulen, 4.3.1939). Für das neu zu schaffende Erzieherkorps galten u.a. folgende Bedingungen: „Alter zwischen 25 und 30 Jahren, Mindestgröße 1,60 m, Mitglied der Partei, nachweisbar erfolgreiche aktive Tätigkeit in der Partei, der Hitler-Jugend oder in einer Gliederung der Partei, langjährige Erfahrungen und nachweisbare Erfolge in der Jugendführung und -erziehung, vollkommene Gesundheit, keine körperliche Mißbildung, keine Brillenträger, Nachweis der arischen Abstammung, Nachweis der Erbgesundheit und Erbtüchtigkeit der Sippe, gutes Aussehen und Auftreten." Durch den Krieg hatte sich auch der Aufbau der Erzieher-Akademie verzögert; bis für die Erzieherfrage, die „für die Adolf-Hitler-Schulen von entscheidender Bedeutung“" war, ,eine wirklich befriedigende Lösung“ gefunden war, mußte man ,auf andere Lehrkräfte zurückgreifen“. Die Gauschulungs- und -personalämter wurden aufgefordert, entsprechende Kräfte abzustellen, die in Einzelfallprüfungen durch den Gauleiter zu bestätigen waren. Gefordert wurden ,nicht nur politisch unbedenkliche Erzieher, sondern Männer, die neben ihrer fachlichen Aufgabe auch den ihnen von der Partei zuteil werdenden politischen Auftrag erfüllen“ konnten. BA, NS 22/2207 (Rundschreiben Nr. 14/43 des Hauptpersonalamtes der Reichsorganisationsleitung der NSDAP, 9.8.1943).

122 Kaufmann, Das kommende Deutschland, S. 165.

123 BA, NS 26/358 (Kriegsgeschichte der HJ, 1944).

124 Münchener Neueste Nachrichten, 3.4.1941. Zu den Unterrichtsinhalten vgl. auch Klüver, Adolf-Hitler-Schulen, S. 21 ff. Nach Kaufmann, Das kommende Deutschland, S. 168 ff., gehörten zum „Kernfach" Volkskunde die Disziplinen Deutsch, Geschichte, Erdkunde und Religionskunde; das „Kernfach“ Biologie bestand zumeist aus Rassenkunde und einer Aufklärung über die „Zusammenhänge des Lebens und seine Gebote“. Mathematik, Chemie und Physik gehörten ebenso zum Lehrplan wie Latein und Englisch und eine Wahlsprache. 1942 hätten vom ältesten Jahrgang 15 Jungen Griechisch, 100 Russisch und 150 Französisch gelernt. Zur musischen Ausbildung gehörten Unterweisungen in theoretischem Kunstunterricht, handwerkliche Ausbildung, Geschmacksbildung und musikalische Erziehung. Gefördert wurde die „Erziehung zum Kampfgespräch und zur freien Rede“.

125 BA, NS 26/358 (Kriegsgeschichte der HJ, 1944). 
Nachdem der - ungewollt symbolträchtige - Umzug der Adolf-Hitler-Schulen von den Ordensburgen der Partei in die Behelfsunterkünfte der jeweiligen Gaue gerade vollzogen war ${ }^{126}$, befanden sich nach der Einberufung der 'Ausgelesenen' des Geburtsjahrganges 1931 zum Ende des Jahres 1943 insgesamt 2.027 Jungen in den Adolf-Hitler-Schulen (1941: 1.800); das waren weniger als 0,4 Prozent der höheren Schüler des Reiches. Reichsweit betrachtet und angesichts der diesem Personenkreis zugedachten Aufgaben stellte diese Schülerzahl also eine immer noch zu vernachlässigende, unbedeutende Größe dar, die nicht einmal ausgereicht hätte, um die in den Kreisleitungen der NSDAP vakanten Planstellen zu übernehmen. Nachdem im Frühjahr 1942 der erste Jahrgang der 1937 eingeschulten Adolf-Hitler-Schüler, 280 Jungen $^{127}$, die Schulen verließ und geschlossen zur Wehrmacht einrückte, sind die Musterungs- und Einberufungszahlen auf 450, 1943 auf 556 gesteigert und gleichzeitig die Auslesekriterien verschärft worden. Denn Ley hatte im Mai 1942 feststellen müssen, daß „die Ergebnisse der Ausmusterung der Adolf-Hitler-Schüler in den vergangenen beiden Jahren im Vergleich zur Vorkriegszeit ein Absinken des Erfolges der Auslese erkennen" ließen, was zu „starken Ausfällen“ und leistungsbedingten „Entlassungen“" geführt habe. Hinzu kamen die starken Ausfälle von NSDAP-Funktionären an den Fronten, was - perspektivisch betrachtet - für die Nachkriegszeit erhebliche Probleme verursacht hätte. Deswegen, so ermahnte Ley die Kreisleiter, dürfe die „für die Zukunft der Partei so ungeheuer wertvolle Aufgabe der Auslese von Adolf-Hitler-Schülern ... unter keinen Umständen scheitern“. Um Qualität und Quantität der Ausleseergebnisse zu erhöhen, verlangte Ley eine „,persönliche, intensive Einschaltung des Kreisleiters“. Dessen Aufgabe sei es, sowohl die Eltern bzw. Angehörigen des Jungen auf ihre Einstellung zur nationalsozialistischen Weltanschauung und ihre Lebensbewährung zu überprüfen wie auch die bisherigen Ergebnisse des Schulbesuches des Jungen festzustellen“, um sich so „ein Gesamtbild über die Charakterwerte und über die bisherige Haltung des Jungen“"zu verschaffen. Diese schon vor den HJ-Ausleselagern zu praktizierende „Sippenauslese“ sei ,für die Beurteilung der Pimpfe von ausschlaggebender Bedeutung“. ${ }^{128}$

Ley hatte allen Grund zur Beunruhigung. Zwar wurden die Absichten der ersten beiden Absolventenjahrgänge der Adolf-Hitler-Schulen, nach dem Krieg zu mehr als 60 Prozent die hauptberufliche politische Führerlaufbahn einzuschlagen - und also dem Sinn dieser Schulen zu entsprechen -, als Erfolge gefeiert. Aber erstens konnte bei einem totalen Anspruch selbst ein ZweidrittelErgebnis nicht befriedigen, und zweitens war die Tendenz schon innerhalb dieser beiden Jahrgänge abnehmend. ${ }^{129}$ Deshalb wies der Reichsorganisationsleiter aus Anlaß der Entlassung des zweiten Lehrgangs der Adolf-Hitler-Schüler und ihres Übergangs zur Truppe im Frühjahr 1943 die Gauleiter der Partei auf „die Notwendigkeit hin, während der Zugehörigkeit der Jungen zur Wehr-

126 Vgl. dazu BA, Sammlung Schumacher/270, Bl. 17 ff. (Sonderbericht des RSM über die Entwicklung der AdolfHitler-Schulen im Jahre 1943). Danach befand sich etwa je ein Drittel der Adolf-Hitler-Schüler in den improvisierten Schulen in den Gauen sowie auf den Ordensburgen Sonthofen und Vogelsang; die 1.750 Schüler wurden von einem Stab von 707 Personen (Erzieher, Verwaltungspersonal und Angestellte) betreut.

127 Entgegen anderslautenden Behauptungen entsprach die soziale Zusammensetzung der Adolf-Hitler-Schüler keineswegs einem ,Querschnitt durch die Volksgemeinschaft"; zwar erfolgte die Ausbildung auf den Schulen unentgeltlich, was auch den Kindern weniger bemittelter Eltern den Zugang sichern sollte. Ausweislich der Berufe der Väter jener Kinder, die 1938 auf die Adolf-Hitler-Schulen kamen - das bislang einzige Jahr, für das halbwegs verläßliche Angaben der Reichsorganisationsleitung und zum Teil divergierende (hier in Klammern nachgestellte) Zahlen der HJFührung vorliegen -, dominierten mit 28,1\% (18,3\%) die Kinder von Angestellten und mit $21,3 \%(21,3 \%)$ die von Beamten; die Kinder von Eltern mit freien und akademischen Berufen hatten einen Anteil von 12,8\% (3\%), die von Industriearbeitern von $9,2 \%(26 \%)$, die von Bauern und Landwirten von 5,8 $(6,3 \%)$ und die von Land- und Holzarbeitern von 1,6\%; vgl. BA, Film Nr. 18774 (Anlage zum Rundschreiben Nr. 38 des Amtes Adolf-Hitler-Schulen im Hauptschulungsamt der Reichsorganisationsleitung der NSDAP, 12.10.1938), und BA, NS 26/358 (Kriegsgeschichte der HJ, 1944).

128 BA, NS 22/2007 (Rundschreiben 8/42 des Reichsorganisationsleiters, 15.4.1942).

129 In der Präsentation für die Öffentlichkeit wurde die Berufswahl der Adolf-Hitler-Schüler zwar als ,,völlig frei“ bezeichnet, sie führe ,also nicht ausschließlich in politische Laufbahnen“; intern wurde jedoch „von jedem früheren Adolf-Hitler-Schüler die spätere Aufnahme einer politischen Führungsaufgabe ohne weiteres erwartet". Nach der letzten HJ-amtlichen Darstellung hatten sich die Absolventen des Eintrittsjahrgangs $1937 \mathrm{zu} 67,23 \%$ für eine politische Führerlaufbahn entschieden, die des Jahrgangs 1938 schon nur noch zu $62 \%$; daneben wollten von den 1938 Eingeschulten und nunmehrigen AHS-Absolventen etwa $9,4 \%$ Offizier werden, $10 \%$ in wissenschaftliche und technische Berufe gehen und $8 \%$ land- und forstwirtschaftliche Berufe ergreifen; die Berufswünsche für medizinische, erzieherische, Beamten- oder freie Berufe lagen zwischen 1,7\% und 3\%. BA, NS 26/358 (Kriegsgeschichte der HJ, 1944). 
macht engste Verbindung mit ihnen zu halten“. In ihnen müsse das Bewußtsein „,erhalten bleiben und gestärkt werden, daß sie in erster Linie der Partei gehören und ihr engstens verbunden“ blieben. Neben Kontakten zur Front sollten sich vor allem die Kreisleiter bei Heimaturlauben ,nach Möglichkeit selbst“ den Jungen widmen. „Durch eine geschickte Behandlung dieser sehr wichtigen Aufgabe" müsse erreicht werden, ,daß die Jungen ihre Hauptaufgabe und ihr Ziel in erster Linie in der Partei sehen und ihr unbedingt die Treue halten". ${ }^{130}$

Das Ziel, die ausgewählten Jungen zu einem 'Eigentum' der NSDAP werden zu lassen - zuerst sollte den Eltern das 'Zugriffsrecht' auf ihre Kinder genommen und anschließend die ausgelesenen Jungen sich selbst entfremdet werden - war schon 1937 intendiert. So sollte in den Adolf-Hitler-Schulen „die Partei bis zum 18. Lebensjahre die Verantwortung für den Jungen und damit die gesamte Fürsorge für denselben“ übernehmen; die Eltern hatten sich zu, ,verpflichten, die Jungen für diese Zeit der Partei in Obhut zu geben“. ${ }^{131}$ Der Eintritt in eine dieser Eliteschulen bedeutete, „daß das Elternhaus mit seinen Ansprüchen an das Leben des Jugendlichen weitgehend zurücktreten" mußte; nunmehr galt das Gaupersonalamt als ,diejenige Dienststelle der Partei, an die sich die Eltern mit ihren Sorgen und Wünschen wenden" konnten, und ,von wo aus auch der zukünftige Lebensweg des Adolf-Hitler-Schülers beobachtet und ... durch Förderung gelenkt und beeinflußt werden ${ }^{\text {‘l132 }}$ sollte.

Als in der Parteiführung ein Vierteljahr nach Leys Betreuungsorder jedoch klar geworden war, daß die Kreisleiter mit den politischen Tagesaufgaben der Organisation des totalen Krieges an der Heimatfront hoffnungslos überfordert waren und durch sie ,eine individuelle Behandlung des einzelnen Jungen ... natürlich nicht stattfinden" könne, andererseits aber nach wie vor die Prämisse galt, daß ,in den früheren Adolf-Hitler-Schülern das Bewußtsein wachgehalten werden“ müsse, „daß sie der Partei gehören“, beschloß das Hauptpersonalamt der NSDAP, ,eine zusätzliche, zentrale Verbindung zu diesen Jungen aufzunehmen“. Weil man glaubte, daß die Jungen ,immer wieder von der Partei angesprochen" werden müßten, sollte nunmehr über „Frontbriefe" des Reichsorganisationsleiters die ,politische Verpflichtung in den Jungen wach gehalten“ werden. Als Ziel galt, daß diese ,in der Partei ihre Aufgabe und Verpflichtung“ zu sehen hatten. ${ }^{133}$

Derartige Erwartungen an die Absolventen der Adolf-Hitler-Schulen stellten sich auch deshalb als Wunschdenken heraus, weil 1943 selbst der eigentliche Schulbetrieb nur noch unvollkommen aufrechterhalten werden konnte. Wie in anderen Tätigkeitsfeldern der HJ-Arbeit, so nahm man auch im Bereich der Adolf-Hitler-Schulen durch die Einberufung weniger, keinesfalls kriegsentscheidender Erzieher und HJ-Führer die faktische Einstellung eines ganzen Arbeitsgebietes in Kauf. Während sich schon 1943 ,die Mehrzahl der Erzieher ... im Fronteinsatz“ befand, wurde der verbliebene Rest ,,in mehreren Gruppen in den Reichskommissariaten Ostland und Ukraine zur Erarbeitung wesentlichen wissenschaftlichen Materials ... eingesetzt"; diese in Zusammenarbeit mit den Ostexperten der SS angefertigten Studien ,etwa über Aufbau und Organisation bolschewistischer Einrichtungen, über Geschichte und Lebensweise völkischer Splittergruppen“, war zwar „nach Aussage berufener Persönlichkeiten überwiegend erstmaliger Art", hatte mit dem Schulzweck der Adolf-Hitler-Schulen jedoch nichts zu tun. Die weitgehend führer- und lehrerlosen Eliteschüler sind ,für die Dauer von mindestens drei Monaten“ derweil „als Lagermannschaftsführer ... in KLV-Lagern" eingesetzt worden. ${ }^{134}$

Anfang 1945, als sich ,,in der Heimat, aber auch an der Front, ein fühlbarer Mangel an befähigten Nationalsozialisten bemerkbar" machte, war die Lage aus Sicht des Hauptpersonalamtes alarmierend. Das Amt Führernachwuchs der NSDAP wurde - man fragt sich heute, mit welchem Realitätsbezug? - erneut beauftragt, ,der Partei ständig fähige Nachwuchskräfte zuzuführen und

130 BA, NS 22/2008 (Rundschreiben Nr. 5/43 des Reichsorganisationsleiters, 8.4.1943). Ley forderte die Kreisleiter auf, den Jungen das für sie ,Wissenwerteste und Wesentlichste aus ihrer Heimat, und zwar insbesondere auf dem Gebiet der Partei laufend“ mitzuteilen, sie im Gegenzug ,,zur Abgabe von Erlebnisberichten aufzufordern“" und durch ,regelmäßige Sendung von Feldpostpäckchen" bei Laune zu halten.

131 Denkschrift Die Adolf-Hitler-Schule, S. 10.

132 Kaufmann, Das kommende Deutschland, S. 164 f., 170.

133 BA, NS 22/2027 (Rundschreiben Nr. $3 / 43$ des Hauptpersonalamtes der Reichsorganisationsleitung der NSDAP, 12.7.1943).

134 BA, NS 26/358 (Kriegsgeschichte der HJ, 1944). 
dafür Sorge zu tragen, daß dieser Zustrom niemals aufhört". Aber außer den Angehörigen der auf der Ordensburg Sonthofen und an der Akademie für Jugendführung in Braunschweig laufenden Kriegsversehrtenlehrgängen war im Reichsgebiet nicht mehr viel zu mobilisieren. Von den mittlerweile annähernd tausend Jungen, die die Adolf-Hitler-Schulen absolviert hatten, waren bis zu diesem Zeitpunkt „leider etwa 100 gefallen“; von dem „Rest aber“ - so der Zweckoptimismus der Parteizentrale - „wollen 500 bis 600 Politische Leiter werden“. Den Gaupersonalämtern wurde aus dem Münchener Hauptpersonalamt bedeutet, daß ,Adolf-Hitler-Schulen und Ordensburgen [weiterhin als] das tragende Fundament" für die Rekrutierung von Führernachwuchs zu betrachten seien, die deshalb, was man in den vergangenen Jahren nicht geschafft hatte - im Januar 1945! -, „bis zur letzten Konsequenz ausgebaut werden“ sollten.

Offensichtlich von hochgradigem Realitätsverlust geprägt, versuchte das Hauptpersonalamt die nachgeordneten Stellen mit Führerworten - der Führer habe die Adolf-Hitler-Schulen ,in seinen Reden mehrmals ... als vorbildlich für die gesamte deutsche Jugenderziehung hingestellt ${ }^{\text {t135 }}$ - zu motivieren, Worten, die jedoch angesichts der sich zunehmend ausprägenden Zusammenbruchsgesellschaft jede Bedeutung verloren hatten. Denn schon im Dezember 1944 hatte Hitler angeordnet, daß ,in Zukunft der aktive Offiziers- bzw. Führernachwuchs des Heeres und der Waffen-SS vor seinem Eintritt in die Wehrmacht in Nationalpolitischen Erziehungsanstalten [und] Adolf-HitlerSchulen“" zu erziehen sei; von dieser Zweckentfremdung der einstigen Eliteschmiede der Partei ist die Reichsjugendführung nicht einmal mehr informiert worden. ${ }^{136}$ Zum ersten Kriegslehrgang des Offziersnachwuchses des Heeres und der Waffen-SS, der am 5. Februar 1945 auch in den Adolf-HitlerSchulen begann, konnten gerade 2.000 Bewerber einberufen werden, deren ,yormilitärische Erziehung und Ausbildung nach den Richtlinien der Reichsjugendführung durchgeführt werden “ sollte. ${ }^{137}$

Gemessen an dem mit der Gründung der Adolf-Hitler-Schulen verbundenen Anspruch, „,ür den Nachwuchs auf den Ordensburgen ... die Besten aus den Adolf-Hitler-Schulen und damit die Besten unseres Volkes“ zu rekrutieren und auszubilden, so „daß wir für die Partei das beste Führerkorps erhalten, das irgendeine Organisation in der Welt aufzuweisen hat: groß im Wissen, blind im Gehorsam, fanatisch im Glauben “138, war die Realisierung dieses Vorhabens geradezu stümperhaft, stand in umgekehrt proportionalem Verhältnis zu den vollmundigen Ankündigungen und bewegte sich - was Organisation, Strukturen und Inhalte betraf - weit unter dem Niveau der HJFührerschulen und der höheren staatlichen Schulen, als deren reformierte und revolutionierte Synthese die Adolf-Hitler-Schulen galten.

\section{3 Die Erweiterte Kinderlandverschickung}

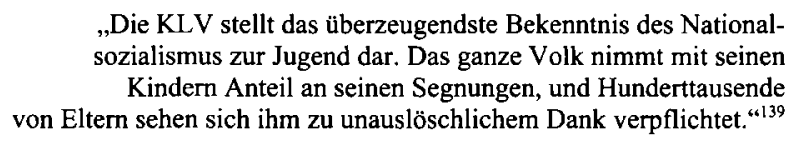

Die Einrichtung der Erweiterten Kinderlandverschickung ist von der Reichsjugendführung als ein weiterer schulpolitischer Glücksfall betrachtet worden, vermeinte sie doch über diesen Bereich die angestrebte Übernahme des gesamten Bildungswesens - und damit die ,Vollendung der Einheit der Jugenderziehung" unter ihrer Führung - zwar noch unter Ausnahmebedingungen, aber immerhin schon einmal in größerem Stil testen und damit vollendete Tatsachen schaffen zu können. Dies wurde von der HJ-Zentrale 1944 zwar vorsichtig, keineswegs aber undeutlich ausgedrückt: Neben ihrer ,programmatischen Anteilnahme an der Entwicklung des deutschen Schulwesens nahm die Hitler-Jugend jede Gelegenheit wahr, auch die praktische Zusammenarbeit mit der

135 BA, NS 22/2027 (1. Rundbrief des Amtes Führernachwuchs im Hauptpersonalamt des Reichsorganisationsleiters, 20.1.1945).

136 BA, Sammlung Schumacher/270 III, Bl. 29 (Führererlaß, 7.12.1944).

137 BA, NS 19/665 (Berger an Himmler, Februar 1945).

138 Denkschrift Die Adolf-Hitler-Schule, S. 15.

139 BA, NS 26/358 (Kriegsgeschichte der HJ, 1944). 
Schule zu vertiefen. Als eine solche Gelegenheit erwies sich in wachsendem Maße die Erweiterte Kinderlandverschickung“. Der „Kampf um die Durchführung“ der Erweiterten Kinderlandverschickung habe ,auf wesentlichen Gebieten der Jugendbetreuung, so auf dem der Ernährung, der schulischen Ausbildung, der Zusammenarbeit zwischen Hitler-Jugend und Schule und der geschlossenen Gemeinschaftserziehung, bahnbrechende Wirkung gezeigt."

Als ,grundsätzlich“ sei „festzuhalten, daß keine Maßnahme in dieser Unmittelbarkeit das gemeinsame Vorgehen von Schule und Hitler-Jugend verlangt und gefördert hat wie diese. Im KLVLager lernt der Jugendfuihrer die Arbeit des Schullehrers aus anderer als nur der Schülerperspektive kennen und schätzen, wie umgekehrt dieser einen Einblick in die Praxis der Erziehungsarbeit der Hitler-Jugend gewinnt. Beide, Lehrer und Jugendführer, stehen in einem klaren disziplinären Verhältnis zueinander, einer ist auf den anderen angewiesen, und nur aus dem einträchtigsten Zusammenwirken beider wächst die Erfüllung der gemeinsamen Aufgabe". Lehrer und Jugendführer arbeiteten ,im gleichen erzieherischen Raum“, dies sei „das ganze Geheimnis““ ${ }^{40}$ Und da in wenigen Jahren der gesamte Lehrernachwuchs ohnehin aus der HJ stammen und an HJ-kontrollierten Schulen ausgebildet würde, und die Berufsbilder des Lehrers und des HJ-Führers dann in der Figur des multivariabel einsetzbaren nationalsozialistischen Jugendführers verschmolzen wären, könne sich dieser Tätigkeitsbereich zur eigentlichen Probe aufs Exempel nationalsozialistischer Erziehungskonzeptionen entwickeln.

Am 27. September 1940 - dem Tag, an dem Adolf Hitler, Außenminister Galeazzo Ciano und Botschafter Saburo Kurusu in Berlin den Dreimächtepakt unterzeichneten, in dem Deutschland, Italien und Japan vereinbart hatten, ,sich mit allen politischen, wirtschaftlichen und militärischen Mitteln gegenseitig zu unterstützen" - unterrichtete Martin Bormann die Gauleiter der NSDAP in einem ,streng vertraulichen“ Rundschreiben von einer Anordnung des Führers, wonach „die Jugend aus Gebieten, die immer wieder nächtliche Luftalarme haben, auf der Grundlage der Freiwilligkeit in die übrigen Gebiete des Reiches geschickt werden" solle. ${ }^{141}$

Nach dieser Anordnung Hitlers, die den offiziellen Auftakt zu der später Erweiterte Kinderlandverschickung (EKLV) genannten Aktion bildete, war vorgesehen, daß unter Führung des Reichsleiters für die Jugenderziehung der NSDAP, Baldur von Schirach, die NS-Volkswohlfahrt, die Hitlerjugend und der NS-Lehrerbund in ,engster Zusammenarbeit“ die Verschickungsmaßnahmen von Minderjährigen aus bombengefährdeten Gebieten durchzuführen hätten, wobei die NSV die Umsiedlung der vorschulpflichtigen Kinder und der Kinder der ersten vier Schulklassen, die HJ dagegen die Unterbringung der Kinder vom fünften Schuljahr an zu übernehmen hatte und der NSLB für die Sicherstellung des Unterrichts der schulpflichtigen Jahrgänge verantwortlich war. Für die am 3. Oktober 1940 anlaufende Aktion, für deren regionale Organisation die Gauleiter verantwortlich gemacht wurden, sollte eine öffentliche Propaganda zunächst ebenso unterbleiben wie nach einer Anordnung Hitlers vorerst lediglich von einer Landverschickung und nicht von einer Evakuierung der Großstadtjugend zu sprechen war. ${ }^{142}$

In einer ersten Durchführungsanweisung über die ,Landverschickung der Jugend aus Großstädten" vom 2. Oktober 1940 hatte Schirach erste Maßnahmen zur Erweiterten Kinderlandverschickung angeordnet, die zunächst ausschließlich Kinder und Jugendliche aus Hamburg und Berlin betrafen ${ }^{143}$ - noch im Oktober und November 1940 wurden aus diesen beiden Städten be-

140 Ebenda.

141 VHB, S. 3113 (Rundschreiben Bormanns an die Gauleiter, 27.9.1940, streng vertraulich).

$142 \mathrm{Vgl}$. ebenda. Erst ab etwa 1942/43 wurde in gewissem Umfang eine zentral gelenkte ,aufklärende“ und eine regional differenzierte, von den jeweiligen Gauleitungen gesteuerte, ,werbende“ Propaganda zugelassen und gefordert. Vgl. dazu etwa RL-Rundschreiben KLV, 5/42, 23.12.1942 (Propagandarichtlinien für die Erweiterte Kinderlandverschickung); auch in: Gebrdschr. RJF, 2/43, 27.2.1943. vgl. auch Vorschriftensammlung KLV, B 3a (Richtlinien der Reichspressestelle zur Behandlung der Erweiterten Kinderlandverschickung in den Tageszeitungen).

$143 \mathrm{Vgl}$. BA, R 2/11914, Bl, 41 ff. (Durchführungsanweisung zur Landverschickung der Jugend aus Großstädten, 2.10.1940); danach konnten HJ, NSV und NSLB im Rahmen ihrer Zuständigkeiten unmittelbar eigene Anweisungen erlassen, über die die Reichsdienststelle zu unterrichten war; vgl. auch Schulz, Die erweiterte Landverschickung von Kindern aus Großstädten. 
reits 190.000 Kinder verschickt ${ }^{144}$-, sich jedoch durch die rasche Ausdehnung der Aktion auf die industriellen Ballungsgebiete des Reiches infolge der Zunahme des Bombenkrieges bald als überholt erwiesen und durch eine neugeschaffene Reichsdienststelle in einem eigenen Befehlsblatt ${ }^{145}$ laufend erweitert und präzisiert werden mußten.

Da bei der Betrachtung sowohl der zeitgenössischen Veröffentlichungen als auch der heutigen Publizistik oftmals der Eindruck entsteht, die (Erweiterte) Kinderlandverschickung sei ein Werk der Hitlerjugend gewesen - damals wurden derartige Kontextzusammenhänge aus politischer Berechnung bewußt inszeniert, heute werden sie vielfach aus Unkenntis kolportiert -, soll zunächst skizziert werden, was unter Kinderlandverschickung im Allgemeinen und was unter einem Teilaspekt lediglich eines ihrer Bestandteile, den $\mathrm{HJ}$-geführten Lagern der Erweiterten Kinderlandverschickung - und nur diese waren mit der NS-Jugendorganisation verbunden -, im Besonderen zu verstehen ist. Kinderlandverschickung, eine mehrwöchige bis mehrmonatige Entsendung von zumeist aus industriellen Großstädten stammenden Kindern und Jugendlichen in Heime und private Pflegestellen in ländlichen Gegenden zum Zwecke der Erholung, der Regeneration, der Gesundung und Rekonvaleszenz gab es in Deutschland zumindest seit der Jahrhundertwende. Seit etwa 1916/17 hatte sich die „Reichszentrale Landaufenthalt für Stadtkinder e.V.“ zunächst zur größten, schließlich zur einzigen Koordinierungsinstanz für die Kinderlandverschickung entwickelt; sie koordinierte die von öffentlichen und Betriebsfürsorgeeinrichtungen, von Verbänden der Wohlfahrtspflege, vom Deutschen Roten Kreuz, der Inneren Mission und dem Caritas Verband, ab 1933 auch von der NSV und der HJ organisierten Verschickungsaktionen, das heißt, sie kümmerte sich um Fragen der Registrierung und Anmeldung, der Unterbringung, des Transports und der Verpflegung, der rechtlichen und Versicherungsangelegenheiten der zu verschickenden Kinder. Zwischen 1917 und dem Herbst 1940, dem Beginn der Erweiterten Kinderlandverschickung, wurden durch die Reichszentrale etwa 5.144.000 Kinder aufs Land, 4.509.000 in Kindererholungsheime, 564.000 ins Ausland und 450.000 Kinder in örtliche Pflegestellen vermittelt, insgesamt also fast elf Millionen Kinder verschickt. ${ }^{146}$

1916 mit der Absicht gegründet, „Schutzmaßnahmen für die heranwachsende Großstadtjugend gegen die Hungerblockade der Feindmächte" zu ergreifen, hatte sich der Aufgabenbereich der von den jeweiligen Reichsbehörden unterstützten und mit den Landesfürsorgeverbänden auch institutionell verquickten Reichszentrale seitdem erheblich gewandelt und erweitert. Die ursprüngliche Heil- und Gesundheitsfürsorge trat ab 1933 sukzessive in den Hintergrund, die ,vorbeugenden Gesundheitsmaßnahmen" erhielten mit der nationalsozialistischen Grundierung einen ideologischen Hintergrund. Ab 1933 etablierten sich die HJ - die im Rahmen ihrer Gesundheitsorganisation jährlich Zehntausende ihrer Mitglieder für eine Landverschickung warb - und besonders die NSV zu den größten Entsendeeinrichtungen, deren Aktionen auch im Dritten Reich von der Reichszentrale organisiert und abgestimmt wurden. Diese war 1935 „nach dem Führerprinzip ausgerichtet" und faktisch in die NSV integriert worden ${ }^{147}$.

Nach Ausschaltung konkurrierender Institutionen wurden von Hermann Althaus „einheitliche Richtlinien zur Durchführung der gesamten deutschen Jugenderholungspflege“ ausgegeben. Danach sollten ,an sich gesunde, jedoch in irgendeiner Form gesundheitsgefährdete und somit erholungsbedürftige Kinder wieder voll leistungsfähig gemacht" werden, eine Aufgabe, die ,nicht nur in volkspflegerischer Beziehung und in fürsorgerischer Hinsicht Bedeutung" habe, ,sondern besonders auch in politischer und bevölkerungspolitischer Hinsicht", denn die Jugend sei „das Volk

144 Vgl. Kock, Kinderlandverschickung, S. 136. Ungeachtet einer Reihe von sachlichen und daraus resultierenden interpretatorischen Fehlem stellt die Studie von Kock die bislang beste und ausführlichste Arbeit zum Gegenstand dar; vgl. auch die zeitgenössische Darstellung bei Schulz, Der Aufstieg der deutschen Kinderlandverschickung.

$145 \mathrm{Vgl}$. Mitteilungsblatt für die erweiterte Kinderlandverschickung.

146 Vgl. BA, R 36/2045 (Althaus an Deutschen Gemeindetag, 19.1.1942: Übersendung der Jahresberichte der Reichszentrale 1938 - 1941 und zusammenfassender Bericht 1917-1941).

147 Vorsitzender der Reichszentrale Landaufenthalt für Stadtkinder e.V. war der ursprünglich aus der Inneren Mission stammende Hermann Althaus, der - als Stellvertreter des NSV-Chefs Erich Hilgenfeldt - im Dritten Reich gleichzeitig als Reichsamtsleiter im Hauptamt für Volkswohlfahrt tätig war und dort das Amt Wohlfahrtspflege und Jugendhilfe leitete. 
von morgen“, die Kinder seien „,die künftigen Arbeitsträger, denen besonders nach siegreich beendetem Krieg in den künftigen Jahren bedeutende Aufgaben“ erwüchsen. Die Jugend gesund zu erhalten sei daher eine Aufgabe, ,die über das Heute hinaus ein dringendes Erfordernis“ der $\mathrm{Zu}$ kunft sei, und nur ,,durch letzten Einsatz aller verfügbaren Kräfte und Mittel, durch letzte einheitliche Ausrichtung" durchgeführt werden könne. ${ }^{148}$

Der Vorgang Kinderlandverschickung stellte also bis ins Jahr 1940 sowohl als Sachverhalt wie als Terminus technicus im Bewußtsein der Bevölkerung ein weithin bekanntes, völlig normales, eher postiv besetztes Geschehen dar. Der Wandel von einer sozial- und heilfürsorgerischen Einrichtung zu einem Instrument nationalsozialistischer Bevölkerungs- und Wirtschaftspolitik ist in der breiten Öffentlichkeit weitgehend unbemerkt geblieben. Denn auch im Zweiten Weltkrieg ging die 'normale', allgemeine Kinderlandverschickung zunächst unvermindert weiter, die Verschickungszahlen erhöhten sich vorerst sogar leicht: Nach 1938 (656.000 verschickte Kinder) wurden 1939 rund 682.000 und 1940 etwa 693.000 Kinder über die Reichszentrale aufs Land gebracht. Der zwischenzeitliche 'Einbruch' von 1941, als durch die Reichszentrale 'nur' noch 350.000 gesundheitsgefährdete Kinder zur Landverschickung gelangten, ergab sich dadurch, daß in diesem Jahr - parallel zur Weiterführung der regulären KLV - die Erweiterte Kinderlandverschickung begonnen wurde, die Ressourcen wie Verpflegung, Transport- und Unterbringungsmöglichkeiten aus der allgemeinen Kinderlandverschickung abzog und mit der es gelang, in diesem Jahr bereits 481.000 Kinder aus luftkriegsbetroffenen Gegenden zu verschicken.

Ab 1940/41 begann sich die bislang praktizierte Kinderlandverschickung also in zwei Teile zu spalten: So lief die reguläre, seit 1917 andauernde und bis 1943/44 beibehaltene, vor allem von der Reichszentrale und der NSV organisierte Kinderlandverschickung weiter, innerhalb derer trotz aller nationalsozialistischen Ausrichtungsversuche noch der Gesundheits- und Erholungscharakter dominierte und in deren Rahmen bis 1943/44 jährlich zwischen 350.000 und 700.000 Kinder verschickt wurden. ${ }^{\lfloor 49}$ Diese allgemeine oder reguläre Kinderlandverschickung, die auch im Dritten Reich quantitativ den größten Anteil aller Kinderverschickungen ausmachte, blieb in den meisten Darstellungen der NSDAP und der Reichsjugendführung aus der Kriegszeit vollständig außerhalb der Betrachtung, obgleich sie bis 1940 die öffentliche Meinung zu diesem Aspekt weitgehend geprägt hatte.

Die NS-Behörden versuchten gezielt, das weithin positive Ansehen der bisherigen Kinderlandverschickung auf die im Herbst 1940 etablierte Erweiterte Kinderlandverschickung zu übertragen. Dies mißlang fast vollständig: Ende September 1940, nur wenige Tage nach Bekanntwerden der Einrichtung der Erweiterten Kinderlandverschickung, reagierte die Berliner Bevölkerung mit „wilder Gerüchtebildung und Beunruhigung“ auf diese neue Verschickungsart, die von vielen völlig zu Recht - als Evakuierung und damit als Anzeichen von Gefahr empfunden wurde. Kennzeichnend für das seismographische Gespür und die labile Stimmungslage der Bevölkerung war, daß unmittelbar nach Bekanntgabe des Anlaufens der HJ- und NSV-geführten Erweiterten Kinderlandverschickung die ,wildesten Gerüchte über einen angeblichen englischen Großangriff und die Eröffnung des Gaskrieges" entstanden und auf fruchtbaren Boden fielen und, wie der SD registrierte, ,zur stärksten Beunruhigung seit Kriegsbeginn“ beitrugen, weil sofort eine „getarnte Zwangsverschickung“" vermutet wurde. ${ }^{150}$

Dieser neue und zweite Bestandteil der Verschickung von Kindern, die im September 1940 geschaffene Erweiterte Kinderlandverschickung, hatte weniger den Gesundheitsaspekt als vielmehr die physische Bewahrung der Kinder vor Bombenschäden und - später hinzutretend - ihre von Elternhaus und traditionellem Schulwesen getrennte, weitgehend ungestörte NS-Indoktrination zum Ziel. ${ }^{151}$ Gerade den letztgenannten Aspekt hatte Schirach anläßlich der Übergabe der Lagerordnung an die Leiter der Kinderlandverschickungslager der $\mathrm{HJ}$ prononciert hervorgehoben: „Grundsatz unserer Lagerführung der Erweiterten Kinderlandverschickung“ sei „die Erziehung des Pimpfen und des Jungmädels zur nationalsozialistischen Volksgemeinschaft". Lagerleiter und

148 Vgl. BA, R 36/2045 (Jahresberichte der Reichszentrale 1938 - 1941 und zusammenfassender Bericht 1917 - 1941 ).

149 Vgl. BA, R 2/11914 (Reinhardt an Bormann, 26.11.1942).

150 Meldungen aus dem Reich, S. 1622, 1647 (Berichte vom 30.9. und 7.10.1940)

$151 \mathrm{Vgl}$. dazu Gehrken, Nationalsozialistische Erziehung. 
Lagermannschaftsführer hätten ,innerhalb unserer Aktion die bisher einmalige Möglichkeit, nicht nur in kurzen Dienst- oder Schulstunden auf dieses Ziel hinzuwirken“, sondern könnten nunmehr „Tag für Tag ihre Jungen und Mädel auch außerhalb dieser Zeit“ betreuen. ${ }^{152}$

Die mit modifizierten Intentionen als Sonderform der allgemeinen Kinderlandverschickung etablierte Erweiterte Kinderlandverschickung bestand aus vier Komponenten, von denen lediglich eine [!], die von der HJ geleiteten KLV-Lager, in den Zuständigkeitsbereich der HJ-Zentrale fiel. ${ }^{153}$ Obwohl die HJ-geführten KLV-Lager also nur eine Facette der vielfältigen Verschickungspraktiken in der Kriegszeit darstellten, sind sie - wenn auch mit durchaus unterschiedlichen Intentionen - durch die zeitgenössische Propaganda und die Nachkriegspublizistik derart in den Mittelpunkt gerückt und kaum noch als pars pro toto, sondern vielmehr als die 'eigentliche' Kinderlandverschickung dargestellt worden, so daß es scheint, als hätten die KLV-Lager der HJ den gesamten Inhalt des Komplexes KLV ausgemacht; angesichts des im Vergleich zu anderen Formen der Kinderlandverschickung tatsächlich eher geringen Umfangs der von der HJ geführten KLV-Lager steht diese Betrachtungsweise jedoch in einem gravierendem Gegensatz zur Realität.

Auslöser für die Einrichtung der Erweiterten Kinderlandverschickung insgesamt und für deren konkreten Beginn zu diesem Zeitpunkt war die Entwicklung des Luftkriegs gegen England. Nach dem siegreichen Frankreichfeldzug waren in der deutschen militärischen Führung zunächst alle kritischen Stimmen an Hitlers Kriegführung verstummt, und in weiten Kreisen der Bevölkerung verschwand parallel zum wachsenden Wunsch nach Frieden die Kriegsangst - Deutschland schien unüberwindlich. Die am 10. Juli 1940 begonnene Bombardierung militärischer Ziele in Südengland und britischer Geleitzüge im Kanal ist - als Reaktion auf die von britischer Seite abgelehnten Friedensvorstellungen Deutschlands - mit Hitlers Weisung über den ,verschärften Luftkrieg gegen England" vom 1. August 1940 wesentlich ausgeweitet worden. Als Vorbereitung auf die Operation „Seelöwe“ - die geplante Besetzung Großbritanniens - wurden ab Mitte August die Bombardements auch auf britische Städte ausgeweitet, am 24. August fielen die ersten Bomben auf Londoner Wohnviertel. Die Royal Air Force, die schon Mitte Mai mit Hamburg die erste deutsche Großstadt bombardiert hatte, reagierte mit Angriffen auf Berlin und andere deutsche Städte. Im Laufe des September 1940 wuchs in der NS-Führung die Skepsis, daß angesichts der starken britischen Luftabwehr ein schneller Sieg über England möglich sein könnte. Statt dessen griffen nun immer öfter britische Flugzeuge Städte im Reichsgebiet an; dadurch entstand trotz zunächst noch geringer Verluste - von Mai bis Oktober kamen 950 Deutsche durch Bombenangriffe ums Leben, 2.600 wurden verletzt - zumindest der Eindruck der Verwundbarkeit auch des Reiches.

Die britischen Bombenangriffe vom 23. bis zum 25. September 1940 auf Berlin, die 22 Menschenleben forderten, waren schließlich der unmittelbare Anlaß für die Einrichtung der Erweiterten Kinderlandverschickung, die ,also zeitlich mit der Erkenntnis zusammen [fiel], daß Großbritannien weder kapitulieren würde noch innerhalb kürzester Zeit militärisch bezwungen werden könnte“. ${ }^{154}$ Die auch Hitler bekannte Tatsache, daß in Großbritannien schon im September 1939 Evakuierungen größeren Ausmaßes stattgefunden hatten - noch vor der offiziellen Kriegserklärung an Deutschland war in Erinnerung an den Ersten Weltkrieg ab 1. September dort mit der Umsiedlung von 1,5 Millionen Menschen begonnen worden ${ }^{155}$-, mag mit zu seiner Entscheidung beigetragen haben, Ende September 1940 auch in Deutschland eine Reichsorganisation zu etablieren, die - zunächst noch unter Vermeidung des Begriffes - die massenpsychologisch bedeutsame Evakuierung von Kindern und Jugendlichen vornahm.

152 Mitteilungsblatt KLV, Sonderdruck 2/41, 1.6.1941; dort auch die Lagerordnung für KLV-Lager.

153 Nimmt man die im Kriege weiterlaufende allgemeine Kinderlandverschickung hinzu, setzte sich der Gesamtkomplex der KLV sogar aus acht Bestandteilen zusammen, also aus zwei Hauptverschickungsarten mit jeweils vier Kompetenzbereichen, womit sich - wie zu zeigen sein wird - der Stellenwert der HJ-geführten KLV-Lager weiter verringert. Werden darüber hinaus noch die bis Anfang 1943 in der Zuständigkeitssphäre der Kirchen erfolgenden Kinderlandverschickungen berücksichtigt, die Lammers im Auftrage Hitlers am Ende 1942 verbot - vgl. RL-Rundschreiben KLV, 5/42, 23.12.1942 (darin Lammers an Muhs, 11.11.1942); vgl. auch Rundschreiben des Stabsfuihrers, 14/42, 15.12.1942, ergänzt durch RLRundschreiben KLV, 2/43, 1.3.1943; vgl. auch Gebrdschr. RJF, 3/43, 25.3.1943 und Gebrdschr. RJF, 4/43, 30.3 .1943 -, reduziert sich die Bedeutung des Anteils der HJ an der Gesamt-KLV noch weiter.

154 Kock, Kinderlandverschickung, S. 82.

$155 \mathrm{Vgl}$. Kressel, Evakuierungen, S. 11, $29 \mathrm{ff}$., $69 \mathrm{ff}$. 
Tatsächliche Belege dafür, daß dazu ,schon vorher ausführliche Planungen stattgefunden“ “156 haben, daß also Evakuierungsmaßnahmen größeren Ausmaßes überhaupt Gegenstand deutscher Kriegsplanungen waren, existieren nicht. Die in der Folge mit dieser Aktion befaßten Parteidienststellen und staatlichen Behörden hatten, so ist aus den gegenseitigen Unterrichtungen im Schriftverkehr und der Art und dem Inhalt der entsprechenden Erlasse zu erkennen, keine Kenntnis von einem derartigen Vorhaben und sind nicht in entsprechende Vorarbeiten einbezogen worden, so daß das ganze Unternehmen ad hoc und als großangelegte Improvisation begann. ${ }^{157}$ Gegen zentrale, langfristig vorbereitete und vorausschauende Planungen spricht auch, daß die am 3./4. Oktober beginnende Erweiterte Kinderlandverschickung zunächst auf die bislang am stärksten von Bombardements betroffenen Städte Hamburg und Berlin beschränkt blieb.

Möglichen Unwägbarkeiten, die aus der Beauftragung staatlicher Stellen mit bislang ungewohnten Kriegsmaßnahmen hätten entstehen können - und dann auch entstanden -, versuchte Hitler dadurch zu begegnen, daß er den Reichsleiter für die Jugenderziehung der NSDAP, Baldur von Schirach, der wenige Monate zuvor noch als Reichsjugendführer amtiert hatte und nun als Beauftragter der Führers für die Inspektion der HJ fungierte, mit der Organisation und Durchführung der Erweiterten Kinderlandverschickung betraute und ihn als Chef einer nur ihm, dem Führer, unterstellten Sonderbehörde des Reichs ermächtigte, sich der HJ, der NS-Volkswohlfahrt und des NSLehrerbundes, also Einrichtungen der Partei zu bedienen. Ansprüche, Wünsche und Bestrebungen anderer Parteistellen sowie staatlicher, privater und konfessioneller Einrichtungen, sich an der Erweiterten Kinderlandverschickung zu beteiligen, wurden abgewiesen. ${ }^{158}$ Im Reichsfinanzministerium, dessen Beamte verärgert registrierten, daß ,mit der Durchführung dieser Maßnahme die Parteiorganisationen beauftragt" worden waren, während das Reich die Kosten tragen müsse, wurden die neue Sonderbehörde und deren Aufgaben in legalistischem Politikverständnis dahingehend interpretiert, daß ,die Durchführung der Kinderlandverschickung“ rechtlich ,,als auftragsweise Erfüllung einer Aufgabe der staatlichen Verwaltung durch Einrichtungen der Partei“ anzusehen sei ${ }^{159}$; tatsächlich gestaltete es sich jedoch genau anders herum: Die Partei-Kanzlei hatte einen 'Führerwillen' artikuliert und zu seiner Realisierung ausschließlich NSDAP-Einrichtungen beauftragt, die sich zur Erfüllung dieser Aufgabe staatlicher Einrichtungen und Etats bedienten.

Die Beauftragung Schirachs, der zu diesem Zeitpunkt noch hoch in Hitlers Gunst stand, dessen Kompetenz in Jugendfragen von Hitler noch anerkannt war und dessen Vorschlägen Hitler - wenn es in sein Konzept paßte - mitunter aufgeschlossen gegenüberstand, hing auch mit den Bestrebungen Schirachs und zahlreicher Amtschefs der Reichsjugendführung zusammen, neben ihrer Alleinzuständigkeit für die außerschulische Jugenderziehung auch Kompetenzen im Bildungsbereich zu erlangen. Der seit der Machtübernahme zwischen HJ und Schule, zwischen der Reichsjugendführung und dem Reichserziehungsministerium schwelende Konflikt schien einmal, zu Kriegsbeginn, fast schon entschieden. Im September 1939 hatte Schirach seine nächste Umgebung schriftlich wissen lassen, daß beabsichtigt sei, ihm ,die Zusammenfassung aller erzieherischen Kräfte während des Krieges zu übertragen " ${ }^{\text {"160 }}$, also auch die Leitung des Reichserziehungsministeriums. Wie gezeigt, schreckte Hitler jedoch trotz seiner kritischen Einstellung zu Bernhard Rust und einer oft vernichtenden Bewertung von dessen Amt und Amtsführung letztlich davor zurück, ihm das

156 So Kock, Kinderlandverschickung, S. 40 f. mit nicht überzeugender Indizienkette; vgl. auch Kressel, Evakuierungen, S. $39 \mathrm{ff}$.

157 So wurde dem Finanzministerium erst am 1.10.1940 von Bormann mitgeteilt, daß es die Finanzierung der Aktion zu übernehmen habe, vgl. BA, R 2/11814, Bl. 27, am 2.10.1940 teilte das Reichserziehungsministerium seinen nachgeordneten Dienststellen den Beginn der Aktion am nächsten Tag mit, vgl. BA, R 21/510, Bl. 1 f., und erst am 9.10.1940 begann die Regelung der finanziellen Modalitäten zwischen Reichsschatzmeister Schwarz und Finanzstaatssekretär Reinhardt, vgl. ebenda, Bl. $32 \mathrm{ff}$.

158 Das betraf bis zur Stillegung und Auflösung des NSLB vor allem das Reichserziehungsministerium, das insbesondere wegen der von der KLV betroffenen Beeinträchtigung der Schulpflicht Zuständigkeiten für sich reklamierte. Aber noch Ende 1942 mußte Lammers die Obersten Reichsbehörden „im Auftrag des Führers" darauf hinweisen, "daß andere Stellen als die vom Führer damit beauftragten sich mit Kinderlandverschickung nicht zu befassen haben"." RLRundschreiben KLV, 5/42, 23.12.1942 (Lammers an Oberste Reichsbehörden, 11.11.1942).

159 BA, R 2/1 1914, B1. 27 (Aktenvermerk RFM, 8.10.1940); ebenda, R 2/11915 (Aktenvermerk RFM, März 1942).

$160 \mathrm{BA}$, NS 28/30, B1. 3 (Schirach an die HJ-Gebietsführer und BDM-Obergauführerinnen, 11.9.1939); veröffentlicht bei Jahnke/Buddrus, Deutsche Jugend, S. 309. 
Reichserziehungsministerium zu entziehen und die Führung des Gesamtkomplexes der Jugenderziehung in einer letztlich parteigeführten Dienststelle, der HJ, zu vereinigen. Ein Jahr nach Hitlers Weigerung, ihm das staatliche Bildungsressort zu überlassen, glaubte Schirach, die durch Kriegsumstände hervorgerufene Situation ausnutzen und das angestrebte Ziel - die „Einheit der Erziehung" - doch noch erreichen zu können; die Kinderlandverschickung bildete für ihn eine zunächst verheißungsvolle Möglichkeit, das staatliche Schulwesen durch eine zunächst kriegsbedingt zu motivierende Assoziation von Schul- und HJ-Strukturen, wie sie sich in der Erweiterten Kinderlandverschickung zu verkörpern begann, doch noch in die Hand zu bekommen.

An der Spitze der Erweiterten Kinderlandverschickung stand offiziell der Reichsleiter für die Jugenderziehung der NSDAP, der gerade zum Gauleiter und Reichsstatthalter von Wien ernannte Baldur von Schirach. Als „Beauftragter des Führers für die Erweiterte Kinderlandverschickung“ ließ er eine gleichnamige Reichsdienststelle errichten, die formal in seinem Büro in der Reichskanzlei angesiedelt war, aus Praktikabilitätsgründen jedoch in der Reichsjugendführung residierte. Weil der in Wien residierende Schirach sich zumindest bis Ende 1942 persönlich nur wenig um die Kinderlandverschickung kümmerte ${ }^{161}$, hatte er den erst seit wenigen Tagen im Amt befindlichen Stabsführer der Hitlerjugend, Helmut Möckel, zu seinem Stellvertreter und ständigen Vertreter im Amt des „Beauftragten des Führers“ ernannt. Möckel, der als Geschäftsführer des Arbeitsausschusses für HJ-Heimbeschaffung seit 1937 faktisch das gesamte Heimbauprogramm der HJ leitete, als Leiter der Behördenabteilung der Reichsjugendführung die Kontakte der HJ-Zentrale zu sämtlichen Reichsbehörden koordinierte und darüber hinaus als Führer des HJ-Gebietes Sachsen und nunmehr als Stellvertreter des neuen Reichsjugendführers Axmann amtierte, war Schirach als hervorragender Organisator bekannt.

In der faktisch vom Stabsführer der Reichsjugendführung geleiteten „Reichsdienststelle Erweiterte Kinderlandverschickung" ließ Helmut Möckel die mit Organisationsfragen befaßten Hauptabteilungen Führung und Ausrichtung, Unterbringung und Transport, KLV-Schulerziehung, Gesundheitsdienst, Verwaltung und Ernährung, Geschäftsführung und Reichsinspektion einrichten. $\mathrm{Da}$ diese Dienststellen zumeist von HJ-Führern wie Horst Hechler, Gerhard Dabel, Eberhard Grüttner, Richard Heil oder Walter Rätz geleitet wurden, trug dazu bei, den damals HJ-seitig gezielt begründeten und später kolportierten Eindruck hervorzurufen, die Erweiterte Kinderlandverschickung sei eine Einrichtung der HJ. Wegen Personalmangels, aus dienstrechtlichen und Effizienzgründen, aber auch wegen der selbstüberschätzenden Eigensicht auf diesen Gegenstand und usurpatorischer Tendenzen der HJ-Zentrale waren durch Schirach und Möckel natürlich vorwiegend Personen aus dem Organisationszusammenhang der HJ - dagegen kaum Funktionäre aus der NSV oder dem NSLB - mit Leitungsfunktionen betraut worden, die sowohl in der Reichsdienststelle Kinderlandverschickung als auch in der wenig später installierten, organisatorisch und strukturell analog aufgebauten KLV-Dienststelle der Reichsjugendführung die entsprechenden Funktionen in Personalunion wahrnahmen.

Denn parallel zur Reichsdienststelle EKLV - die in Erledigung der Schirach von Hitler übertragenen Aufgaben die Erweiterte Kinderlandverschickung weit über den Zuständigkeitsbereich der HJ hinaus organisieren sollte - wurde im Februar 1941 auch die KLV-Dienststelle der Reichsjugendführung geschaffen, die eigentlich nur für die $\mathrm{HJ}$-spezifischen Belange der Erweiterten Kinderlandverschickung zuständig war. ${ }^{162}$ Die vielfach in Personalunion besetzten Funktionen der Reichs- und der HJ-Dienststelle und deren weitgehend identische inhaltliche Aufgabenstellung ließen es bald nicht mehr zu, beide Behörden voneinander zu unterscheiden, was durchaus im Inter-

$161 \mathrm{Vgl}$. dazu die detaillierte Auflistung der Aktivitäten Schirachs seit Sommer 1940 in: Reichsleiter Baldur von Schirach. Tätigkeit als Reichsstatthalter und Gauleiter in Wien.

162 Die in der Reichsjugendführung zur „zusammenfassenden Bearbeitung der Aktion der Erweiterten Kinderlandverschickung“ eingerichtete Dienststelle Kinderlandverschickung, war in folgende Abteilungen gegliedert, die denen der Reichsdienststelle entsprachen und mit den sachlich entsprechenden Fachämtern der HJ-Zentrale kooperierten: Geschäftsführung, Unterbringung und Verpflegung, Transportwesen, Lagerführung und Inspektion, Finanzverwaltung, Gesundheitsaufsicht. Der Dienststelle war ein Ausbildungslager für die Lagermannschaftsführer und eine Stelle für die Betreuung der volksdeutschen Jugend in den Lagem angeschlossen. Rundschreiben der NSDAP/RJF, Folge 5/41, 3.2.1941. 


\section{Aufbau und Gliederung der Dienststelle Erweiterte KInderlandverschickung in der Reichsjugendführung und ihrer nachgeordneten Strukturen, 1944}

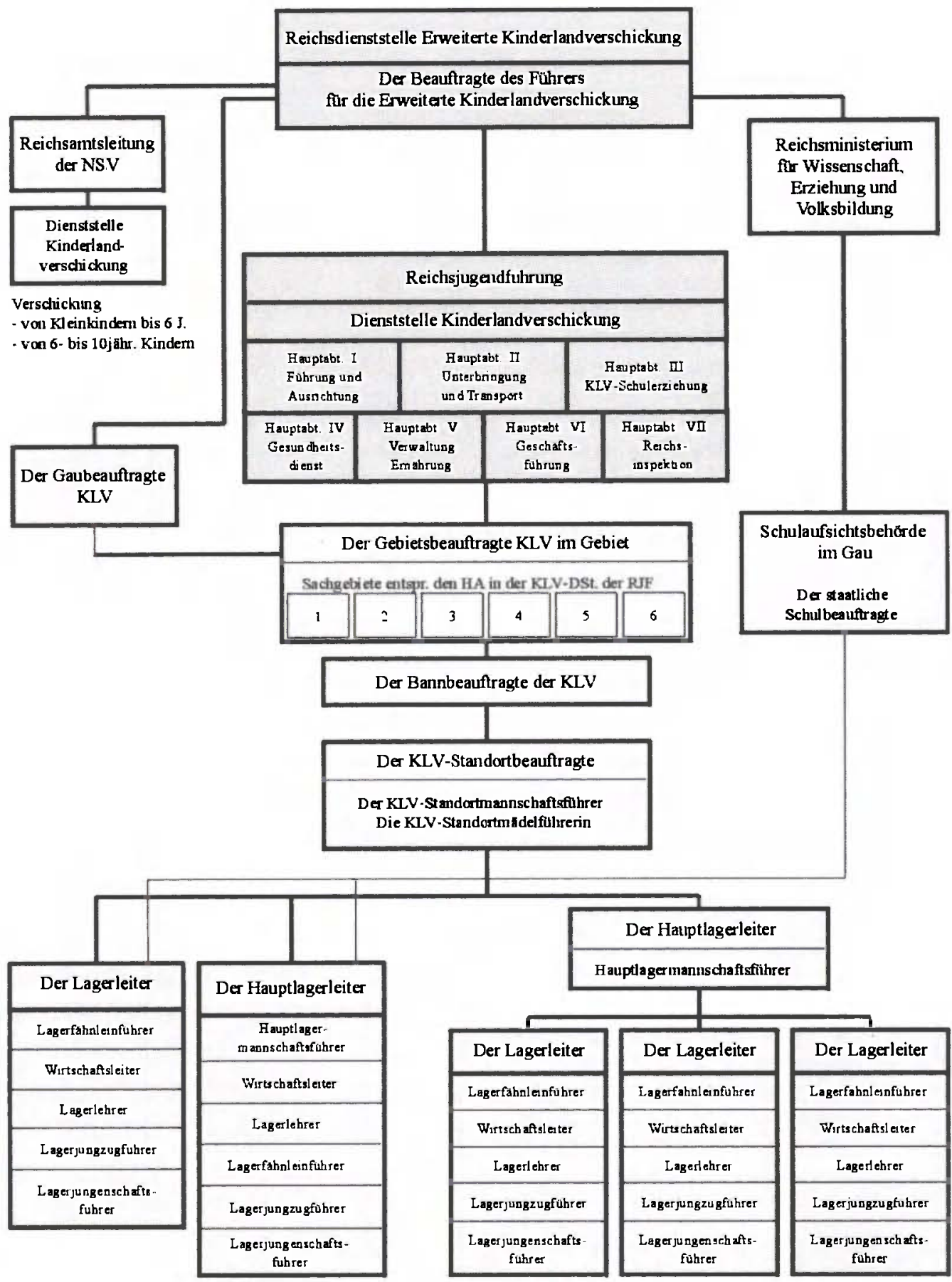

KLV-Lager bis 100 Jungen
KLV-Hauptlager über 100 Jungen in einem Gebāude
KLV-Hauptlager

über 100 Jungen in melureren Gebăuden

Die Bezeichnungen fürdie Mădchenlager sind entsprechend. 
esse der HJ-Führung lag, die sich als Gesamtorganisator darstellen konnte. Die KLV-Dienststelle der Reichsjugendführung ist zunächst von Heinrich Schulz geleitet worden, der zugleich als KLVInspekteur für das gesamte Reichsgebiet in der Reichsdienststelle tätig war. Der ursprünglich aus der Behördenabteilung der HJ-Zentrale stammende Schulz wurde im Juni 1942 von Eberhard Grüttner abgelöst, der sich zuvor als Führer des Traditionsbannes „Herbert Norkus“ im HJ-Gebiet Berlin profiliert hatte und nach seiner Berufung in die HJ-Führung zunächst als Hauptabteilungsleiter in der neugeschaffenen Inspektionsdienststelle tätig und dann im Organisationsamt der Reichsjugendführung für die Vorbereitung und Durchführung aller reichsweiten HJ-Veranstaltungen zuständig war. Bevor Grüttner die Leitung der KLV-Dienststelle der Reichsjugendführung übernahm, ist auch er KLV-Reichsinspekteur in der Reichsdienststelle KLV gewesen und amtierte dort zugleich als Organisationsleiter. Als Stabsführer Möckel - der bisherige faktische Leiter der Reichsdienststelle - Ende 1942 zur Luftwaffe einberufen worde, übernahm Grüttner neben der Leitung der KLV-Dienststelle der Reichsjugendführung auch die Führung der Reichsdienststelle EKLV; damit waren beide Einrichtungen in Personalunion besetzt. ${ }^{163}$

Diese Vermischung zweier Bereiche darf jedoch nicht zu dem Schluß verleiten, daß die Erweiterte Kinderlandverschickung vorrangig oder gar ausschließlich eine Angelegenheit der HJ gewesen sei. Während in der Reichsdienststelle alle zentralen Fragen der Erweiterten Kinderlandverschickung bearbeitet und in Zusammenarbeit mit der NSV und dem NSLB alle zentralen Entscheidungen zur Evakuierung von Kindern und Jugendlichen getroffen wurden, war die in der Reichsjugendführung eingerichtete KLV-Dienststelle formal nur für den in der Zuständigkeit der HJ liegenden Teil der Erweiterten Kinderlandverschickung, das heißt lediglich für die Unterbringung der mehr als zehn Jahre alten Kinder und Jugendlichen in den von der HJ organisierten Lagern verantwortlich, obwohl sich die Aufgabengebiete beider Dienststellen im Alltag in mehrfacher Hinsicht zwangsläufig sachlich und personell überschnitten. Nach 'unten' setzten sich die HJ-Strukturen der Erweiterten Kinderlandverschickung in Form der (NSDAP-/ bzw. Luft-)Gaubeauftragten KLV fort, die der Reichsjugendführung direkt unterstellt waren; diesen unterstanden in den HJ-Gebieten, dem eigentlichen Wirkungsraum der EKLV, die KLV-Gebietsbeauftragten mit entsprechenden Arbeitsstäben ${ }^{164}$, und diesen waren die KLV-Bannbeauftragten der HJ mit einem analogen Verwaltungsapparat zugeordnet. Ähnliche Strukturen wie in der Reichsjugendführung und ihren nachgeordneten Einrichtungen wurden in den Zentralen der NS-Volkswohlfahrt und des NS-Lehrerbundes geschaffen, die die speziellen Aufgabengebiete ihrer Organisationen im Rahmen der Erweiterten Kinderlandverschickung zu bearbeiten hatten. ${ }^{165}$

Innerhalb des Gesamtkomplexes der Erweiterten Kinderlandverschickung nahmen die von der NSV organisierten Verschickungen, also die Evakuierung von Kindern bis zu zehn Jahren, den quantitativ größten Raum ein. Bei dieser Form der NSV-organisierten Kinderlandverschickung wurden die Kinder nicht in Lagern, sondern entweder in Familienpflegestellen oder zusammen mit ihren Müttern in Gastfamilien oder in Mutter-und-Kind-Heimen der NSV untergebracht; „die Mutter-und-Kind-Verschickung war das Angebot im Rahmen der KLV, das am meisten von der Bevölkerung akzeptiert wurde." "166 Dabei wurden Mütter mit ihren zunächst bis zu drei, später bis zu sechs Jahre alten Kindern bei Gastfamilien in ländlichen Regionen untergebracht, wo sie den

163 Als Grüttner im Herbst 1944 zur Waffen-SS einberufen wurde, ist Richard Heil zum Leiter der KLV-Dienststelle ernannt worden, der bisher als HJ-Landesjugendführer und Beauftragter für die Kinderlandverschickung in der Slowakei gewirkt hatte. Im Januar 1945 wurde dann Gerhard Dabel, der zunächst die KLV-Lager im Sudetenland beaufsichtigt hatte, mit der Dienststellenleitung beauftragt, die nunmehr jedoch nur noch mit Abwicklungsaufgaben betraut war.

164 In allen von der Erweiterten Kinderlandverschickung betroffenen sogenannten Entsende- und Aufnahmegebieten ist im Rahmen der jeweiligen HJ-Gebietsführung ein Gebietsbeauftragter für die KLV eingesetzt worden, dessen Ressort zu einer eigenen Abteilung ausgebaut wurde, der folgende, von hauptamtlichen Sachbearbeitern geführte Referate angehörten: Geschäftsführung, Unterbringung und Verpflegung, Transportwesen, Inspektion, Gesundheitsaufsicht sowie eine Stelle für die Betreuung der volksdeutschen Jugend in Lagern. Neben dem Stellvertreter des Gebietsbeauftragten gehörten auch die BDM-Sachbearbeiterin zum Gebietsstab KLV, die dort die „Mädelbelange“" wahrnahm, sowie der Inspekteur bzw. Inspektionsbeauftragte und ein Schulinspekteur. Vgl. Rundschreiben der NSDAP/RJF, Folge 5/41, 3.2.1941.

165 Vgl. dazu Kock, Kinderlandverschickung, S. 84 ff.; Dabel, KLV, S. 11 ff.; Rüdiger, Hitler-Jugend, S. 290 ff.

166 Kock, Kinderlandverschickung, S. 108. 
Gastgebern bei häuslichen Arbeiten zur Hand gehen, die von ihnen verursachten Kosten also abarbeiten sollten. Ältere Geschwister konnten in diesen Fällen ihre Mütter begleiten und brauchten nicht an den HJ-geführten KLV-Lagern teilzunehmen; schwangere Frauen und Mütter mit Säuglingen konnten, sofern es die Aufnahmekapazitäten zuließen, auch in NSV-eigenen Heimen untergebracht werden. Neben der erhofften günstigen psychologischen Auswirkung auf die zumeist an den Fronten stehenden Väter und Ehemänner, die ihre Familien in Sicherheit wähnen sollten, erzielten die NS-Behörden eine weitere vorteilhafte Auswirkung dadurch, daß sie bei dieser Verschickungsform - die ab 1942/43 durchaus mehrere Jahre dauern konnte - über die Wohnungen der verschickten Familien verfügen und sie ausgebombten, in kriegswichtigen Bereichen tätigen Personen als Ausweichwohnraum zuweisen konnten. ${ }^{167}$

Darüber hinaus wurden in großem Stil auch sechs- bis zehnjährige Kinder aus bombengefährdeten Großstädten ohne ihre Mütter unter der Regie der NSV verschickt; diese ,,vergleichsweise erfolgreiche Aktion“, eine zweite Komponente im Rahmen der Erweiterten Kinderlandverschickung, „entsprach in weiten Teilen der bislang praktizierten Erholungsverschickung. Die Kinder wurden in den Aufnahmegemeinden, in denen sie die örtliche Schule besuchten, in Gastfamilien untergebracht “. ${ }^{168}$ Die Aktivitäten der NSV beschränkten sich bei diesen Verschickungsformen auf die Zusammenstellung und Abwicklung der Transporte, die Quartierbeschaffung und Organisation der Unterbringung in den Aufnahmegebieten und auf gelegentliche Kontrollfunktionen.

Einen Sonderfall und einen dritten Bestandteil der kriegsbedingten Evakuierungen, der im Selbstverständnis der NS-Behörden eigentlich nicht zur parteigeführten Erweiterten Kinderlandverschickung gehörte - diese sogar eher infragestellte und konterkarierte, dennoch aber akzeptiert werden mußte - bildete die sogenannte Verwandtenverschickung. Unter dieser Bezeichnung versuchte die Reichsdienststelle Kinderlandverschickung ab 1943, die in zunehmendem Maße privat und unorganisiert erfolgende Form der Evakuierung von Schulkindern zu ordnen und unter ihre Führung zu bringen. Unter Umgehung der zwar institutionalisierten, bis zum Ende des Dritten Reiches dennoch formal freiwilligen Erweiterten Kinderlandverschickung ${ }^{169}$ sind parallel zur Zunahme des Bombenkrieges immer mehr Eltern, die der NSV-Betreuung und vor allem den KLV-Lagern der HJ ablehnend gegenüberstanden, dazu übergegangen, ihre Kinder in Eigeninitiative zu Verwandten und Bekannten aufs Land zu bringen. Zwar bemühte sich die Reichsdienststelle, etwa über die Zusammenstellung von Transporten oder die Bereitstellung von Transportraum, auch diese Kinder, die immerhin etwa die Hälfte [!] des Gesamtkomplexes der Erweiterten Kinderlandverschickung ausmachten, wenigstens statistisch zu erfassen, um sie als Bestandteil ihrer Tätigkeit ausgeben zu können.

Dennoch war allein die Existenz der von den NS-Behörden nie zu steuernden und nicht zu kontrollierenden Verwandtenverschickung ein Ärgernis und ein unausgesprochenes Eingeständnis des Scheiterns des Konzeptes der Erweiterten Kinderlandverschickung. ${ }^{170}$ Denn im weiteren Verlauf des Krieges nahm die Bereitschaft der Eltern, ihre Kinder der NSV zu übergeben oder sie - vierte Komponente der Erweiterten Kinderlandverschickung - den KLV-Lagern der HJ anzuvertrauen, deutlich ab. Die gezielte „Gegenpropaganda“ der Kirchen, deren Tenor darin bestand, den Eltern zu erklären, der Zweck der Kinderlandverschickung bestünde in dem Bestreben, ,die Kinder den Eltern zu entziehen “171, trug dazu bei, das Mißtrauen der Erziehungsberechtigten gegenüber den institutionalisierten NS-Maßnahmen aufrecht zu erhalten. Bei den durch Gerüchte und Berichte

$167 \mathrm{Vgl}$. ebenda, S. $107 \mathrm{ff}$.

168 Ebenda, S. 112 ff.

169 Wie stark es um den Glauben an die Freiwilligkeit der Erweiterten KLV tatsächlich bestellt war, illustriert eine Einschätzung des SD, wonach erst ,amtliche Verlautbarungen der Presse, daß eine Zwangsverschickung der Kinder aus den luftgefährdeten Gebieten nicht weiter [!] erfolgen werde“, in weiten „Bevölkerungskreisen beruhigend gewirkt" haben; Meldungen aus dem Reich, S. 1905 (Bericht vom 16.1.1941). In den Propagandarichtlinien der Reichspressestelle zur Behandlung der EKLV in den Tageszeitungen hieß es dazu einerseits: „Die KLV ist auf freiwiliger Meldung aufgebaut.“ Andererseits wurde aber gefordert: „Aufgabe der Tagespresse ist es, den Eltern u.a. zu zeigen, auf welchem Wege die Anmeldung erfolgen muß.“ Zitiert nach: Vorschriftensammlung KLV, B 3a.

$170 \mathrm{Vgl}$. dazu Kock, Kinderlandverschickung, S. $117 \mathrm{ff}$.

171 Zu Strategien und Inhalten der „kirchlichen Gegenpropaganda“ vgl. die ausführlichen SD-Berichte in: Meldungen aus dem Reich, S. 2154 ff., S. 3509 ff. (Berichte vom 27.3.1941, 23.3.1942). 
aus den KLV-Lagern verunsicherten Eltern registrierte der SD einen „immer stärker werdenden Widerstand ... gegen eine Verschickung ihrer Kinder“" und - da sie „kein Vertrauen zur HJ“ hätten $^{172}$ - sogar die Tendenz, bereits in KLV-Lagern befindliche Kinder wieder zurückzuholen.

Selbst nach dem Sommer 1943, als infolge zunehmender Bombardierungen deutscher Großstädte vom Generalbevollmächtigten für die Reichsverwaltung die geschlossene Verlegung von Schulen aus den Luftkriegsgebieten angeordnet wurde und die Erweiterte Kinderlandverschickung damit eine neue Dimension erreichte, sank die Bereitschaft der Eltern weiter, die Angebote der in der Reichsdienststelle Kinderlandverschickung vertretenen Organisationen zur Verschickung ihrer Kinder anzunehmen; statt dessen erhöhte sich der Anteil der privat in Sicherheit gebrachten Kinder weiter. So seien etwa von den 260.000 Volks-, Mittel- und Hauptschülern der Reichshauptstadt bis zum Stichtag 30. August 1943 rund 132.000 auf dem Weg der Verwandtenhilfe aus der Stadt gebracht worden, dagegen nur 32.000 über die Kinderlandverschickungsaktionen der HJ und der NSV; und von den Eltern der 85.000 noch in Berlin ansässigen Schüler dieser Schularten weigerten sich die Erziehungsberechtigten von immerhin 62.000 Schülern, ihre Kinder fortzugeben. ${ }^{173}$ Statt dessen würden in den von Schulverlegungen betroffenen Gebieten, in denen trotz aller Verschickungsmaßnahmen noch zahlreiche schulpflichtige und derzeit unbeschulte Kinder vorhanden seien - in Berlin allein 100.000 -, immer mehr Eltern bei den Partei- und Staatsdienststellen „ultimativ“ und „mit Sammeleingaben“" auf eine Wiederaufnahme des Schulunterrichts drängen. ${ }^{174}$ Denn die Schulverlegungen sind - als ein Mittel des indirekten Zwanges - gleichzeitig mit einem Verbot zur Weiterführung des Unterrichts in den Evakuierungsgebieten verbunden worden; die Behörden hofften wegen der Tatsache, daß in den Heimatorten der Schüler kein Unterricht mehr stattfinden durfte, die an einer Schulausbildung ihrer Kinder interessierten Eltern zu Verschickungseinwilligungen bewegen zu können.

Die ab 1943, in einer zweiten Phase der EKLV einsetzende Praxis, nicht mehr nur einzelne Jugendliche zu verschicken, sondern komplette Schulen mit allen Lehrern und Schülern zu verlegen, die dann in den Aufnahmegebieten jeweils ein KLV-Lager bzw. ein KLV-Hauptlager bildeten, bedeutete in zweifacher Hinsicht eine gravierende Änderung des bislang praktizierten Verfahrens. $\mathrm{Da}$ - zum einen - längst nicht alle Schüler diese Verlegungen mitmachten, kam es dazu, daß in den Entsendegebieten zahlreiche nunmehr unbeschulte Kinder und Jugendliche zurückblieben, während in den Aufnahmegebieten oft zuviele Schüler vorhanden waren, deren Unterrichtung wegen des Mangels an Lehrern ebenfalls kaum noch zu realisieren war. Waren - zum anderen - bis Anfang 1943 die Verschickungen in KLV-Lager in der Regel auf sechs Monate begrenzt, wurden durch die Praxis der kompletten Schulverlegungen zwangsläufig nunmehr auch ältere als 14jährige - und also eigentlich nicht mehr KLV-taugliche bzw. KLV-berechtigte Schüler - von den Umquartierungen erfaßt, die, da wegen des zunehmenden Luftkrieges eine Rückkehr in die Entsendegebiete nicht mehr möglich war, oft über längere Zeit - manchmal mehrere Jahre - in den KLV-Lagern verbleiben mußten und von dort aus direkt in die Wehrertüchtigungslager einrückten, als Luftwaffenhelfer oder Rüstungshilfsarbeiter eingezogen bzw. direkt an die Front geschickt wurden. ${ }^{175}$

Es ist schwierig, den exakten quantitativen Umfang des Gesamtbereichs der Erweiterten Kinderlandverschickung zu benennen, da die Berechnungsgrundlagen und Zuordnungen sowohl in den überlieferten amtlichen Unterlagen als auch in den zeitgenössischen und retrospektiven Veröffentlichungen aus politischen und legitimatorischen Gründen stark voneinander abweichen; zudem wurden oft die verschiedenen Verschickungsformen vermengt, bei Zahlenangaben gelegentlich Verschickungszahlen mit Belegzahlen verwechselt oder unterschiedliche zeitliche Bezugsräume gewählt. Nach zeitgenössischen und in diesem Zusammenhang eher als neutral zu bewertenden Einschätzungen des Reichserziehungsministeriums und neueren Untersuchungen ${ }^{176}$ ergibt sich etwa folgendes Bild: Ungefähr die Hälfte aller verschickten Kinder gehörten zum Komplex der in

172 Meldungen aus dem Reich, S. 5827 ff., S. 5917 ff. (Berichte vom 30.9. und 25.10.1943).

$173 \mathrm{Vgl}$. Meldungen aus dem Reich, S. 5829 ff. (Bericht vom 30.9.1943, dort auch Berichte über andere Städte).

174 Ebenda, S. 5919 (Bericht vom 25.10.1943).

$175 \mathrm{Vgl}$. dazu Fehlberg, Die geschlossene Schulverlegung.

$176 \mathrm{Vgl}$. dazu vor allem Kock, S. 134 ff., bes. S. 136, Anmerkung 232. 
Privatinitiative vorgenommenen Verwandtenverschickung, der von den damaligen Organisatoren und späteren Apologeten zwar zum Bereich Erweiterte Kinderlandverschickung hinzugerechnet wurde, logisch und sachlich jedoch nicht dazugehörte ${ }^{177}$; von der verbleibenden anderen Hälfte wurden rund zwei Drittel der Kinder über die NSV in Pflegestellen untergebracht und etwa ein Drittel von der HJ in ihre KLV-Lager umgesiedelt; das bedeutet: Rechnet man die im Rahmen der Verwandtenverschickung privat evakuiertern Kinder zum Komplex der Erweiterten Kinderlandverschickung hinzu, würden die HJ-verantworteten KLV-Lager lediglich 16,6 Prozent des quantitativen Umfangs der Kinderlandverschickung ausmachen; läßt man dagegen die Verwandtenverschickung außerhalb der Betrachtung, dann hätte der HJ-Anteil an den KLV-Aktionen des Zweiten Weltkriegs bei rund einem Drittel gelegen.

Die in neueren Untersuchungen vorgelegten Zahlen bestätigen diese Annahmen. Danach wurden zwischen Oktober 1940 und dem Frühjahr 1945 von der Reichsdienststelle Kinderlandverschickung im Rahmen der Erweiterten Kinderlandverschickung etwa 850.000 Kinder zwischen zehn und 14 Jahren in die KLV-Lager der HJ gebracht, rund die gleiche Zahl von Kindern zwischen sechs und zehn Jahren befand sich - organisiert von der NSV - in Familienpflegestellen, und zirka 500.000 Kinder unter sechs Jahren sind - ebenfalls über die NSV - mit ihren Müttern in Heime und Pflegestellen verschickt worden; zusammengenommen erreichte die Erweiterte Kinderlandverschickung also einen Umfang von etwa 2,2 bis 2,3 Millionen Kindern. ${ }^{178}$ Die in der neueren Forschungsliteratur berechneten Angaben über den Umfang der Erweiterten Kinderlandverschickung bewegen sich in erstaunlicher Nähe zu den von der Reichsjugendführung in ihrer letzten amtlichen Darstellung zur Veröffentlichung vorgesehenen Zahlen; diese scheinen, was den HJ-Anteil an der Erweiterten Kinderlandverschickung betrifft, authentisch zu sein. Danach wurden zwischen Oktober 1940 und April 1944 etwa 705.000 Kinder und Jugendliche in rund 3.500 KLVLager verschickt ${ }^{179}$; hinzu kamen noch etwa 100.000 Jugendliche, die wegen fehlender Lagerkapazitäten in von der HJ organisierten Familienpflegestellen untergebracht waren und tagsüber an sogenannten offenen KLV-Lagern teilnahmen. ${ }^{180}$

Der von Kock für die gesamte Kinderlandverschickung behauptete Rückgang der Verschickungszahlen ab 1942 - nach einem Höhepunkt 1941 - läßt sich zumindest für die KLV-Lager, also für den von der $\mathrm{HJ}$ verantworteten Teil der Erweiterten Kinderlandverschickung nicht in vollem Umfang bestätigen. Nach einer kurzfristigen leichten Reduzierung im Jahre 1942 - hier lagen die Verschickungszahlen bei einem Wert von 81 Prozent der Evakuierungsmaßnahmen von 1941 stiegen die Verschickungszahlen 1943 sogar auf 153 Prozent des Jahres 1941. Deutlich wird also, daß zumindest bei dem in HJ-Regie, also in KLV-Lager verschickten Teil der Kinder von einem drastischen Einbruch nach 1941 nicht gesprochen werden kann, sondern daß statt dessen - nach 1940 - die Verschickungen in KLV-Lager im Jahre 1943 einen Höhepunkt erreichten. Bei der hier zu Vergleichszwecken unterstellten Annahme einer monatlich jeweils konstanten Zahl von verschickten Kindern, sind im Monatsdurchschnitt des Jahres 1944 sogar noch weit mehr Kinder verschickt worden als im Jahre 1941, das Kock für den Zeitraum der größten Verschickungszahlen hält. Und betrachtet man Anfang und Ende dieses HJ-getragenen Teils der KLV-Aktion, so wurden im Monatsdurchschnitt des Jahres 1940 etwa 23.000 Kinder und 1944 durchschnittlich immer

177 Deshalb kommen etwa Dabel, KLV, oder Larass, Der Zug der Kinder, auf etwa fünf Millionen verschickte Kinder.

$178 \mathrm{Vgl}$. Kock, Kinderlandverschickung, S. 142 f. Zwar kann den von Kock verwandten Berechnungs- und Schätzungsverfahren nicht zugestimmt werden; aber auch mit einem korrekten Verfahren kommt man, wenn auch aus anderen Gründen, letztlich auf dieselbe Zahl.

179 Absolute und monatliche Durchschnittszahlen der im Rahmen der EKLV in Zuständigkeit der HJ in KLV-Lager verschickten Kinder; berechnet nach: BA, NS 26/358 (Kriegsgeschichte der HJ, 1944).

$\begin{array}{lrc}\frac{\text { Jahr }}{1940} \text { (ab Oktober) } & \frac{\text { absolut }}{69.034} & \text { im Monatsdurchschnitt } \\ 1941 & 165.850 & 23.011 \\ 1942 & 135.306 & 13.821 \\ 1943 & 254.597 & 11.276 \\ 1944 \text { (bis April) } & 79.910 & 21.216 \\ & 19.976\end{array}$

$180 \mathrm{Vgl}$. ebenda. Diese 805.000 Jugendlichen stimmen mit den von Kock, Kinderlandverschickung, S. $134 \mathrm{ff} ., 142$, berechneten Werten annährend überein; Kock, der diese Materialien nicht verwandt hat, kam bis Sommer/Herbst 1944 auf eine Zahl von 800.000 HJ-verschickten Kindern, bis zum Frühjahr 1945 auf einen (Schätz-)Wert von 850.000. 
noch fast 20.000 Kinder pro Monat verschickt. ${ }^{181}$ Unbekannt sind jedoch genauere Zahlen des wesentlich größeren Teils der über die NSV verschickten Kinder, so daß zuverlässige Angaben über Gesamtverschickungszahlen nach wie vor nicht möglich sind, die sich aber etwa um 2,3 Millionen bewegen dürften.

Ungeachtet dieser nicht unbedeutenden Zahlen, hinter denen ein enormer logistischer Aufwand stand, bedeuteten diese Werte aber auch, daß die Abneigung der Eltern, ihre Kinder über die Erweiterte Kinderlandverschickung in Sicherheit zu bringen, trotz der zunehmenden Bombenangriffe konstant blieb und sich eher verstärkte; die meisten Eltern behielten ihre Kinder entweder bei sich oder versuchten, sie in privater Initiative bei Freunden oder Angehörigen auf dem Lande unterzubringen oder in weniger bombengefährdeten Gebieten einzuquartieren - auch wenn es diese kaum noch gab. In einer für die Gauleiter bestimmten Interpretation entsprechender Führeräußerungen zur Luftkriegslage mußte Goebbels im Januar 1944 nämlich eingestehen, daß ,inzwischen das gesamte Reichsgebiet als mehr oder weniger luftgefährdet betrachtet werden“ müsse und ,die größten Schwierigkeiten“ bestünden, „Schulkinder in geschlossenen Heimen unterzubringen“. Hitler, der nicht wünschte, ,daß Eltern, die ihre Kinder nicht umquartiert haben und sie infolge der Schulschließung nicht zur Schule schicken [konnten], für jeden Tag Schulversäumnis mit einer Geldstrafe belegt" würden, und der auch dagegen war, „zur Verhinderung der unerwünschten Rückkehr" von evakuierten Eltern und Kindern die „Sperrung [von] der[en] Lebensmittelkarten“ zu veranlassen, erwartete von Goebbels - dessen Kinder nie in einem NSV- oder KLV-Lager waren - und von den Gauleitern, „daß andere Mittel und Wege gefunden werden“ müßten, um nichtverschickungswillige „Volksgenossen zur Umquartierung ihrer Kinder zu bewegen“; Hitler und Goebbels glaubten, ,daß das erstrebte Ziel insbesondere auch durch Propagandaaktionen erreicht werden" könne. ${ }^{182}$

Als Aufgabe der Propaganda galt, herauszustellen, daß es sich „bei der Erweiterten Kinderlandverschickung um das größte Jugenderholungswerk im Freiheitskampf des deutschen Volkes“ handele. Deshalb sei es die „Aufgabe der Presse, durch immer erneute und vielseitige Aufsätze und Berichte stets das erzieherische Moment dieser Aktion in den Vordergrund zu stellen und klarzulegen, daß die KLV die Erziehung der Jungen und Mädel auch während des Krieges zu gesunden, frohen und getreuen Gefolgsleuten des Führers zur Aufgabe“ habe. ${ }^{183}$ Mit der Betonung der Tatsache, daß in den parteigeführten Evakuierungslagern junge Nationalsozialisten herangebildet werden sollten, trafen derartige Richtlinien zwar die Intentionen der HJ-Führung, aber weniger die Interessen der Eltern.

So wurden auch mit den in Form von Elternversammlungen inszenierten Aufklärungsaktionen eher negative Erfahrungen gemacht. Ungefähr zwei Wochen nach Goebbels' Anweisungen an die Gauleiter berichtete etwa der SD, daß, in den letzten Wochen durch die Partei, die Hitlerjugend, die Dienststellen der Kinderlandverschickung, die NSV und die Schulen größere Werbeaktionen für die Schulverlegung durchgeführt" worden sind, „um die noch verhältnismäßig hohe Zahl von Kindern in den luftgefährdeten Gebieten zu verringern". Dabei habe sich - „bedauerlicherweise" ein immer noch ,erheblicher Teil der Eltern zur Verschickung ihrer Kinder nicht bereitgefunden“ und sich auf entsprechenden Versammlungen ,gegen die Kinderevakuierung“ [!] ausgesprochen.

181 Ausgehend von den durchschnittlichen monatlichen Verschickungsquoten des HJ-geführten Teils der Erweiterten Kinderlandverschickung $(1940-23.011 ; 1941-13.821 ; 1942-11.276 ; 1943-21.216 ; 1944-19.976)$ liegt der Durchschnittswert für den gesamten Zeitraum von 1940 bis 1944 bei monatlich 16.388 verschickten Kindern. Unter Einbeziehung der 100.000 zwar von der HJ verschickten, jedoch in Familienpflegestellen, also nicht direkt in HJgeführten KLV-Lagern untergebrachten Júgendlichen, sind monatlich sogar durchschnittlich 18.721 Kinder über den NS-Jugendverband evakuiert worden; berechnet nach: BA, NS 26/358 (Kriegsgeschichte der HJ, 1944).

182 BA, R 21/510, B1. 27 ff. (Goebbels an alle Gauleiter, 28.1.1944). Dabei sei herauszustellen, daß die Leistungen der Erweiterten $\mathrm{KLV}$,in ihrem umfassenden Charakter alle Erwartungen“ übetreffen und ,ein lebendiger Ausdruck der Vielfalt der fürsorgenden Maßnahmen“ seien, , die Partei und Staat besonders während des Krieges für unser Volk getroffen haben. Als solche sind sie immer wieder herauszustellen und der Allgemeinheit bekanntzugeben". Dennoch - und das relativierte die geforderte Demagogie - galt auch dabei der „Grundsatz“, da $\beta$, die Landverschickung immer nur in dem Umfang und Ausmaß zu propagieren“ sei, ,wie Transportmöglichkeiten bestehen“. RL-Rundschreiben KLV, 5/42, 23.12.1942 (Propagandarichtlinien für die EKLV); auch in: Gebrdschr. RJF, 2/43, 27.2.1943.

183 Richtlinien der Reichspressestelle zur Behandlung der Erweiterten Kinderlandverschickung in den Tageszeitungen, hier zitiert nach: Vorschriftensammlung KLV, B 3a. 
Redner der Partei würden mit „Zwischenrufen“ und Unmutsbekundungen unterbrochen oder mit „lautem Gelächter" abgelehnt, und deren unklare Antworten auf deutliche Fragen der Eltern würden gelegentlich mit dem massenhaften Verlassen der Versammlung quittiert; so konnte in Berlin die Selbstauflösung einer Informationsveranstaltung ,vom Versammlungsleiter auch nicht durch die versuchte Führerehrung verhindert werden".

Als ein anderer Versammlungsredner der NSDAP „,zum Ausdruck brachte, daß Kinder nicht nur Eigentum der Eltern, sondern ebenso wie der Boden, der vom Landmann bearbeitet werde, auch Eigentum des Staates seien, erhob sich ein Soldat und verließ wortlos die Versammlung"; andere Eltern skandierten „Zwischenrufe wie: 'Wir haben die Kinder aber in die Welt setzen dürfen, mußten sie großziehen und jetzt gehören sie uns nicht mehr. Das sind ja bolschewistische Zustände." Auch Ausführungen über die Betreuung in den Lagern wurden ,,durch Zwischenrufe gestört", so etwa einer Mutter: „Ich habe meinen Jungen acht Monate in der KLV gehabt. Dort kommt er nie wieder hin, da die Jungens von unreifen HJ-Führern geschunden werden." Als daraufhin der Redner „die Notwendigkeit zum Zwang andeutete, für den Fall, daß der Aufruf an die Freiwilligkeit ohne Erfolg bleibe, habe ein großes Trampeln" eingesetzt. ${ }^{184}$

Insgesamt blieben die Erfolge derartiger Elternveranstaltungen, Aufklärungsmaßnahmen und Propagandaaktionen auch in vom Bombenkrieg stark betroffenen Gebieten offensichtlich gering; so hätten sich in Köln die Eltern von nur 15,1 Prozent zur Evakuierung vorgesehener Kinder mit einer Verschickung einverstanden erklärt, und in Berlin - wo bereits mehr als 155.000 Kinder auf dem Weg der Verwandtenverschickung außerhalb der Stadt untergebracht worden sind, dagegen nur 37.700 in Kinderlandverschickungslagern der HJ - weigerten sich die Eltern von mehr als 78.000 Kindern weiterhin, einer Verschickung zuzustimmen. Berücksicht man hier noch die Zahl der zur Einschulung anstehenden Kinder, wäre es - so die städtische Schulverwaltung - ,nach wie vor bedenklich, daß nach dem Aufhören jeden Unterrichts mehr als 100.000 Schulkinder der Reichshauptstadt nicht mehr unterrichtlich versorgt werden und ohne jeden erzieherischen Einfluß der Schule" blieben. Allein zwischen Ende November 1943 und Ende Februar 1944 seien 159 Kinder bei Bombenangriffen ums Leben gekommen, 95 erlitten Unfälle. ${ }^{185}$

Die Finanzierung der Erweiterten Kinderlandverschickung erfolgte aus Mitteln des Staatshaushalts, die dem Reichsschatzmeister der NSDAP, der die beteiligten NS-Organisationen etatrechtlich beaufsichtigte, vom Reichsfinanzministerium überwiesen wurden. Nach den überlieferten Aufstellungen des Reichsfinanzministeriums und des Reichsschatzmeisters läßt sich feststellen, daß allein zwischen Oktober 1940 und Dezember 1944 insgesamt 1,2 Milliarden Reichsmark für die Erweiterte Kinderlandverschickung bereitgestellt wurden. Am 23. März 1945 wurde die Reichshauptkasse - wahrscheinlich letztmalig - angewiesen, dem Reichsschatzmeister für die Kinderlandverschickung 50 Millionen Reichsmark zur Verfügung zu stellen. ${ }^{186}$ Insgesamt gesehen wurden in den 54 Monaten der Existenz der Erweiterten Kinderlandverschickung monatlich durchschnittlich 23,2 Millionen Reichsmark an Staatsmitteln verbraucht ${ }^{187}$; aber das war noch nicht alles.

Aus der unterschiedlichen Höhe der Aufwendungen pro Jahr oder Monat monokausal und eindimensional auf einen steigenden oder schwindenden Umfang der im Rahmen der Erweiterten Kinderlandverschickung evakuierten Kinder zu schließen und damit eine These belegen zu wollen, wonach die Verschickungszahlen der Erweiterten Kinderlandverschickung im Jahre 1941 einen Höhepunkt erreichten und dann rapide abnahmen ${ }^{188}$, ist kurzschlüssig und geht an der zumeist übersehenen Tatsache vorbei, daß die Erweiterte Kinderlandverschickung ein mehrgliedriges System mit verschiedenen Zuordnungen war. Die vom Finanzministerium über den Reichsschatz-

184 BA, R 21/510, Bl. 22 ff. (SD-Berichte zu Inlandsfragen des Chefs der Sicherheitspolizei und des SD, 10.2.1944).

185 Ebenda, Bl. 24, 30 ff. (Stadtpräsident der Reichshauptstadt an RMWEV, 23.2.1944). Zur Situation in Dortmund vgl. die Untersuchung von Sollbach, Luftterror.

186 Vgl. BA, R 2/11914 und 11915 (entsprechende Belege und diverse Aufstellungen des RFM, 1940 - 1945).

187 In den Jahren 1940 - 1945 wurden monatlich durchschnittlich folgende Beträge für die EKLV aus Reichsmitteln zur Verfügung gestellt: 1940 - 28.333.000 RM; 1941 - 33.750.000 RM: 1942 - 21.667.000 RM; 1943 - 20.000.000 RM; 1943 - 22.500.000 RM; 1945 - 16.667.000 RM; berechnet nach ebenda.

188 So etwa Kock, Kinderlandverschickung, S. 139 ff. 
meister geleiteten Beträge wurden bis 1943 auch für die von der NSV getragenen Maßnahmen innerhalb der Kinderlandverschickung gezahlt; ab 1943 wurden dagegen aus Reichsmitteln nur noch die von der $\mathrm{HJ}$ durchgeführten KLV-Aktionen unterstützt, während die NSV ihre Maßnahmen aus organisationseigenen Mitteln nunmehr weitgehend eigenständig finanzierte, bis Anfang 1944 allein mit 500 Millionen Reichsmark. Im Reichsfinanzministerium wurde dazu festgehalten: „Infolge dieser Neuregelung werden jetzt von der HJ mehr Mittel zur Durchführung der erweiterten Kinderlandverschickung benötigt, während die NSV nur noch verhältnismäßig wenig Reichsmittel für diesen Zweck in Anspruch nimmt. ${ }^{\text {“189 }}$ Daraus wird klar, daß es unsinnig wäre, aus den geringer werdenden Reichsmittelzuwendungen auf eine zahlenmäßige Abnahme der Verschickungszahlen innerhalb der Erweiterten Kinderlandverschickung zu schließen, wobei hier noch nicht einmal die sich im Laufe der Zeit verändernden Preisstrukturen für im Rahmen der Kinderlandverschickung verbrauchte Sachleistungen oder die durch die Anwendung des Reichsleistungsgesetzes bei Quartierfragen eingesparten Kosten berücksichtigt wurden.

Rechnet man die 500 Millionen Reichsmark, die von der NSV bis März 1944 über Spenden und Beiträge aufgebracht und der Erweiterten Kinderlandverschickung zugeführt wurden, zu den 1,25 Milliarden Reichsmark hinzu, die vom Reichsfinanzministerium bis März 1945 für die Erweiterte Kinderlandverschickung gezahlt wurden, ergibt sich eine Mindestsumme von 1,75 Milliarden Reichsmark. Das bedeutet, daß im Durchschnitt mindestens 32.407.400 Reichsmark pro Monat [!], also etwa eine Million Reichsmark pro Tag [!], für die Kinderlandverschickung aufgewendet wurden. Geht man davon aus, daß im Rahmen der KLV etwa 2,3 Millionen Kinder verschickt wurden, bedeutet dies, daß für den Transport, die Unterbringung, Verpflegung und Betreuung pro Kind etwa 761 Reichsmark verwandt wurden. ${ }^{190}$

Nach entsprechenden Gesundheits- und Entsendeappellen sind die Kinder aus ihren „Entsendegauen “"191 in mehreren von den HJ-Transportsachbearbeitern geplanten, großangelegten logistischen Unternehmungen mit mindestens 1.080 Sonderzügen der Deutschen Reichsbahn und 146 Schiffstransporten, mit Bussen und Pferdefuhrwerken in die KLV-Lager der „Aufnahmegaue“ gebracht worden. Diese Lager befanden sich in den weniger ,luftgefährdeten“"Gebieten des Reiches ${ }^{192}$, aber auch im Baltikum, in Bulgarien, in Dänemark, im Generalgouvernement, in Italien, im Protektorat Böhmen und Mähren, in Rumänien, in der Slowakei, in Südtirol und in Ungarn, und sind dort in Schulen, früheren Hotels und Pensionen, in leerstehenden oder geräumten Villen und Schlössern sowie in RAD-Lagern eingerichtet worden. Auf dem Höhepunkt der Ausdehnung des HJ-betriebenen KLV-Systems unterstanden der Dienststelle Kinderlandverschickung der Reichsjugendführung 1944 insgesamt 3.508 verschieden große KLV-Lager mit unterschiedlichen Belegungszahlen.

Die in der Geschichte der HJ bisher einmalige Situation einer längerfristigen, teilweise mehrjährigen Lagerunterbringung eines nicht unerheblichen Teils ihrer Mitglieder, eröffnete mit den KLV-Lagern die Gelegenheit, ,die Jungen und Mädel Tag für Tag und Stunde für Stunde unablässig [!] erzieherisch zu betreuen", und zwar nach Maßgabe der im HJ-Gesetz festgelegten Erziehungsgrundsätze der HJ, wonach die deutsche Jugend „körperlich, geistig und sittlich im Geiste des Nationalsozialismus zum Dienst am Volk und zur Volksgemeinschaft“ zu erziehen sei. Die Möglichkeiten, das ,Verhalten [der Jugendlichen] zu beobachten und positiv auf sie einzuwirken“, hätten sich durch die langfristigen Lager ,bedeutend erweitert", während dem ,entgegenstehende oder ablenkende Erziehungseinflüsse so gut wie ausgeschaltet“ und die ,,aufbauenden Tendenzen des Gemeinschaftslebens voll zur Entfaltung ${ }^{\star 193}$ gebracht werden könnten. Durch die gezielte, mit Strafandrohungen untersetzte Fernhaltung der Eltern, deren beschränkter und kanalisierter $\mathrm{Zu}-$

189 BA, R 2/11915 (Referentenvermerk RFM, 30.3.1944).

190 Hierin sind noch nicht die Kosten für die Beschulung, die medizinische Versorgung oder die Versicherung der Kinder enthaiten.

191 Das waren vor allem die „luftkriegsbedrohten“ HJ-Gebiete Berlin, Düsseldorf, Hamburg, Hessen-Nassau, Köln-Aachen, Kurhessen, Mecklenburg, Niedersachsen, Nordmark, Nordsee, Osthannover, Ruhr-Niederrhein, Westfalen-Nord und Westfalen-Süd; hinzu kamen die Städte Mannheim und Ludwigshafen aus den HJ-Gebieten Baden bzw. Saarpfalz.

192 Vorzugsweise in den HJ-Gebieten Bayerische Ostmark/Bayreuth, Mark Brandenburg, Oberdonau, Ostland/Ostpreußen, Sachsen, Schlesien, Sudetenland, Thüringen und Wartheland.

193 BA, NS 26/358 (Kriegsgeschichte der HJ, 1944). 
gang zu ihren Kindern offiziell mit Transportschwierigkeiten und militärischen Erfordernissen begründet wurde - dasselbe galt für die Möglichkeiten der Kinder, ihre Eltern zu besuchen ${ }^{194}$-, und durch den im Lagerleben weitgehend minimierten Einfluß der Kirchen waren zwei der wichtigsten, von der HJ ansonsten kaum zu beeinflussende Sozialisationsfaktoren ausgeschaltet worden.

Von der HJ-Führung wurden die sich daraus ergebenden Potenzen konzentrierter und längerfristiger nationalsozialistischer Indoktrinationsmöglichkeiten quasi unter Laborbedingungen ebenso befriedigt konstatiert wie die Tatsache, daß die Teilnahme an einem KLV-Lager als Bestandteil der Erfüllung der gesetzlich vorgeschriebenen Jugenddienstpflicht galt; dies bedeutete: „Wer vorher nicht Mitglied der Hitler-Jugend war, gilt mit der Zugehörigkeit zu einem KLV-Lager als zur Erfüllung der Jugenddienstpflicht einberufen und findet damit Aufnahme in die Hitler-Jugend. ${ }^{\star 195}$ So konnte der Versuch unternommen werden, auch die noch nicht der HJ angehörenden Kinder - in den vierziger Jahren immerhin eine nicht unerhebliche Minderheit - über die Teilnahme an einer scheinbar humanitären, teilweise von der HJ getragenen Aktion des Reiches zu Mitgliedern des NS-Jugendverbandes zu machen.

Diese hier gleichermaßen kühl wie emphatisch kalkulierten Möglichkeiten der Erweiterten Kinderlandverschickung, deklariert als ,großzügige Erholungsverschickung während des Krieges“, hätten, wenn sie denn aufgegangen wären, möglicherweise tatsächlich „,bahnbrechende Wirkungen" zeitigen können; sie standen dennoch oder gerade deswegen in diametralem Gegensatz zur offiziellen HJ-Präsentation, die die Erweiterte Kinderlandverschickung als ,politische und soziale Großtat“, als „Erholungswerk“, als „überzeugendstes Bekenntnis des Nationalsozialismus zur Jugend“ feierte. Die Behauptung, daß ,die Jugend als Zukunft der Nation im Mittelpunkt aller öffentlichen Bemühungen“" des Dritten Reiches gestanden habe, besaß zwar eine systemimmanente Logik, war hinsichtlich der EKLV aber nur unter entgegengesetzten Vorzeichen richtig; so entsprach diese auf die Erweiterte Kinderlandverschickung übertragene Einschätzung, daß dieses Unternehmen ein 'Sozialwerk' gewesen sei, vielleicht dem Wunsch und möglicherweise auch dem subjektiven Empfinden einiger Sozialpolitiker der Reichsjugendführung, nicht aber der Realität. Denn insgesamt gesehen war gerade die Erweiterte Kinderlandverschickung kein Beispiel für eine pflegende oder schützende Sozialpolitik, ging es bei ihr neben der hier möglichen Indoktrination unter 'Laborbedingungen' doch in erster Linie um eine allenfalls befristete Rettung sogenannter volklicher oder völkischer Substanz - ,asoziale Elemente“ und ,fremdvölkische Kinder und Jugendliche“ blieben von der Verschickung ausgeschlossen ${ }^{196}$; denn nach der lediglich temporären 'Zwischenlagerung' von Kindern und Jugendlichen waren - nach Wehrertüchtigungslagern, Einsatz als Luftwaffenhelfer und im Reichsarbeitsdienst - auch diese für den Einsatz in der Kriegswirtschaft oder für den unmittelbaren Kriegseinsatz an den Fronten vorgesehen - gelegentlich ohne vorher noch einmal nach Hause fahren zu können.

Insofern diente die Erweiterte Kinderlandverschickung nicht einem „Schutz der Jugend" an sich, sondern stellte in erster Linie den Versuch dar, künftiges 'Kanonenfutter' kurzfristig zu sichern, vor zufälliger Vernichtung zu bewahren, um es später effektiv und gezielt einsetzen zu können. Denn wenn die Erweiterte Kinderlandverschickung lediglich ein „typisch nationalsozialistisches“ Erholungswerk gewesen wäre, und sich der Schutz der Jugend tatsächlich ,wie ein roter Faden

194 Vgl. dazu etwa die Vorschriftensammlung KLV, H 5b; Vorschriftensammlung KLV C 8; Gebrdschr. RJF, 22/41, 25.7.1941 (Anordnungen der RJF über Modalitäten zur Rückkehr und Rückholung von Kindern aus der KLV). Darin hieß es u.a.: „Um zu verhindern, daß Eltern aus nichtigen Gründen oder aus krankhaftem Eigennutz nach Ausnutzung der einmaligen Betreuung ohne Rücksicht auf die Gesamtlage, welche eine geregelte Rückführung erforderlich macht, ihre Kinder wahllos aus den Lagern entfernen oder entführen, darf der Lagerleiter nur unter Vorzeigung oder bei Übersendung der vom Gaubeauftragten des Entsendegaues ausgestellten 'Genehmigung zur Rückholung aus dem KLV-Lager' den Jugendlichen aus dem KLV-Lager entlassen. Jede durch List oder Gewalt erzwungene Rüickholung Jugendlicher aus dem KLV-Lager ohne Genehmigung ist vom Lagerleiter unverzüglich zu melden. Die Personen, welche die widerrechtliche Rückholung durchführten, können bestraft werden."

195 BA, NS 26/358 (Kriegsgeschichte der HJ, 1944).

196 Etwas anders sind die Sonderschüler behandelt worden, die zwar „keine vollwertigen Glieder der Volksgemeinschaft“, aber immerhin „Reichsdeutsche“ waren: Die ebenfalls verschickten Sonderschüler, gemeint waren Hilfsschüler sowie seh- und gehörgeschädigte Jugendliche, galten der HJ-Führung "nicht von vornherein als minderwertig“; sie wurden in ,gesonderte Lager verschickt", denn auch aus ihnen sollte "die Erziehungsarbeit [in den KLVLagern] brauchbare und einsatzfähige Volksgenossen machen“. Ebenda. 
durch die Arbeit der nationalsozialistischen Partei und des von ihr gelenkten Staates ${ }^{« 197}$ hindurchgezogen hätte, würde sich natürlich auch die Frage ergeben, warum man dann mit der Einrichtung der Erweiterten Kinderlandverschickung bis zum Herbst 1940, dem Beginn der britischen Bombardements gewartet hat.

Bis auf wenige kurze Erwähnungen der NSV, nach denen auch die NS-Wohlfahrtsorganisation an der Erweiterten Kinderlandverschickung beteiligt und - so sollte suggeriert werden - quasi als Juniorpartner vorwiegend mit technischen Aufgaben betraut gewesen war, erscheint in den HJDarstellungen die gesamte Verschickungsaktion als alleiniges Werk der HJ; sowohl die angeführten Gesetze, Verordnungen und organisatorischen Aktivitäten als auch die Zahlen der Leistungsbilanzen beziehen sich etwa in der letzten HJ-amtlichen Darstellung nur auf den von der HJ verantworteten Teil der Erweiterten Kinderlandverschickung, die KLV-Lager, die aber innerhalb des gesamten Komplexes - wie gezeigt - den zahlenmäßig kleineren Teil ausmachten. Mit diesem Taschenspielertrick wollte sich die Reichsjugendführung als alleiniger Organisator der Erweiterten Kinderlandverschickung präsentieren.

Die 805.000 in den HJ-geführten KLV-Lagern befindlichen Kinder und Jugendlichen sind nach Angaben der Reichsjugendführung von 6.800 Lehrern, 4.500 HJ-Führern und 13.000 Wirtschaftskräften betreut worden; hinzu kamen etwa 2.100 Ärzte sowie 1.000 Feldschere und 850 Krankenschwestern. Geht man von der Existenz von rund 3.500 KLV-Lagern aus, die 1944 bestanden haben, würde das bedeuten, das pro Lager weniger als 4 Wirtschaftskräfte, weniger als 2 Lehrer und etwa 1,3 HJ-Führer zur Verfügung standen; damit ist zugleich ein wichtiges und wesentliches Manko angedeutet, das den Totalitätsanspruch der HJ massiv behinderte: die sich aus dem Personalproblem ergebende Führungssituation. Die ohnehin unter gravierendem Führermangel leidende HJ, die nicht einmal über genügend Führer für den normalen Einheitendienst in den Heimatstandorten verfügte, war nicht in der Lage, für die offiziell $\mathrm{HJ}$-geführten, in den meisten Fällen relativ gut ausgestatteten ${ }^{198}$, ausreichend verpflegten und medizinisch gut versorgten Lager - die Quote der Krankheits- und Todesfälle soll hier geringer gewesen sein, als wenn die Jugendlichen ohne Kriegseinwirkungen zu Hause geblieben wären ${ }^{199}$ - das entsprechende Stammführungspersonal zur Verfügung zu stellen, weder in quantitativer noch in qualitativer Hinsicht.

Seitdem nach der Verschärfung des Luftkriegs die Kinder nicht mehr nach Geburtsjahrgängen, sondern klassen- und schulweise verschickt wurden, bildeten die Schüler einer Klasse ein KLVLager, die Kinder einer Schule ein KLV-Hauptlager. Die KLV-Lager wurden von einem Lehrer als Lagerleiter und einem HJ-Führer als Lagermannschaftsführer geleitet. ${ }^{200}$ Diese „Lehr- und Führungskräfte“ sollten sich „zu enger Gemeinschaftsarbeit zusammenfinden und als Führungseinheit in Erscheinung treten". Die von der Reichsjugendführung erstrebte Dominaz der HJ ergab sich aber allein schon dadurch, daß - nach der 1943 erfolgten Auflösung des NS-Lehrerbundes die Lagerleiter „,von der Hitler-Jugend bestätigt ${ }^{\star 201}$ werden mußten; auch die als Hauptlagerleiter fungierenden Schuldirektoren der verlegten Schulen wurden durch den jeweiligen Gebietsbeauftragten KLV bestellt, der zumeist höherer HJ-Führer war. Da die als paritätische Lagermannschaftsführer eingesetzten HJ-Führer dem Gebietsbeauftragten $\mathrm{KLV}$,unmittelbar disziplinar

\section{Ebenda.}

198 Vgl. dazu Vorschriftensammlung KLV, F 2 (Vorschrift über die Einrichtung von KLV-Lagem); vgl. auch Anweisungen für die Jungen- und Mädellager (KLV-Lager), Berlin 1943, S. 56 ff.

199 Vgl. dazu Conti, Volksgesundheit im 5. Kriegsjahr, S. 15 f. Danach bestanden für den Gesamtbereich der KLV 3.000 Krankenstationen, 150 Hilfskrankenhäuser und neun Leichtkrankenhäuser sowie eine Reihe von Erholungs- und Genesungslagern. Vom Mai 1941 bis zum Oktober 1943 seien in den KLV-Lagern 297 Kinder gestorben. Laut Sterbestatistik des Reiches seien aber unter Friedensbedingungen und bei häuslicher Unterbringung mindestens 360 Sterbefälle zu erwarten gewesen. Auch dadurch habe die neue Lebensform der KLV-Lager ihre Überlegenheit erwiesen. Halte man außerdem „diesen geringen Todeszahlen die Zahlen gegenüber, die an Kindern als Todesopfer der feindlichen Terrorangriffe in unseren Städten zu beklagen sind und denkt daran, wie viele [Kinder] Todesopfer dieser Angriffe geworden wären, wenn die vielen, ja Hunderttausende von Kindern, die durch die KLV aus den Städten herausgebracht sind, dort verblieben wären, so sieht man klar, daß die KLV Tausenden von Kindern das Leben gerettet" habe. Ebenda.

200 Für Mädchenlager galt analoges; dort war eine Lehrerin Lagerleiterin, und eine BDM-Führerin fungierte als Lagermannschaftsführerin.

201 BA, NS 26/358 (Kriegsgeschichte der HJ, 1944). 
unterstellt" gewesen sind, war faktisch eine Führung der KLV-Lager durch die HJ gegeben, auch wenn sich diese Situation im Alltag gelegentlich durch das erfahrene Agieren der Lehrer und Schuldirektoren und das Versagen der Lagermannschaftsführer der HJ anders darstellte.

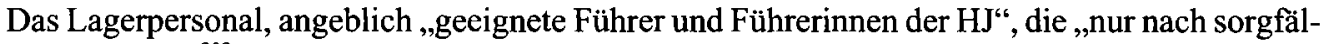
tigster Auslese ${ }^{\text {'202 }}$ und Ausbildung in der eigens eingerichteten KLV-Schule für Lagerleiter zum Einsatz kamen, waren in Wirklichkeit zumeist dienstrangniedere Schüler der 6. bis 8. Klassen der höheren Schulen sowie Lehrlinge aus Bereichen der nichtkriegswichtigen Industrie, die als Lagermannschaftsführer dienstverpflichtet wurden. Da ihnen jedoch die zunächst drei-, später sechsmonatige und länger währende KLV-Zeit nicht auf die Schul- bzw. Ausbildungszeit angerechnet wurde, ergaben sich für sie teilweise erhebliche Nachteile bei Schul- oder Lehrabschlüssen. Die einzige Qualifikation, über die diese dienstverpflichteten HJ-/KLV-Führer verfügten, war ein vierzehntägiger Einweisungslehrgang auf der im November 1943 - drei Jahre nach [!] dem Beginn der Erweiterten Kinderlandverschickung - im böhmischen Bad Podiebrad eingerichteten KLVLagerleiterschule. Die sich daraus ergebenden Lagerverhältnisse sind bislang eher in der belletristischen Literatur beschrieben worden. ${ }^{203}$

Der Lageralltag war quasimilitärisch organisiert und an die Rituale eines HJ-Lagers angepaßt, so daß über entsprechende Dienstpläne eine 'Rundumbetreuung' und eine totale Verfügung über die Kinder und später auch Jugendlichen gegeben war. Während der Vormittag zumeist der schulischen Bildung vorbehalten war, die angeblich viel effektiver als zu Hause absolviert werden konnte, da „Störungen des Unterrichts aus kriegsbedingten Gründen“ - wie Überbelegung von Schulen, Unterrichtsausfall infolge von Luftangriffen oder durch Kriegseinsätze im Rahmen der HJ - wegfielen, gehörte der Nachmittag dem HJ-Dienst ${ }^{204}$ Daneben wurden die Angehörigen der KLV-Lager „,in erheblichem Maße zu Hilfeleistungen auf dem Lande eingesetzt"; sie leisteten „,bei der Frühjahrsbestellung, beim Kräuter- und Holzsammeln, beim Beerenlesen und bei der Hopfenernte sowie im Haushalt der alleinstehenden Frauen und bei Erntearbeiten wertvolle Hilfe", allein 1943 mindestens 4.964.177 Arbeitsstunden. ${ }^{205}$

Jost Hermand, der als Jugendlicher mehrere Jahre in KLV-Lagern verbracht hatte und sich als einer der ersten in einer autobiografisch geprägten, gleichwohl wissenschaftlichen und tatsächliche Hintergründe auslotenden Studie mit der Thematik Erweiterte Kinderlandverschickung befaßte, hob hervor, daß man ,vor der seltsamen Tatsache [stehe], daß eine der größten Bevölkerungsbewegungen des 20. Jahrhunderts, und zwar der Abtransport von über zwei Millionen Kindern und Jugendlichen" bei den Betroffenen kaum nachhaltige Spuren hinterlassen zu haben scheine. Das Thema sei in der publizistischen Öffentlichkeit ,auf eine geradezu auffällige Weise tabuiert worden ${ }^{6206}$; und tatsächlich: Während dieser Gegenstand lange Zeit vor allem durch ehemalige Nationalsozialisten oder deren Epigonen monopolisiert wurde ${ }^{207}$, sind, nach Hermands Vorstoß 1993, erst in jüngerer Zeit Versuche zu beobachten, das Thema wissenschaftlich zu bearbeiten ${ }^{208}$.

Während die Darstellungen der ehemaligen Organisatoren zumeist darauf abheben, daß diese Lager „harmlos oder gar positiv“ gewesen seien und „für viele ein schönes Erlebnis“ darstellten, müsse man jedoch - so Hermand - fragen, ob nicht auch ,viele Kinder und Jugendliche unter Min-

202 Ebenda.

203 Vgl. z.B. Bremer, Muckefuck und Kameradschaft; vor allem Hermand, Als Pimpf in Polen.

204 Der „von der Reichsjugendführung ausgearbeitete Rahmenplan einer Woche", nach welchem ,dem [HJ-]Dienst genügend Raum gegeben“" werden sollte, stellte sich folgendermaßen dar: ,7.00 Wecken, Waschen, Bettenbauen, Stubendienst, Gesundheitsappell; 8.00 Flaggen- bzw. Morgenappell; 8.15 Frühstück; 8.45 - 13.00 Unterricht; 13.00 15.00 Mittagessen, Bettruhe oder Freizeit; 15.00 - 18.00 Hitler-Jugend-Dienst mit Sport, Werkarbeit, Bildbandvorführung, Singen, Musik, Geländespielen, Wanderungen usw. Einmal wöchentlich ist Heimnachmittag. Sonst wird der Nachmittag und die Zeit nach dem Abendessen mit Schulaufgaben, Putz- und Flickstunden, Schreib- und Lesestunden ausgefüllt. 21.00 Zapfenstreich, so daß eine zehnstïndige Nachtruhe gewährleistet ist. An den Sonntagen finden [HJ-]Morgenfeiern statt." BA, NS 26/358 (Kriegsgeschichte der HJ, 1944).

205 Ebenda.

206 Hermand, Als Pimpf in Polen.

207 Vgl. etwa die einschlägigen Veröffentlichungen von Griesmayr/Würschinger, Blohm, Taege, Kaufmann, Rüdiger, Dabel oder Larass.

208 Vgl. etwa Kock, Kinderlandverschickung; Kressel, Evakuierungen; Krause, Bombenkrieg; Klee, Luftschutzkeller; Sollbach, Luftterror. 
derwertigkeitskomplexen, ständiger 'Schleiferei', übelster Brutalisierung, endlosen Geländemärschen, strapazenreichen Wehrsportübungen, plumpen Indoktrinierungsversuchen" und all jenen Erscheinungen zu leiden gehabt hatten, die man als „Verrohung in der Horde“ umschreiben könnte. Hermand betont, daß es ,nicht leicht [sei], im Hinblick auf die Lager der 'Erweiterten Kinderlandverschickung' zwischen 1940 und 1945 irgendwelche generalisierenden Urteile zu fällen. Es gab in ihnen fast alles: väterliche und mütterliche Besorgtheit, gläubiges Vertrauen auf das ursprünglich Gute im Menschen, naiven Idealismus, aber auch faschisierende Indoktrinierung, öde Routine, bewußte Verrohung und Brutalisierung, wenn nicht gar übelsten Sadismus“; und er stellt die Frage: Mußte es nicht in Lagern, ,in denen weniger die Lehrer als die [von der HJ gestellten] Lagermannschaftsführer ... die Befehlsgewalt hatten, zwangsläufig zu ideologischer Überfanatisierung und sadistischen Exzessen kommen, unter denen alle Lagerinsassen zu leiden hatten und in denen sich der terroristische Grundzug der gesamten NS-Hierarchie manifestierte?"209

Im Sommer und Herbst 1944, als die Reichsjugendführung die Bilanz ihrer bisherigen Kriegsaktivitäten zog, befanden sich die meisten der an der Peripherie des Reiches gelegenen KLV-Lager bereits im Status der Auflösung, im Zustand der Verlegung bzw. der Rückführung. Davon wird im Resümee der HJ-Zentrale überhaupt nichts erwähnt, sondern die Fiktion aufrechterhalten, die KLV-Lager stünden auf dem Höhepunkt ihrer Entwicklung, in einem ständigen Ausbau. Tatsächlich erzwang die militärische Lage bereits seit Frühjahr/Sommer 1944 die Räumung zahlreicher Lager im Baltikum, in Böhmen, in Bulgarien und Dänemark, im Generalgouvernement, in Mähren, in Rumänien, in der Slowakei, in Südtirol und in Ungarn. Die Evakuierungen und Rückführungen der Kinder erfolgten zumeist nicht nach Hause, sondern überwiegend in die Auffanglager nach Bayern und die österreichischen Gaue, da die meisten der ehemaligen Entsendegebiete im Westens Deutschlands, aus denen das Gros der verschickten Kinder kam, unmittelbar von den Westalliierten bedroht und die Städte vielfach zerstört ${ }^{210}$ waren; zudem befanden sich zu diesem Zeitpunkt die meisten männlichen Familienangehörigen in den verschiedenen Formen des militärischen Kriegseinsatzes, und auch die weiblichen waren oft zu Rüstungsarbeiten außerhalb der Heimatgemeinden dienstverpflichtet worden, so daß für die rückgeführten Kinder vielfach kein Zuhause mehr vorhanden war.

Bereits im August 1944, so ein damals verantwortlicher KLV-Funktionär retrospektiv, konnte „von einer geordneten Übermittlung der notwendigen koordinierten Weisungen zwischen Berlin und den Randgebieten nicht mehr gesprochen werden". ${ }^{211} \mathrm{Da}$ Hitler sich die Genehmigungen für alle Rückzüge und Evakuierungen selbst vorbehalten hatte, zwischen ihm und dem formellen Leiter der Erweiterten Kinderlandverschickung, dem bei Hitler in Ungnade gefallen Schirach, aber keine Besprechungen oder gar Abstimmungen mehr stattfanden, weil die Reichsdienststelle Kinderlandverschickung inzwischen ins böhmische Bad Podiebrad ${ }^{212}$ verlegt worden war und in Berlin nur noch ein fünfköpfiger Arbeitsstab bestand und weil die Reichsjugendführung aus fehlerhaf-

209 Auf solche Fragestellungen mit „Ja“ oder „Nein“ zu antworten, sei nicht leicht, wie sich generell auf diesem Gebiet kaum verallgemeinerbare Aussagen treffen ließen; keinesfalls könne man sagen, daß diejenigen Lager, ,in denen Lehrer oder Lehrerinnen mehr zu sagen hatten als die Lagermannschaftsführer oder Lagermädelführerinnen [der HJ], zwangsläufig die besseren, humaneren waren. Es gab auch unter Lehrern und Lehrerinnen üble Nazis, ... und es gab sowohl vernünftige als auch niederträchtige Lagermannschaftsführer ..., je nachdem, ob sie ihrer Rolle menschlich gewachsen waren oder die ihnen zugedachte Machtposition ebenfalls in einem despotischen Sinne mißbrauchten". Trotz einer "diffusen Aufspaltung in eine unübersehbare Fülle an Möglichkeiten, besonders in ideologischer, moralischer und psychologischer Hinsicht" sei sicher, daß diejenigen KLV-Lager, ,"in denen das fürsorgliche Element überwog", sicher nicht zu jenen Erziehungsstätten gehörten, "welche die auf Kampf und Sieg eingeschworenen Fanatiker innerhalb der NS-Führungsgremien im Auge hatten". Hermand, Als Pimpf in Polen, S. 9 ff.

210 In einer Übersicht des Reichsministeriums für Rüstung und Kriegsproduktion über die 43 vom Bombenkrieg am schwersten zerstörten deutschen Städte vom 1.5.1944 rangierten Aachen, Offenbach, Köln, Mannheim, Düsseldorf, Kassel, Essen, Hamburg, Remscheid und Frankfurt/M. auf den ersten zehn Plätzen der absolut bzw. prozentual am stärksten zerstörten Städte; Berlin, das zwar 311.419 schwere und 196.053 Totalschäden des Wohnungsbestandes zu verzeichnen hatte - und damit im Reichsmaßstab absolut am schwersten betroffen war - rangierte jedoch erst auf Platz 28, weil diese Schäden 'lediglich' 21 bzw. 13 Prozent des Wohnungsbestandes der Reichshauptstadt betrafen; vgl. BA, R 3/1588, Bl. $63 \mathrm{ff}$. (Speer an Lammers, 19.9.1944)

211 Dabel, KLV, S. 275 ff.

212 Im ehemaligen Staatsbad Bad Podiebrad befand sich einer der größten KLV-Lagerkomplexe; in zahlreichen Hotels, Heimen und Pensionen wurden bis zu 10.000 Kinder beherbergt; außerdem waren hier die KLV-Reichsschule und ab November 1943 auch die Fachabteilungen der Reichsdienststelle KLV untergebracht. 
ter Lagebeurteilung und ideologischer Verblendung keine Genehmigungen für die Rückführung bzw. Verlegung von KLV-Lagern erteilte, endete die größte deutsche Evakuierungsaktion so, wie sie begonnen hatte, als ,überdimensionale Improvisation". Während also die Reichsjugendführung und die Reichsdienststelle Kinderlandverschickung - ohne zentrale Weisungen - die Rückführung der KLV-Lager so lange wie möglich hinauszuzögern suchten, „um die Endsiegpropaganda nicht

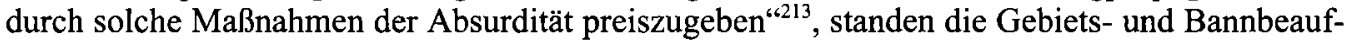
tragten der Kinderlandverschickung unvermittelt ohne Anleitung da und entschieden sich - im Zwiespalt zwischen verbotenen Rückzügen und der realen bedrohlichen militärischen Lage - in den meisten Fällen und oft in letzter Minute zur Evakuierung der Lager. So handelte etwa der Chef der Befehlsstelle Ostland der Reichsjugendführung, Heinrich Lüer, im Zusammenspiel mit dem Reichskommissar für das Ostland, Hinrich Lohse, gegen das nach Rückfrage von der Reichsjugendführung ausdrücklich erteilte Rückführungsverbot und ließ die Rigaer KLV-Lager nach Marienburg evakuieren. ${ }^{214}$

Anfang Januar 1945 erkannte man auch in der Berliner KLV-Organisation, daß die ,bisherigen Anordnungen und Maßnahmen mit der Zeit und durch die Verhältnisse überholt" waren, da - so die verhüllende Umschreibung der gravierenden Gebietsverluste - die ,meisten und größten Berliner Aufnahmegaue (Generalgouvernement, Wartheland, Ober- und Niederschlesien, Ostpreußen, Danzig-Westpreußen, Pommern und Brandenburg) ausgefallen" seien. Die Kinder strömten in zumeist unorganisierten Transporten oder individuell nach Berlin zurück. Eine - tatsächlich zumindest erwogene - „neue Verschickung“ der etwa 150.000 in Berlin weilenden schulpflichtigen Kinder wurde dann ,,aus räumlichen und stimmungsmäßigen Gründen nicht nur [für] unzweckmäßig, sondern überhaupt [für] unmöglich“ gehalten. Außerdem sei mittlerweile ,die Gefährdung des Lebens und der Gesundheit der Kinder auch in Berlin nicht größer als in weiten Gebieten des übrigen Reiches“. 215 